\title{
PERSPECTIVA DE GÉNERO Y EDUCACIÓN \\ ESTUDIO DE CASO DE LA I. E. M. SAGRADO CORAZÓN DE JESÚS
}

JULLY VANESSA CUASES GONZÁLEZ

\author{
UNIVERSIDAD DE MEDELLÍN \\ FACULTAD DE DERECHO Y CIENCIAS POLÍTICAS \\ MAESTRÍA EN DERECHOS HUMANOS Y DIH \\ SAN JUAN DE PASTO
}

2019 


\title{
PERSPECTIVA DE GÉNERO Y EDUCACIÓN \\ ESTUDIO DE CASO DE LA I. E. M. SAGRADO CORAZÓN DE JESÚS
}

JULLY VANESSA CUASES GONZÁLEZ

\author{
Asesoras \\ CATALINA PÉREZ MESA (Universidad de Medellín) \\ LINA MEJÍA TORRES (Universidad Santo Tomas) \\ Trabajo de Grado presentado para optar al título de Mg. en Derechos \\ Humanos y DIH
}

\author{
UNIVERSIDAD DE MEDELLÍN \\ FACULTAD DE DERECHO Y CIENCIAS POLÍTICAS \\ MAESTRÍA EN DERECHOS HUMANOS Y DIH \\ SAN JUAN DE PASTO \\ 2019
}




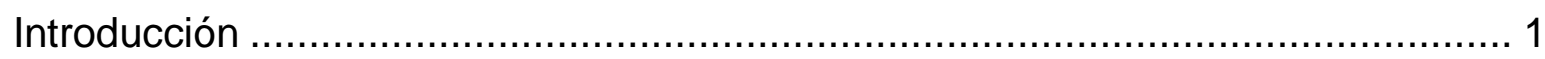

1. Marco General de la Investigación ................................................................ 4

1.1 Formulación del problema.................................................................... 4

1.1.1 Descripción del problema........................................................... 4

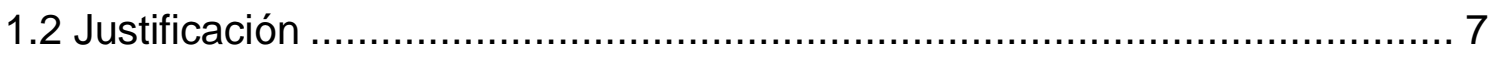

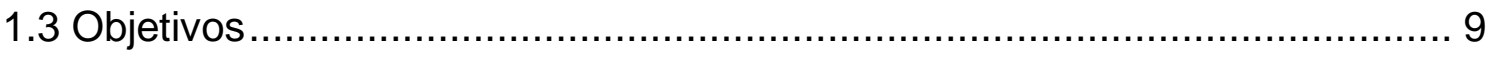

1.3.1 Objetivo General ................................................................... 9

1.3.2. Objetivos específicos ............................................................... 9

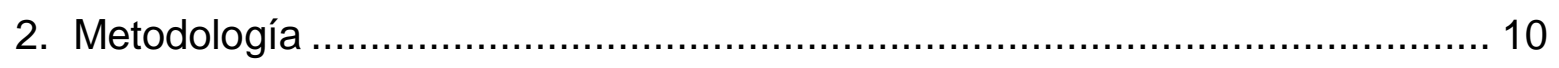

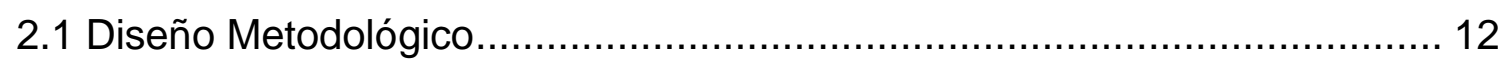

2.1.1 Técnicas de Recolección de Información ......................................... 12

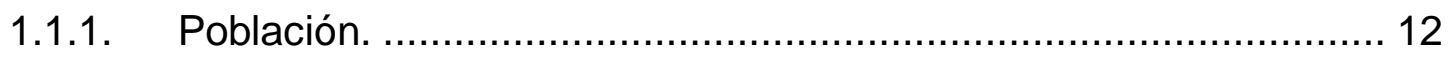

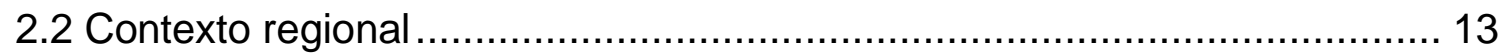

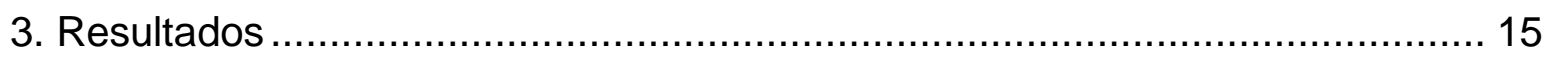

3.1 La perspectiva de género en la educación nacional de Colombia desde la

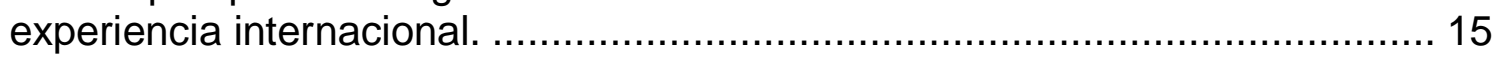

3.1.1 Los organismos internacionales frente a la educación con perspectiva

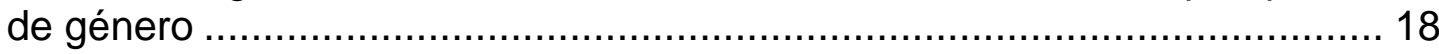

3.1.2 Educación para todos, una iniciativa para superar la discriminación e inequidad basada en género .................................................................... 19

3.1.3 Declaración de Incheon: el móvil para una educación inclusiva, equitativa y de calidad. 
3.1.4 Otros pronunciamientos anexos.

3.1.5 La perspectiva de género en la educación nacional de Colombia 23

3.1.6 Ley general de educación y su decreto reglamentario 1860 del 3 de Agosto de 1994.

3.1.7 Estrategias del Gobierno Nacional para el adelanto de la perspectiva de género como principio rector de las políticas de educación 25

3.1.8 Desde la perspectiva de género hacia la construcción de un modelo de coeducación. La experiencia del gobierno Vasco.

3.2 La perspectiva de género en la educación nacional de Colombia desde los proyectos educativos institucionales: estudio de caso .................................. 33

3.2.1 Contexto social e identificación del municipio El Tambo, Nariño ......... 34

3.2.2 Caracterización de la Institución Educativa Municipal Sagrado Corazón de Jesús

3.2.3 Análisis del Proyecto Educativo Institucional y el Manual de convivencia adscritos a la Institución Educativa Municipal Sagrado Corazón de Jesús .. 37

3.2.4 Resultados del Estudio de Caso .................................................... 40

3.3 Análisis de la inclusión de la perspectiva de género en el contexto social de la Institución Educativa Municipal Sagrado Corazón de Jesús........................ 54

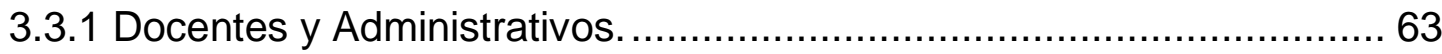

3.3.2 La perspectiva de género y los estudiantes. .................................. 67

3.3.3 Contexto familiar de la IEM Sagrado Corazón de Jesús .................... 72

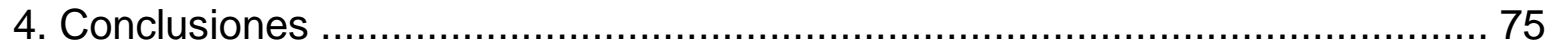

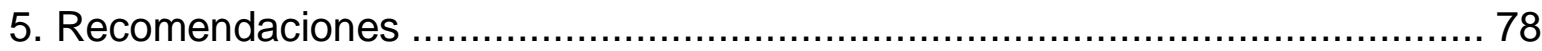

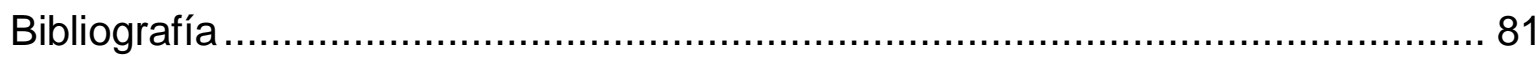

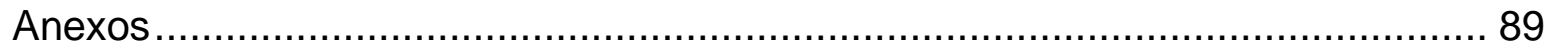




\section{Lista de Tablas}

Pág.

Tabla 1. Resumen del marco jurídico referente en materia de igualdad y educación en el Gobierno Vasco

Tabla 2. Número de estudiantes matriculados por grado en la Institución Educativa Sagrado Corazón de Jesús. 2016

Tabla 3. Principales categorías de perspectiva de género encontradas en la IEM 


\section{Lista de Gráficos}

Pág.

Gráfico 1. Conocimiento y percepción de docentes frente al PEI y Manual de convivencia.

Gráfico 2. Percepción de los docentes frente a la discriminación de género.

Gráfico 3. Percepción de los padres de familia frente a la perspectiva de género.

Gráfico 4. Percepción de los padres de familia frente a la discriminación por género.

Gráfico 5. Percepción de los estudiantes frente a la inclusión de la perspectiva de género por parte de la Institución

Gráfico 6. Percepción de los estudiantes sobre la perspectiva de género incluida en los planes de estudio de la Institución.

Gráfico 7. Percepción de los estudiantes frente al respeto de la identidad de género en la Institución. 


\section{Lista de anexos}

Pág.,

Anexo 1. Encuesta para estudiantes sobre apreciación de la perspectiva de género en el Proyecto Educativo Institucional PEl y el Manual de Convivencia ... 90

Anexo 2. Entrevista para estudiantes sobre apreciación de la perspectiva de género en el Proyecto Educativo Institucional PEl y el Manual de Convivencia ... 93

Anexo 3. Encuesta para personal administrativo y docentes sobre la apreciación de la perspectiva de género en el proyecto educativo institucional PEl y el Manual de Convivencia................................................................. 96

Anexo 4. Entrevista para docentes sobre la apreciación de la perspectiva de género en el Proyecto Educativo Institucional PEI

Anexo 5. Encuesta para padres de familia sobre la apreciación de la perspectiva de género en el Proyecto Educativo Institucional PEI y el Manual de Convivencia 


\section{Introducción}

Constantemente en el discurso político se ha utilizado la expresión "El futuro del país está en las manos de las nuevas generaciones"; sin embargo, la presencia de figuras como la discriminación e inequidad dentro de las entidades educativas encargadas de la preparación del individuo parece obstaculizar dicho fin. No es posible hablar de una generación de cambio si la misma se cimienta en la violencia, irrespeto e intolerancia por la diferencia; en este sentido, conforme amplias disposiciones normativas, principalmente en la Constitución Política, el Estado Colombiano en aras de garantizar la construcción de un país en paz y la protección de derechos fundamentales, ha puesto en marcha a través de la educación diferentes mecanismos de enseñanza destinados a cambiar dicho paradigma.

Es claro que en Colombia, existe una gran cantidad de sesgos respecto a temas que no han sido bien vistos por la cultura tradicional que siempre ha gobernado, razón por la cual la identidad de género es tal vez uno de los conceptos más desconocidos o incomprendidos por la mayoría de la población, y más aún, por aquella que mantiene una cultura conservadora.

Es por eso que ante el inconveniente de la falta de conocimiento sobre la identidad de género, se busca determinar cómo la misma es enfrentada en espacios como las aulas estudiantiles, por lo cual en el presente texto se aborda lo referente a la discriminación e inequidad basada en género dentro de las instituciones, pues en una sociedad reacia a aceptar las múltiples facetas que puede identificar al ser humano sin necesidad de coincidir con los roles culturalmente impuestos a un sexo en particular.

Como consecuencia de lo anterior, la presente investigación se encuentra dirigida puntualmente a estudiar desde la perspectiva de género las estructuras normativas nacionales e internacionales que apuntan a una coeducación en género, como base para la superación de la discriminación e inequidad existente; así mismo con el objetivo 
de visibilizar la situación real y el impacto de dichas disposiciones legales se trabajó con la Institución Municipal Sagrado Corazón de Jesús del municipio del Tambo Nariño en el periodo 2017-2018 lo correspondiente a la inclusión de la perspectiva de género dentro de su Proyecto Educativo Institucional -PEI- y su Manual de Convivencia y los mecanismos mediante los cuales se difunde en la comunidad educativa.

Ahora bien, el desarrollo de la presente investigación parte de un diseño cualitativo, ya que la información que se quiso obtener principalmente fue conocer sobre la situación real en un contexto natural e histórico; a su vez se utilizó una fase descriptiva y exploratoria para identificar la inclusión de la perspectiva de género en las instituciones, con el fin de realizar una comparación del ser y del deber ser. Todo lo anterior se llevó a cabo a través de diversos tipos de entrevistas, tanto a directivos de la Institución objeto de estudio como a los docentes, estudiantes y padres y/o madres de familia, indagando con respecto a la perspectiva de género y como la misma ha impactado en la educación de los menores.

A su vez, se realizó un análisis doctrinal y jurídico mediante información bibliográfica, legal y jurisprudencial que abarque el concepto de género, complementándose esto con un enfoque critico-social para la obtención de transformación social.

Ahora bien, el presente la investigación inicia explicado, brevemente, la metodología utilizada para la recolección de información primaria que permita hacer dicha identificación, para, en segundo lugar, abordar la caracterización del contexto social e identificación de la Institución Municipal.

Luego, se indican los resultados obtenidos a partir de la aplicación de encuestas y entrevistas con los involucrados, con el propósito de dar a conocer sus percepciones en la problemática de estudio, así como su conocimiento sobre el PEI y el manual de convivencia, datos que respaldan la posición crítica de este estudio los cuales demuestran la situación interna de la institución educativa; y finalmente, se procedió a 
efectuar un estudio detallado de las políticas, planes y proyectos pedagógicos contenidos dentro del Proyecto Educativo Institucional, así como de su Manual de Convivencia vigente hasta la fecha. 


\section{Marco General de la Investigación}

\subsection{Formulación del problema}

¿Cómo se ha implementado la perspectiva de género en el PEI y en el Manual de Convivencia de la Institución Educativa Municipal Sagrado Corazón de Jesús del municipio del Tambo - Nariño para el periodo 2017-2018?

\subsubsection{Descripción del problema}

Histórica y culturalmente la sociedad colombiana se ha visto permeada por una concepción sesgada de lo que representa ser hombre y ser mujer, marcando para las mismas pautas de comportamiento y roles específicos que desconocen los intereses propios del individuo, y lo que es más grave aún, vulneran de manera sistemática derechos básicos e inherentes a la condición del ser humano.

Lo anterior encuentra su sustento en la Encuesta Nacional de Demografía y Salud - ENDS - realizada por Profamilia (2015), cuyos resultados apuntan a que las percepciones generales de hombres y mujeres sobre atribuciones a la masculinidad y la feminidad aún se insertan en la construcción de roles rígidos de género, la subvaloración de las mujeres, la legitimación de la violencia y los roles o concepciones tradicionales en el ejercicio de la sexualidad (Profamilia, 2015, pág. 44)

Colombia ha interiorizado tanto el asunto, que todavía hoy se evidencian manifestaciones conductuales de hombres y mujeres, infantes o adultos que refuerzan los estereotipos de género enmarcados en una cultura predominantemente patriarcal.

En este entendido, y conforme los resultados de la encuesta en cita se encontró que las actividades domésticas, de cuidado; y de mantenimiento del hogar, recaen en más del 80 por ciento en las mujeres, y en lo que tiene que ver con el cuidado de hijas o hijos en más del 50 por ciento (...) por su parte, en relación a la proporción sobre 
gastos del hogar que cubren hombres y mujeres, sin bien se muestra una mayor participación de las mujeres en la contribución a los gastos del hogar, el rol de proveedor sigue estando en cabeza de los hombres.

En la ENDS 2015 también se incluye una serie de preguntas para establecer las percepciones y actitudes hacia las personas gays, lesbianas, bisexuales y transgenero (LGBT). Al respecto, se encontró que el 86.8 por ciento de las mujeres y 82.7 por ciento de los hombres consideran que las personas homosexuales tienen los mismos derechos que las personas heterosexuales. El 67.2 por ciento de las mujeres y el 58.8 por ciento de los hombres aprueba que se reconozcan derechos a las parejas homosexuales; y el 29.7 por ciento de las mujeres y el 26.2 por ciento de los hombres manifiestan estar de acuerdo con que las parejas homosexuales adopten. (Profamilia, 2015, pág. 44)

Si bien los resultados descritos en los párrafos precedentes evidencian una marcada visión machista respecto de los comportamientos atribuidos a la condición de ser mujer $u$ hombre, los seres humanos se comportan de maneras más diversas. Hay múltiples formas de ser mujer y hombre y no una manera hegemónica de serlo; sin embargo, esta concepción no ha sido del todo aceptada y su reconocimiento ha requerido de grandes esfuerzos de hombres y mujeres activistas que buscan la igualdad de género en cada una de las esferas en las que se desenvuelve el ser humano.

Dicho lo anterior y haciendo un particular énfasis en materia educativa acerca de cuál es el objeto de estudio del presente proyecto, es menester resaltar las disposiciones normativas que de manera conjunta propician las condiciones necesarias para formar a la persona teniendo en cuenta la inclusión de la perspectiva de género como principio transversal de los PEI y los manuales de convivencia al interior de las instituciones de enseñanza.

Así las cosas, se tiene que dentro de la estructura normativa de Colombia, entre ellas la ley 115 de 1994, por la cual se expide la ley general de educación, se empieza a concebir la educación como un proceso de formación permanente, personal, cultural y social que se fundamenta en una concepción integral de la persona humana, de su dignidad, de sus derechos y de sus deberes (Congreso de la República, 1994) y si bien 
no se expone de manera taxativa una educación en género; de la lectura íntegra del documento y una interpretación análoga de la misma, se desprende la necesidad de educar en derechos y propender por el respeto a la dignidad e integralidad de la persona. Es así como a partir del decreto 1860 de 1994, por el cual se reglamenta parcialmente la Ley 115 de 1994, en los aspectos pedagógicos y organizativos generales, se ordena a las instituciones de enseñanza elaborar y poner en práctica, un proyecto educativo institucional que exprese la forma cómo se ha decidido alcanzar los fines de la educación definidos por la ley, teniendo en cuenta las condiciones sociales, económicas y culturales de su medio (Decreto 1860 de 1994,1994 ).

Este proyecto educativo institucional -PEI- dentro de sus componentes debe complementarse adicionalmente con el Plan Nacional de Educación en Derechos Humanos -PLANEDH- y el Plan Nacional Decenal de Educación2016-2026-PNDE-, puesto que los mismos se establecen como una hoja de ruta para avanzar, precisamente, hacia un sistema educativo de calidad que promueva el desarrollo económico y social del país, y la construcción de una sociedad cuyos cimientos sean la justicia, la equidad, el respeto y el reconocimiento de las diferencias (Ministerio de Educación Nacional, 2017).

Sin embargo, y a pesar de contar con las anteriores disposiciones normativas señaladas, en materia de género la situación dista de ser garantista, pues tanto instituciones como padres de familia le restan la importancia necesaria para ser implementada dentro de los PEI y los Manuales de Convivencia.

Conforme lo señalado hasta el momento, se hace evidente la necesidad de cambiar el paradigma desde el que se está preparando a la comunidad estudiantil en aras de preparar a una persona íntegra capaz de respetar, tolerar y aceptar los roles que cada individuo, sea hombre o mujer, adopte como su modelo y proyecto de vida; para ello, es hora de empezar no solo a implementar políticas de género en los entes educativos sino evaluar la metodología con la que la enseñan e imparten entre los 
directivos y estudiantado, tratando así de superar las tasas de discriminación y situaciones de inequidad en las que hoy se desarrolla la comunidad educativa.

\subsection{Justificación}

Tal y como se señaló anteriormente, Colombia aún presenta grandes desafíos en cuanto a la superación de la discriminación e igualdad de género se trata; lo anterior debido a que el ambiente al interior de las instituciones educativas conforme los resultados obtenidos de la encuesta de Convivencia Escolar y Circunstancias que la Afectan, realizada por el DANE a Estudiantes de $5^{\circ}$ a $11^{\circ}$ en Bogotá durante 2011 parece no estar acorde a las necesidades y requerimientos del estudiantado, dado que aún persisten estereotipos de género basados en el sexo del individuo, lo que conlleva en muchas ocasiones no solo a la marginalidad de determinados grupos sino inclusive a la deserción estudiantil. (Gutiérrez, 2017)

En este orden de ideas, cabe precisar la iniciativa del gobierno colombiano por superar la inequidad basada en género; lo anterior a través de la implementación de la ley 1620 de 2013, por la cual se crea el Sistema Nacional de Convivencia Escolar y Formación para el Ejercicio de los Derechos Humanos, la Educación para la Sexualidad y la Prevención y Mitigación de la Violencia Escolar la cual, el decreto 1860 de 1994, el PLANEDH y el PNDE 2016-2026; que se convierten en la guía estructural para una educación inclusiva y garantista de los derechos humanos.

Así las cosas y partiendo de la estructura normativa que exhorta a las instituciones educativas a elaborar un PEI y un Manual de Convivencia que incluya derechos humanos con perspectiva de género, surge paralelamente la necesidad de evaluar la acogida de dichos lineamientos dentro de las instituciones, ya que no basta con implementar políticas que no impacten realmente a la población hacia la cual se encuentran dirigidas; puesto que como lo señalan Subirats y Brullet (1992) lograr la equidad de género significa erradicar todas las formas de manifestación del sexismo en los procesos educativos (Solís, 2016) 
Conforme lo señalado, la presente investigación encuentra su razón de ser en tres lineamientos puntuales a saber:

En primer lugar, es de suma importancia identificar las principales prerrogativas legales que respaldan la educación en género a nivel Nacional, así como la experiencia internacional respecto a la implementación de dicho modelo educativo, basándonos en diferentes estamentos de carácter internacional como el Fondo de las Naciones Unidas para la infancia -UNICEF- con su pronunciamiento Recomendaciones de Política de Igualdad de Género en Educación, (2016) la Organización de los Estados AmericanosOEA-con el pronunciamiento conjunto sobre igualdad de género y violencia contra la mujer (2017) o la Organización de las Naciones Unidas para la Educación, la Ciencia y la Cultura -UNESCO- con la adopción del Marco de Acción de Dakar (2000) que han impulsado estructuras que sirvan de base para el desarrollo de modelos de educación integral en materia de derechos humanos con perspectiva de género.

Ahora bien, en un segundo lugar se considera pertinente examinar la acogida de dichas directrices dentro del PEI y del Manual de Convivencia, en este caso dentro de la institución Municipal Sagrado Corazón de Jesús del municipio del Tambo - Nariño, toda vez que en materia educativa las instituciones parecen no darle la importancia necesaria a la implementación de la perspectiva de género como eje transversal del PEI y/o de los manuales de convivencia, ni la necesidad de educar en género. Así las cosas, examinar si se ha implementado o no la educación en género dentro de dicha institución permitirá pasar a señalar si existe un impacto en la comunidad educativa y si el mismo se hace en términos positivos, o por el contrario, propicia condiciones de inequidad y discriminación basada en género. 


\subsection{Objetivos}

\subsubsection{Objetivo General}

Establecer cómo se ha implementado la perspectiva de género en el PEl y el Manual de Convivencia de la institución Municipal Sagrado Corazón de Jesús del municipio del Tambo - Nariño para el periodo 2017-2018

\subsubsection{Objetivos específicos}

- Examinar el marco normativo nacional e internacional referente a la perspectiva de género en la educación como base para superar la discriminación e inequidad basada en género.

- Identificar en el PEI y en el Manual de Convivencia de la Institución Municipal Sagrado Corazón de Jesús del Municipio del Tambo - Nariño la inclusión de la perspectiva de género y formas de difusión de la educación en género.

- Analizar el impacto de la perspectiva de género contemplada en el PEI y el Manual de Convivencia y la educación en género en la comunidad educativa de la institución Municipal Sagrado Corazón de Jesús del municipio del Tambo - Nariño. 


\section{Metodología}

El desarrollo de la presente investigación parte de un diseño exclusivamente cualitativo, pues conforme lo señala Rodríguez y Valldeoriola (2014), las metodologías cualitativas se interesan por la vivencia concreta en su contexto natural y en su contexto histórico, por las interpretaciones y los significados que se atribuyen a una cultura (o subcultura) particular, por los valores y los sentimientos que se originan. Desde esta visión y de acuerdo a los objetivos planteados, el estudio de caso dentro de esta categoría metodológica resulta totalmente indispensable, pues tal y como se señala a lo largo del presente documento, la investigación está dirigida a abordar las estructuras normativas nacionales e internacionales dentro del contexto; es decir, comprender el fenómeno que se está estudiando desde el punto de vista de las personas que lo protagonizan (Duran, 2002 citado en Rodríguez y Valldeoriola, 2007).

Ahora bien, la metodología señalada tiene como base una fase descriptiva y una exploratoria. La primera de ellas en cuanto se pretende identificar y describir la inclusión de la perspectiva de género como eje transversal del PEI y del Manual de Convivencia de la Institución Educativa Municipal Sagrado Corazón de Jesús del municipio del Tambo - Nariño; y la segunda en tanto se pretende conseguir un acercamiento entre las teorías inscritas en el marco teórico y la realidad objeto de estudio.

Así las cosas, entendiendo el estudio de caso como una estrategia de investigación dirigida a comprender las dinámicas presentes en contextos singulares (Eisenhardt, 1991), en esta investigación devino imperante el recoger evidencia cualitativa con el fin de describir, analizar, verificar e identificar el fenómeno social objeto de estudio, por medio del análisis de las siguientes fuentes:

- Primarias: Proyecto Educativo Institucional PEI, Manual de Convivencia, Encuestas y Entrevistas a padres de familia, estudiantes, docentes y administrativos.

- Secundarias: Normativa, Jurisprudencia y Doctrina. 
Ahora, debe mencionarse que la Institución Educativa escogida para el estudio de caso presta el ambiente necesario para establecer un primer panorama, si quiera a nivel municipal o departamental, de cómo se abordan los temas de género e inclusión en los centros educativos públicos dirigidos por comunidades religiosas en un país laico como Colombia; y, teniendo en cuenta la cantidad población estudiantil que cuentan en sus aulas, cómo aquellos conceptos impactan otra población de la institución que no son estudiantes pero son igual de importantes a nivel social: las familias de aquellos estudiantes. Así, en primer lugar, se desarrollaron y aplicaron entrevistas a los directivos de la institución Municipal Sagrado Corazón de Jesús del municipio del Tambo - Nariño con el fin de establecer la adopción de la perspectiva de género y a partir de ello analizar el impacto de la educación en género en la comunidad educativa; para ello se elaboraron tres encuestas; una para cada actor: estudiantes, padres y docentes.

Las encuestas estuvieron compuestas por preguntas cualitativas que evalúan la percepción del encuestado con respecto a tres componentes el primero evaluara el conocimiento de los encuestados respecto del PEI y el Manual de Convivencia y la implementación de la perspectiva de género en sus componentes; el segundo respecto a la posición de cada encuestado frente a la perspectiva de género y la educación en género y finalmente como tercer componente se analizó el impacto que se ha percibido por cada encuestado con respecto a la implementación y abordaje de la perspectiva de género y educación en género.

Por otra parte, y bajo este enfoque, es indispensable partir del análisis doctrinal y jurídico que gira en torno a género y educación en género, para lo cual se diseñaron e implementaron las respectivas fichas de recolección de información (bibliográfica, legal y jurisprudencial) con las cuales se pretendió establecer los marcos respectivos y la identificación de los hitos más significativos a nivel nacional e internacional en cuanto al tratamiento, evolución y actualidad de la concepción de género y su implementación. 
De igual forma, el desarrollo de este trabajo investigativo se encuentra bajo los lineamientos propios de un enfoque Crítico-Social, pues la misma se caracteriza no sólo por el hecho de indagar y comprender la realidad en la que se inserta la investigación pertinente, sino por provocar transformaciones sociales en ésta, teniendo en cuenta el aspecto humano de la vida social. De esta forma, el enfoque crítico, se caracteriza no sólo por el hecho de indagar, obtener datos y comprender la realidad en la que se inserta la investigación, sino por provocar transformaciones sociales, en los contextos en los que se interviene (Melero, 2011).

\subsection{Diseño Metodológico}

\subsubsection{Técnicas de Recolección de Información}

Considerando la finalidad de la presente investigación, se ha decidido diseñar y aplicar como herramientas de recolección de información dos entrevistas y dos encuestas dirigidas a docentes y estudiantes y una encuesta con preguntas de tipo cerradas y abiertas para padres de familia, con objeto de llevar a cabo un estudio de caso al interior de la Institución Educativa Municipal Sagrado Corazón de Jesús.

Cada uno de estos instrumentos cuenta con un total de doce preguntas que pretenden en su integralidad identificar la inclusión de la perspectiva de género en el PEI y en el Manual de Convivencia de la institución; el impacto de la misma en el estudiantado y la percepción de la comunidad educativa respecto a la inclusión y abordaje de la perspectiva de género desde la administración hasta la pedagogía impartida.

El total de estudiantes encuestados fue de 497 , de un total de 833 , los cuales se encuentran repartidos entre los grados sexto y undécimo, con edades ubicadas entre los 10 y los 19 años. Por su parte, fueron 898 los padres de los estudiantes encuestados que participaron en la investigación: 431 padres y 466 madres; ahora, se encuestaron a 45 personas que laboran en la Institución Educativa, entre los cuales se 
encuentran 30 docentes y 15 administrativos. Se optó por encuestar a la totalidad del personal, exactamente, 30 docentes, 14 administrativos y 1 directivo académico, aunque debe advertirse en este punto que a pesar de la buena disposición de la señora Rectora de la Institución para la realización del presente estudio, no fue posible obtener su entrevista.

Respecto a las entrevistas que se llevaron a cabo, se realizaron de manera individual y personal a 12 estudiantes, dos de cada grado, un hombre y una mujer y en cuanto a docentes, se entrevistaron en total a 4.

\subsection{Contexto regional}

El Departamento de Nariño, ubicado al suroccidente de Colombia, cuyo territorio se encuentra limitado al norte por el Departamento del Cauca, al sur por el Ecuador, al oriente por el Departamento del Putumayo y al oriente por el Océano Pacífico, es uno de los departamentos que mayor interés ha mostrado por la problemática de género, de manera que se ha comprometido con su estudio y con la búsqueda de alternativas que permitan hacer del "enfoque de género un elemento clave de las propuestas de desarrollo en la construcción colectiva de la región" (ONU Mujeres, 2017), a través de la formulación de objetivos y acciones de transformación cultural en pro de la equidad de género.

Desde la Gobernación de Nariño se ha trabajado arduamente en la construcción de políticas públicas que permitan un mejor direccionamiento de esta temática, como es el caso de la formulación del documento titulado "Política Pública para la equidad de las mujeres nariñenses desde su diversidad étnica y cultural en un territorio en construcción de paz", acto que da un fuerte impulso social, político, económico y cultural a las mujeres nariñenses. 
A su vez el Observatorio de Género de Nariño (2018), en su estudio denominado "Dinámica sobre la situación de las mujeres en las subregiones del Departamento de Nariño Periodo Enero - Diciembre de 2017", expone que entre los años 2015 - 2017, los eventos de violencia en el departamento de Nariño se han incrementado, y los picos que se han presentado en dicha materia, muestran que las principales víctimas son mujeres, particularmente niñas y adolescentes, quienes han sufrido violencia sexual de manera descomunal. Además, aún no es claro si existe un vacío entorno a conocer si la respuesta institucional ha sido efectiva y las víctimas han tenido acceso a la justicia o si, por el contrario, no han sido eficientes en la protección integral de las víctimas.

No obstante, dentro de los estudios académicos relacionados, es menester recalcar el trabajo realizado por Acosta y David (2011) quienes mediante su investigación "Análisis y seguimiento socioeconómico de la política pública de género en el departamento de Nariño 2009-2011", así mismo, María Navarrete (2013), en su investigación "Enseñando la equidad de género a los estudiantes de grado octavo de la I.E.M Ciudadela Educativa de Pasto", concluyó que dentro de dicha institución se logró enseñar de manera adecuada, mediante diversas estrategias didácticas y pedagógicas, todos los conceptos que se incluyen dentro de este tema, sin embargo, es necesario que para el establecimiento como para los docentes, contar con un fortalecimiento de enseñanza sobre la equidad de género, en toda la población estudiantil, puesto que se logra una formación integral como seres humanos y se puede mejorar el afrontamiento hacia la sociedad como se conoce actualmente, practicando el respeto al otro. 


\section{Resultados}

\subsection{La perspectiva de género en la educación nacional de Colombia desde la experiencia internacional.}

Las actuales sociedades han comenzado a cambiar las concepciones sociales existentes del hombre y de la mujer, en virtud a la concepción de que todos los seres humanos naces libres e iguales en dignidad y derechos $y$, dotados como están de razón y conciencia, y por lo tanto se proscribe cualquier discriminación por raza, color, sexo, idioma, religión, opinión política o de cualquier otra índole. (Naciones Unidas, Declaración Universal de Derechos Humanos, 1948)

En este sentido, primer debe determinarse qué es la perspectiva de género a la luz de éste estudio. Dicha perspectiva nace como una herramienta que permite comprender y entender ésos imaginarios toda vez que, como lo señala la Dra. Martha Novoa (2012), es una herramienta destinada a la consecución de una sociedad más igual y democrática para hombres y mujeres, en todas sus áreas (ej. Trabajo, salud, educación, familia, legal); comprendiendo a los individuos no de forma homogeneizada, sino a través de las diferencias de cada uno y de cómo éstas se manifiestan (pág. 347).

Para entrar a desarrollar la anterior afirmación, cabe recordar al lector que es la educación la institución primordial para generar cualquier cambio de percepciones, paradigmas, valores o idearios colectivos de cualquier sociedad; por cuanto es a través de esta, que se introducen al niño y a la niña en un paradigma conceptual y valorativo, desde el cual se organiza la percepción y la interpretación del mundo (Díaz Rodríguez, 2003).

Entonces, la perspectiva de género debe entendérsela como la herramienta orientada a aprehender las diferencias biológicas y/o antropológicas propias del individuo 'macho' o 'hembra' del ser humano, para identificar, analizar y criticar los 
diferentes roles o presupuestos sociales que se han construido entorno al sexo, es decir, la distribución de papeles sociales que se le asigna a un individuo en virtud a su sexo biológico. En efecto, la perspectiva de género, dentro de los estudios feministas, aparece dentro de una corriente relacionista de estudio de las formas de interacción entre las personas; Martha Novoa (2012) expone al respecto de esta corriente que ella, como se ha manifestado a lo largo de este estudio, aboga por una igualdad de los sexos a través de la apropiación de las diferencias de los mismos, comprendiendo que tales diferencias no son óbice para un trato desigual o subordinado, así mismo, que no se puede descartar lo femenino por cuanto éste necesita de lo masculino para concebir sus diferencias, por cuanto la igualdad no exige "que las mujeres y los hombres realizaran las mismas tareas, ni que las mujeres y los hombres fueran esencialmente idénticos" (Bock, citada en Novoa, 2012), como desarrollo de dicha corriente nace la perspectiva de género ${ }^{1}$.

En suma, dicha perspectiva, según Martha Lamas (1996) implica "reconocer que una cosa es la diferencia sexual y otra cosa son las atribuciones, ideas, representaciones y prescripciones sociales que se construyen tomando como referencia esa diferencia sexual" (pág. 223); por cuanto

\begin{abstract}
Valorar el peso de lo biológico en la interrelación de múltiples aspectos: sociales, ecológicos, biológicos, ha llevado a un reconocimiento de que es perfectamente plausible que existan diferencias sexuales de comportamiento asociadas con un programa genético de diferenciación sexual; sin embargo, estas diferencias son mínimas y no implican superioridad de un sexo sobre otro. Se debe aceptar el origen biológico de algunas diferencias entre hombres y mujeres, sin perder de vista que la predisposición biológica no es suficiente por sí misma para provocar un comportamiento. No hay comportamientos o características de personalidad exclusivas de un sexo. Ambos comparten rasgos y conductas humanas. (Lamas, 1996)
\end{abstract}

\footnotetext{
${ }^{1}$ Aquí la perspectiva se diferencia de la ideología de género, aclarando que no se hace referencia a la concepción errónea difundida por ciertos sectores tradicionales y ultra conservadores de la sociedad, en cuanto dicha ideología aboga por una 'homogenización' de lo masculino y lo femenino, desconociendo las diferencias de los individuos bajo el postulado de que ello implica la perpetuación de las bases de los roles de género, implantados en la sociedad de vieja data, los cuales se buscan deconstruir para la consecución de una sociedad más justas e igual.
} 
En conclusión, y como se ha manifestado lo largo de este trabajo, la perspectiva de género es un elemento que, desde la crítica de lo innato y lo atribuido, pretende evaluar racionalmente los presupuestos sociales actuales con el fin de brindarle al individuo un espacio propicio, de amplias posibilidades, para su desarrollo personal, vocacional, afectivo, personal, etc.

Dicho lo anterior, ha de manifestarse que, históricamente, la sociedad colombiana ha asociado la identidad de género con el sexo de la persona, estableciendo para hombres y mujeres roles específicos para cada uno de ellos (Profamilia, 2015) una manera aceptable y bien vista del papel que cada uno debe representar en la dinámica social; sin embargo, los seres humanos se comportan de maneras más diversas. A pesar de esto, para Colombia dicha concepción aún no es del todo aceptada y por ello desde una sociedad predominantemente machista se vulneran los derechos y la integridad de quienes salen de dicha categoría social.

Es en este contexto que la educación cobra gran importancia para la transformación social y cultural de Colombia pues a través de ella se espera superar la discriminación, violencia e inequidad basada en el género que se presenta en casi todas las esferas de desarrollo del ser humano, sin embargo, hablar de una educación como agente de cambio requiere que el mismo se adecúe y responda a las continuas y cambiantes necesidades de la comunidad académica ya que representa el entorno donde se transmiten y reproducen pensamientos y comportamientos sexistas. Así las cosas, cultivar en la educación la perspectiva de género como eje transversal de la misma resulta totalmente indispensable, pues solo a partir de ello, la transformación hacia una sociedad más tolerante y respetuosa por la diversidad será posible.

De acuerdo con esto, la adecuación del sistema educativo a la inclusión de la perspectiva de género ha sido un tema de relevancia tanto para Colombia como para el mundo en general; diferentes estamentos de orden internacional se han pronunciado con fines de trazar un marco de referencia para transformar el sistema educativo tradicional por un sistema basado en un modelo de coeducación. 
Conforme lo señalado es necesario hacer referencia entonces a tres componentes interconectados entre sí. El primero de ellos aborda la perspectiva de género y la educación desde los estamentos internacionales más importantes en la materia, acogiendo de manera paralela la Declaración Mundial sobre la Educación para Todos (1990) y la Declaración de Incheon (2015) de la UNESCO; en segundo lugar se pone de manifiesto el componente normativo nacional en materia de educación y las principales estrategias para la inclusión de la perspectiva de género en las políticas educativas; finalmente y como tercer componente se hace referencia a la experiencia del Gobierno Vasco en materia de Coeducación, extrayendo de la misma los principales lineamientos aplicables al contexto colombiano; todo lo anterior con el fin último de demarcar el camino de la educación con perspectiva de género hacia un modelo de coeducación que garantice la plena satisfacción de los derechos de igualdad y no discriminación del estudiantado en Colombia.

\subsubsection{Los organismos internacionales frente a la educación con perspectiva de género}

En todas las regiones, hay personas que sufren violencia y discriminación debido a su orientación sexual o identidad de género. En muchos casos, la sola percepción de homosexualidad o identidad transgénero pone a las personas en situación de riesgo. (Naciones Unidas, 2011)en consecuencia, los organismos internacionales han visto en la educación la herramienta más importante para superar dicha problemática y es en este entendido que se plantea la necesidad de repensar la educación como base para la superación de la violencia, discriminación e inequidad presente en la sociedad.

Lo anterior encuentra sus cimientos principalmente en dos pronunciamientos de la Organización de las Naciones Unidas para la Educación, la Ciencia y la Cultura UNESCO-: la Declaración Mundial sobre la Educación para Todos (1990) y la Declaración de Incheon (2015). Estas dos herramientas de manera conjunta contemplan la necesidad de cambiar la estructura educativa con miras hacía una 
educación más equitativa. La primera de ellas, de manera general señala un bosquejo de educación para todos sin distinción alguna; y la segunda, se enfoca de manera particular en la necesidad de abordar la educación desde una perspectiva de género como mecanismo para alcanzar los objetivos de desarrollo plasmados en la agenda 2030, siendo estos los principales pronunciamientos que han aportado instrumentos importantes para la adopción de una educación equitativa y no discriminatoria.

\subsubsection{Educación para todos, una iniciativa para superar la discriminación e inequidad basada en género}

Actualmente la educación es uno de los puntos más importantes dentro de la agenda internacional, y ello se evidencia cuando la Declaración Universal de los Derechos Humanos (1948) contempla a la educación como un derecho de toda persona y la cual tiene como objeto el pleno desarrollo de la personalidad humana y el fortalecimiento del respeto a los derechos humanos y a las libertades fundamentales, sin embargo no es sino hasta la Conferencia de Jomtien convocada por la UNESCO y su Declaración Mundial sobre la Educación para Todos -EPT- (1990), que se empieza a concebir la necesidad de transformar los sistemas de enseñanza a nivel mundial en torno a una educación inclusiva, eliminándose de la educación todos los estereotipos en torno a los sexos y modificando las desigualdades en materia de educación, suprimiendo así la discriminación y disparidad en el aprendizaje. (UNESCO, 1990)

Sin lugar a dudas, una de las iniciativas más ambiciosas y por ello considerada el germen de la inclusión ha sido la EPT (Parrilla, 2002), pues la misma supuso un compromiso internacional para la conquista de una verdadera educación de calidad sin exclusiones, proyecto que implicó la eliminación de procesos y mecanismos de enseñanza excluyentes, motivados por razón de género, etnia, clase social, religión, orientación sexual y discapacidad, (Azorín, 2017)

En este orden de ideas, en el año 2000 se llevó a cabo el Foro de Dakar, al cual acudieron representantes de 164 países y se comprometieron a diseñar y aplicar 
estrategias integradas para lograr la igualdad entre los géneros en materia de educación, basándose en el reconocimiento de la necesidad de cambiar las actitudes, los valores y las prácticas que se desarrollan en la comunidad educativa (UNESCO, 2000); de esta manera y conforme a las disposiciones consagradas en la Convención sobre la eliminación de todas las formas de discriminación contra la mujer - CEDAW(1979), se entiende que dichas estrategias deben estar orientadas a garantizar no solo las oportunidades de acceso a los programas de educación sino a la eliminación de todo concepto estereotipado de los papeles masculino y femenino en todos los niveles y en todas las formas de enseñanza, mediante la modificación de los libros y programas escolares y la adaptación de los métodos de enseñanza.

Así las cosas, de acuerdo a lo planteado hasta el momento, la UNESCO desde su papel promovedor ha abanderado e impulsado en gran medida este proceso de cambio, acogiendo en la misma compromisos de igualdad de género como un aspecto trascendental para el logro de los Objetivos de Desarrollo Sostenible -ODS-; es por ello que en el siguiente acápite se hace referencia quizás a uno de los pronunciamientos más importantes de esta Organización respecto a la inclusión de la perspectiva de género como eje transversal de una educación inclusiva e igualitaria para todos, partiendo de la necesidad conjunta de lograr los objetivos de desarrollo sostenible plasmados en la agenda 2030.

\subsubsection{Declaración de Incheon: el móvil para una educación inclusiva, equitativa y de calidad.}

La Agenda para el Desarrollo Sostenible 2030 (2015)inauguró un nuevo capítulo en la larga lucha encaminada a realizar la igualdad entre los géneros. Su compromiso de "no dejar a nadie atrás" expresa la convicción de que los beneficios del desarrollo deberían alcanzar a niños y niñas, a hombres y mujeres por igual (2018); por lo tanto, ninguna meta de la Agenda puede considerarse como alcanzada si no se incluye la igualdad de género como eje transversal de las políticas adoptadas. La UNESCO (2018)supone que crear un mundo más inclusivo, justo y equitativo, como esencia del 
desarrollo sostenible, implica garantizar que todos en igualdad de condiciones, puedan llevar vidas dignas y ser dueños de su destino.

Así, la Declaración de Incheon y el Marco de Acción para la realización del Objetivo de Desarrollo Sostenible cuatro, cual es Garantizar una educación inclusiva y equitativa de calidad y promover oportunidades de aprendizaje permanente para todos (2015), concretó los compromisos y lineamientos necesarios para lograr un aumento significativo de las inversiones destinadas a mitigar la disparidad entre los géneros y fortalecer el apoyo a las instituciones en relación con la igualdad y el empoderamiento de las mujeres en el plano mundial, regional y nacional; de igual forma, se delimito dentro de la misma, la intención de eliminar todas las formas de discriminación y violencia contra las mujeres y las niñas, mediante la participación de los hombres y los niños, teniendo en cuenta la incorporación sistemática de una perspectiva de género.

Es claro entonces que la igualdad de género se encuentra estrechamente relacionada con el derecho a la educación para todos y lograrla requiere de un enfoque basado en los derechos que garantice no solo que las niñas, los niños, las mujeres y los hombres obtengan acceso a los distintos niveles de enseñanza y los cursen con éxito, sino que adquieran las mismas competencias en la educación y mediante ella.

Así las cosas y a manera de conclusión, el marco de acción de Incheon (Unidas, 2015) prevé que para garantizar la igualdad de género es necesario que en los sistemas educativos se tomen medidas expresas destinadas a acabar con los prejuicios basados en el género y la discriminación, que se derivan de actitudes y prácticas sociales y culturales y de la situación económica.

\subsubsection{Otros pronunciamientos anexos}

Ahora bien, cabe señalar a manera de complemento el pronunciamiento de las Naciones Unidas respecto a la transversalidad del enfoque de género en el desarrollo y ejecución de las políticas, el cual surgió principalmente de las cuatro conferencias 
mundiales sobre la mujer, que se celebraron en Ciudad de México (1975), Copenhague (1980), Nairobi (1985) y Beijing (1995).

La Cuarta Conferencia Mundial sobre la Mujer, celebrada en Beijing en 1995, marcó un importante punto de inflexión para la agenda mundial de igualdad de género. La Declaración y Plataforma de Acción de Beijing, adoptada de forma unánime por 189 países, constituye un programa en favor del empoderamiento de la mujer y en su elaboración se tuvo en cuenta el documento clave de política mundial sobre igualdad de género. De esta forma, cabe precisar que el Programa de las Naciones Unidas para el Desarrollo -PNUD-, adoptó la Estrategia de Transversalización de Género (o gender mainstreaming, en inglés) como el medio más adecuado para avanzar en la equidad de género.

Esta estrategia implica integrar el enfoque de equidad de género de forma transversal en todas las políticas, estrategias, programas, actividades administrativas y financieras del PNUD, así como en la cultura institucional, de modo a contribuir verdaderamente a cerrar las brechas de desarrollo humano que persisten entre hombres y mujeres. (PNUD, 1995).

Lo dicho hasta aquí supone entonces el lineamiento internacional que ha delimitado el quehacer de los Estados en cuanto a la reestructuración de la educación como eje transformador de las disparidades existentes entre hombres y mujeres, estableciendo la necesidad de incluir como principio integral de la misma la perspectiva de género.

Todo lo señalado hasta el momento, encuentra su razón de ser en la iniciativa por eliminar de la educación los estereotipos basados en el sexo y la discriminación e inequidad que se deriva de dicha situación, todo ello a partir de la transformación de la estructura educativa, la cual incluye la transformación del cuerpo institucional abarcando la formación docente y la preparación del estudiantado en derechos humanos y respeto por los mismos. 


\subsubsection{La perspectiva de género en la educación nacional de Colombia}

Ahora bien, una vez delimitadas desde la perspectiva internacional las prerrogativas normativas que conducen a una educación inclusiva y no discriminatoria, es importante pasar a ahondar en el presente capítulo la adopción e implementación de estos criterios en el sistema educativo colombiano y los principales mecanismos mediante los cuales se incluye la perspectiva de género en la preparación académica de la persona.

En este orden de ideas y partiendo de la Constitución Política de Colombia, se hace necesario recordar que la misma establece una serie de principios y derechos que son fundamentales para el desarrollo estratégico y legislativo de mecanismos que garanticen el acceso y permanencia en la educación de todos los niños, niñas y adolescentes sin ningún tipo de distinción. De esta forma, el Estado colombiano reconoce y protege la diversidad étnica y cultural de la Nación (Artículo 7), garantiza la libertad e igualdad de los ciudadanos ante la ley (Artículo 13) y el libre desarrollo de su personalidad (Artículo 16).

Por otro lado, propende por el fomento de prácticas democráticas en todas las instituciones de educación (Artículo 41), contempla además en su artículo 67 que la educación es un derecho de la persona y un servicio público que tiene una función social; con ella se busca el acceso al conocimiento, a la ciencia, a la técnica, y a los demás bienes y valores de la cultura; se establece así mismo que la educación forma al colombiano [sic] en el respeto a los derechos humanos, a la paz y a la democracia.

Conforme a dichas disposiciones constitucionales, el Gobierno Colombiano ha puesto en marcha a través de la ley 115 de 1994 la ley general de educación, la cual de manera conjunta al decreto 1860 de 1994 por el cual se reglamenta parcialmente la Ley 115 de 1994, han sentado las bases para emplear una educación con perspectiva de género entendiendo la necesidad de su abordaje dentro de los proyectos educativos 
institucionales - PEI- y de los Manuales de Convivencia como una herramienta para superar la discriminación e inequidad en las aulas.

Por lo anterior, el Estado Colombiano a través del Ministerio de Educación Nacional -MEN- ha impulsado una serie de políticas encaminadas a promover estrategias de educación en género desde sus diferentes concepciones. Así las cosas, en los siguientes acápites se desarrollarán los principales mecanismos acogidos para implementar la perspectiva de género como principio trasversal de los $\mathrm{PEl}$.

\subsubsection{Ley general de educación y su decreto reglamentario 1860 del 3 de} Agosto de 1994.

Colombia mediante la ley 115 de 1994 (Ley general de educación) señaló a la educación como un proceso de formación permanente que se fundamenta en una concepción integral de la persona humana, de su dignidad, de sus derechos y de sus deberes. (Congreso de la República, 1994); si bien es cierto, la misma no contempla de manera taxativa la perspectiva de género como eje fundamental para su actuar, de la literalidad de la misma se puede extraer algunas disposiciones tendientes a exaltar el papel equitativo, igualitario y no discriminatorio de la educación; en esta línea y conforme al artículo 67 de la Constitución Política, la ley en mención señaló trece fines de la educación, de los cuales vale la pena precisar:

1. El pleno desarrollo de la personalidad sin más limitaciones que las que le imponen los derechos de los demás y el orden jurídico.

2. La formación en el respeto a la vida y a los demás derechos humanos, a la paz, a los principios democráticos, de convivencia, pluralismo, justicia, solidaridad y equidad, así como en el ejercicio de la tolerancia y de la libertad.

3. La formación para facilitar la participación de todos en las decisiones que los afectan en la vida económica, política, administrativa y cultural de la Nación. (Congreso de la República, 1994) 
Situación similar sucede con el contexto del decreto 1860 de 1994, pues si bien establece la hoja de ruta para alcanzar los fines señalados al igual que la ley 115 , no contempla una perspectiva de género dentro de sus mecanismos; sin embargo, vale la pena resaltar el Artículo 14 en el entendido que exhorta a las instituciones educativas a desarrollar con la participación de la comunidad educativa, su Proyecto Educativo Institucional -PEI-.

Ahora bien, este decreto para lograr la formación integral de los educandos señala que el PEI debe contener por lo menos los siguientes aspectos, a saber, los principios y fundamentos que orientan la acción de la comunidad educativa en la institución; el análisis de la situación institucional que permita la identificación de problemas y sus orígenes; los objetivos generales del proyecto; la estrategia pedagógica que guía las labores de formación de los educandos; la organización de los planes de estudio y la definición de los criterios para la evaluación del rendimiento del educando, entre otros.

Así las cosas, una vez señalados los fines de la educación y la hoja de ruta para su desarrollo, resulta necesario abordar aquellos planes de gobierno y normativa conexa a la finalidad de incluir de manera transversal la perspectiva de género en materia educativa, pues la ley general de la educación y su decreto reglamentario por sí solos no la contemplan como una prioridad.

\subsubsection{Estrategias del Gobierno Nacional para el adelanto de la perspectiva de género como principio rector de las políticas de educación}

Si bien es cierto la educación propende por el respeto a los derechos e intereses propios del individuo, la perspectiva de género no aparece de manera taxativa como una prioridad en materia educativa; sin embargo, en el Área de Educación y cultura de la Consejería Presidencial para la Equidad de la Mujer -CPEM- se plantea como objetivo una educación para la vida que promueva el aprecio por la diversidad, la tolerancia y el respeto a las diferencias de género de las personas, así como garantizar, con igualdad y equidad, en todos los niveles, tipos y modalidades 
educativas, atención específica a las niñas y las mujeres, para ampliar su participación y desempeño en todos los campos de la actividad humana con un sentido de justicia, al margen de prejuicios y discriminaciones. (CPEM, 2003)

Ahora bien, al pie de lo anterior el Plan Nacional de Educación en Derechos Humanos -PLANEDH - (2012) contempla la transversalidad de la perspectiva de género en la educación en derechos humanos como el eje fundamental para el desarrollo pedagógico, entendido éste como un proceso de articulación intencionada y permanente de los fundamentos, los principios y los conocimientos de derechos humanos con los contextos donde opera la educación. (Vicepresidencia de la República, 2012); en este entendido, el PLANEDH (2012) señala como aspecto trascendental la transformación de la cultura escolar a través de los proyectos educativos señalados, pues los mismos deben tender a hacer realidad los principios consagrados al respeto de la dignidad humana y al trato digno, y a que no existan tratos discriminatorios basados en prejuicios y en estereotipos no aceptables.

Finalmente, anexo a las anteriores estrategias: el Estado colombiano acoge el Plan Nacional Decenal de Educación 2016-2026 -PNDE- (Ministerio de Educación Nacional, 2017), el cual se establece como una hoja de ruta y horizonte para el desarrollo educativo y como referente obligatorio de planeación para todos los gobiernos e instituciones educativas; plan que se encuentra dirigido al diseño y realización de proyectos pedagógicos orientados al reconocimiento de las diferencias culturales, étnicas, religiosas, políticas, socioeconómicas y de opción de género que garanticen el ejercicio pleno de los derechos humanos y civiles en el marco de la política pública del PLANEDH.

Por otro lado, es necesario señalar también que mediante el convenio 0753 del 2016, las siguientes agencias del sistema: UNICEF - Fondo de las Naciones Unidas para la Infancia -, el UNFPA -Fondo de Población de las Naciones Unidas- y el PNUD Programa de Naciones Unidas para el Desarrollo - asisten técnicamente al Ministerio de Educación Nacional en el mejoramiento de la calidad de la educación como una 
herramienta indispensable para la construcción de una sociedad en paz y equitativa (PNUD, 2016).

Según el PNUD (2016)el propósito de dicha cooperación es brindar herramientas concretas a las instituciones educativas del país para incorporar en sus PEI, de forma coherente y pertinente, estrategias que promuevan el desarrollo de competencias de los niños y las niñas para el ejercicio de su ciudadanía, el goce de sus derechos, la participación efectiva y el respeto y protección de los derechos de los demás.

En este entendido y si bien es cierto las agencias del Sistema de Naciones Unidas valoran positivamente el esfuerzo del Ministerio de Educación Nacional y las Secretarías de Educación, para dar cumplimiento a los compromisos internacionales (PNUD, 2016) la tarea aún dista de dar los resultados esperados, pues todavía hoy se evidencian manifestaciones de discriminación e intolerancia con respecto a la identidad de género dentro de las instituciones de educación; es por ello, que a continuación se expone a manera de ejemplo la restructuración educativa que ha adelantado el Gobierno Vasco hacia un modelo de coeducación; pues el mismo, se convierte en un referente plausible para Colombia en la construcción y adecuación progresiva de un modelo de educación que permita la convivencia pacífica en el marco de la diferencia y la diversidad y contribuya a eliminar dichas manifestaciones de discriminación e intolerancia presentes en la comunidad educativa.

\subsubsection{Desde la perspectiva de género hacia la construcción de un modelo de coeducación. La experiencia del gobierno Vasco.}

Hasta el momento se ha expuesto de manera general los lineamientos nacionales e internacionales adoptados por el Estado colombiano, sin embargo, en aras de exponer la experiencia de países que han acogido y enfocado su atención en promover su educación desde la perspectiva de género, este último capítulo se centra en exponer la importancia y principales lineamientos del modelo coeducativo desde la experiencia del gobierno Vasco, quien como se expondrá a continuación, ha optado por la 
aplicación taxativa y afirmativa de políticas públicas en materia de educación con perspectiva de género, por lo que resulta interesante a la luz del presente estudio conocer qué medidas se han tomado en la materia como quiera que tales medidas sirven como un modelo a seguir dentro del contexto nacional colombiano, más si se tiene en cuenta, que la gran crítica al actual modelo educativo torna en que éste se presenta obsoleto ante los nuevos contextos y requerimientos de la sociedad. La experiencia de este gobierno, a la luz del presente trabajo, se torna como ejemplo fundamental y que debería servir como pilar para la formulación de políticas sobre el tema en cuestión al interior de Colombia.

La coeducación como herramienta de transformación social para el gobierno Vasco: La coeducación supone y exige como derecho humano situaciones de igualdad de oportunidades reales en todos los tipos, niveles y modalidades educativas, de tal modo que nadie por razones de sexo parta de una situación de desventaja o tenga que superar especiales dificultades para llegar a los mismos objetivos (Sanchez \& R, 1992).

Conforme a lo anterior y de acuerdo al Gobierno Vasco (2013), el plan de coeducación se impulsa en el planteamiento educativo, cuyo objetivo es la desaparición progresiva de las desigualdades de género, tanto en la ideología y en la práctica educativa, toda vez que como ya se ha señalado en otras oportunidades, el sistema educativo es un agente de socialización muy significativo, que interviene en la configuración de las identidades de toda la ciudadanía. Es por ello que resulta un sector estratégico en el cambio de valores hacia una sociedad más justa e igualitaria entre mujeres y hombres. De hecho, el sistema educativo y la escuela tienen una responsabilidad ineludible en el avance hacia la igualdad de mujeres y hombres y en la eliminación de la violencia contra las mujeres. (Vasco, 2013)

La Ley $4 / 2005$, de 18 de febrero, para la igualdad de Mujeres y Hombres, aprobada por el Parlamento Vasco, reconoce este papel protagónico del sistema educativo en materia de igualdad. Así en su Título III recoge todo un capítulo dedicado 
a medidas dirigidas a la igualdad en el área de intervención de Educación, tanto en la enseñanza universitaria como en la enseñanza no universitaria.

Pero además de la Ley 4/2005, existe una extensa normativa que afecta al ámbito educativo en materia de igualdad: tanto normativa específica en materia de igualdad, que incluye articulado dirigido a que las administraciones educativas desarrollen medidas a favor de la igualdad de mujeres y hombres en sus políticas, como normativa de carácter sectorial que también incluye mandatos en la materia (Vasco, 2013).

Sin embargo y ante la imposibilidad de abarcar cada una de las normas el siguiente cuadro acoge los principales referentes normativos de la coeducación:

Tabla 1. Resumen del marco jurídico referente en materia de igualdad y educación en el Gobierno Vasco

\section{Marco jurídico en el ámbito educativo}

1. Ley $1 / 1993$ de 19 de febrero, de la Escuela Pública Vasca

2. Ley Orgánica 2/2006, de 3 de mayo, de educación

3. Decreto $201 / 2008$ sobre derechos y deberes de los alumnos y alumnas de los centros docentes no universitarios

\section{Marco jurídico en el ámbito de las políticas de igualdad}

1. Ley $1 / 2004$ de 28 de diciembre, de medidas de protección integral contra la violencia de género.

2. Ley $4 / 2005$ de 18 de febrero, para la igualdad de mujeres y hombres.

3. Ley $3 / 2007$, de 22 de marzo para la igualdad efectiva de mujeres y hombres.

4. VI plan para la igualdad de mujeres y hombres de la CAE

5. II acuerdo interinstitucional para la mejora en la atención a las mujeres víctimas de maltrato en el ámbito doméstico y violencia sexual

6. Recomendación $\mathrm{CM} / \operatorname{Rec}(2007) 13$ del comité de ministros relativa a la integración de la dimensión de género en la educación

7. Ley 14/2012, de 28 de junio, de no discriminación por motivos de identidad de género y de reconocimiento de los derechos de las personas transexuales

Fuente: Gobierno Vasco (2013).

El Gobierno Vasco parece tener una estructura Normativa sólida en cuanto a la inclusión de la perspectiva de género en la educación se trata; sin embargo, tal y como 
se expone dentro del Plan Director para la coeducación y la prevención de la violencia de género en el sistema educativo (2013), el trabajo no ha finalizado y si bien ha habido grandes avances en materia de igualdad de género, aún queda un camino por recorrer en cuanto a una educación en género. Es por ello que a continuación se exponen los principales retos a alcanzar en materia de coeducación:

Retos para la comunidad educativa del gobierno Vasco: El Plan Director para la coeducación y la prevención de la violencia de género en el sistema educativo (Vasco, 2013) señala la importancia y la complejidad de la tarea de transformar los valores sexistas hacia valores de igualdad de mujeres y hombres en este sentido y de acuerdo al plan en cita se describen algunos de los retos que el Gobierno Vasco ha señalado como prioridad en materia de coeducación; en los siguientes términos:

- Ahondar en el modelo de escuela coeducativa e introducir la perspectiva de género en la cultura y en las prácticas de los centros desde un planteamiento integral.

Las investigaciones de la Agencia Ejecutiva en el Ámbito Educativo y Cultural (2010) confirman que el sistema escolar sigue reproduciendo el sexismo y los estereotipos de género a través de diversos aspectos como: la propia organización del centro, las actitudes y expectativas del profesorado, el currículo académico, las materias que se estudian y las que no se estudian, los libros de texto y materiales didácticos, la orientación educativa y profesional, el lenguaje, el espacio, las relaciones con las compañeras y con los compañeros, las relaciones con el profesorado y entre el profesorado y en la metodología de enseñanza - aprendizaje (Vasco, 2013).

Es por ello que en aras de superar esta realidad se acogen algunos aspectos en los que se considera que es necesario seguir trabajando con un enfoque integral, como por ejemplo: la revisión del currículum desde la perspectiva de género, potenciar la elección de libros de textos y materiales didácticos inclusivos y coeducativos, capacitar, 
para ser conscientes sobre las diferentes expectativas que persisten respecto al alumnado entre otros.

- Orientar al alumnado a elegir su itinerario vital, académico y profesional desde la libertad, la diversidad de opciones y sin condicionamientos de género.

A pesar de los avances, las elecciones personales, profesionales y vitales de las alumnas y alumnos siguen estando marcadas por los estereotipos de género. En bachillerato los chicos optan mayoritariamente por la modalidad científico- técnica mientras que las chicas son mayoría en las opciones relacionadas con las ciencias sociales y humanas. Estas opciones condicionan también las posteriores elecciones de las carreras universitarias. (Vasco, 2013)

Por ello, el gobierno mediante Plan Director para la coeducación y la prevención de la violencia de género en el sistema educativo (Vasco, 2013) señala que la coeducación es imprescindible a la hora de equilibrar, ajustar, compensar y neutralizar el género en todo el proceso de socialización. Señala como necesario intervenir en este proceso desde todas las vías: asignaturas, mensajes explícitos e implícitos del profesorado, familias, etc.

- Integrar la perspectiva de género en el abordaje del fracaso escolar y garantizar que el acceso al sistema educativo sea universal, y la continuidad en éste para todas las niñas y niños, teniendo en cuenta la diversidad del alumnado (étnica, cultural, social, económica, funcional, sexual, etc.).

Como ya se ha apuntado, la diferencia de expectativas del profesorado incide en las conductas del alumnado. En este sentido, hay que remarcar que se trata de conductas, generalmente, inconscientes pero que tienen gran repercusión en las vidas del alumnado, ya que se refuerzan comportamientos sexistas. Así, por ejemplo, en los chicos se inculca menos que en las chicas el que sean obedientes, formales, colaboradores, que ayuden a sus compañeras y compañeros, etc, mientras que en las 
chicas se potencia menos el que tomen iniciativas, que tengan su propia opinión, que sean asertivas, etc. (Vasco, 2013).

Este modelo hegemónico de masculinidad y feminidad provoca una gran cantidad de infelicidad tanto en las niñas como en los niños y es uno de los factores responsables de menores logros académicos que incluso provocan manifestaciones de agresividad y violencia en las escuelas, (Vasco, 2013) es por ello que Integrar la perspectiva de género en el abordaje del contexto escolar promueve la eliminación de estereotipos y roles sexistas y contribuye a la superación de la discriminación, violencia e inequidad en las aulas.

- Educar para unas relaciones afectivo sexuales y una convivencia basada en la diversidad sexual y en la igualdad de mujeres y hombres.

En un estudio realizado entre jóvenes por la Universidad del País Vasco, Euskal Herriko Unibertsitatea (2008) revela que las relaciones afectivo sexuales entre jóvenes están marcadas por las ideas sobre lo que es ser un hombre de verdad o ser una buena chica y por los modelos femeninos y masculinos.

En este contexto el Plan Director para la coeducación y la prevención de la violencia de género en el sistema educativo (Vasco, 2013), señala que la escuela debe favorecer la adquisición de competencias en el ámbito de la sexualidad y la afectividad que estén basadas en la igualdad de mujeres y hombres y el respeto a la diversidad sexual, alejadas de los estereotipos sexistas y de las imposiciones sociales. Se trata, por tanto, de lograr que las y los adolescentes, terminada la formación escolar posean los recursos necesarios para gestionar sus necesidades afectivas y sexuales desde modelos donde resulten atractivas las relaciones igualitarias, basadas en el diálogo, el respeto a todas las orientaciones y las opciones personales y el buen trato. 
- Prevenir la violencia de género, detectar de forma precoz los casos y prestar una atención eficaz a las víctimas, implicando de manera especial a toda comunidad educativa.

Trabajar la igualdad de mujeres y hombres y la coeducación en la escuela, constituyen la garantía a largo plazo para acabar progresivamente con el sexismo y en consecuencia con los valores y comportamientos que sostienen la violencia de género. En este sentido y en aras de mitigar la violencia de género que se presentase en las aulas, el plan Director para la coeducación y la prevención de la violencia de género en el sistema educativo acogido por el gobierno Vasco (Vasco, 2013), señala la necesidad de implementar a partir de un marco preventivo y de detección precoz las acciones correspondientes para frenar la violencia y corregir al estudiantado que se desenvuelve en este contexto.

Conforme lo señalado, hasta el momento la experiencia del sistema educativo del Gobierno Vasco respecto a la inclusión de la perspectiva de género en un modelo de coeducación es mucho más garantista que hablar de manera desarticulada de políticas de género aplicables al contexto educativo en Colombia; pues resulta que una educación con miras a erradicar de la comunidad educativa estereotipos de género que conllevan a la violencia, discriminación e inequidad en las aulas, exige de las autoridades educativas una mayor intervención en la materia.

\subsection{La perspectiva de género en la educación nacional de Colombia desde los proyectos educativos institucionales: estudio de caso}

Con miras a exponer lo pertinente, éste acápite de la investigación debe iniciar delimitando el contexto social en el que se desarrolla y opera el colegio que servirá de muestra para, como se expuso en su momento, establecer un primer panorama, si quiera a nivel municipal o departamental, de cómo se abordan los temas de género e inclusión en los centros educativos públicos dirigidos por comunidades religiosas en un país laico como el colombiano; en tal sentido, ha de abordarse con la caracterización 
del municipio de el Tambo seguido de la exposición de la pertinencia del estudio de caso en la Institución Municipal Sagrado Corazón de Jesús para, posteriormente, avanzar con los resultados obtenidos de los diferentes medios de recolección de datos aplicados a la comunidad educativa.

\subsubsection{Contexto social e identificación del municipio El Tambo, Nariño}

El municipio de El Tambo, fue creado mediante la Ordenanza No. 78 del 22 de enero de $1870^{2}$. Se caracteriza por ser un municipio de categoría 6 y cuenta con un total aproximado de 11.531 habitantes (DANE, 2017), de éste municipio ha de exponerse que socialmente es similar a la población del departamento: es de economía agrícola y ganadera, marcadamente tradicionalista y con una mayoría de habitantes que profesan y aplican la fe católica.

En materia de educación, se ha determinado por parte del actual gobierno municipal dentro del Plan de Desarrollo para el periodo 2016 - 2019, que este territorio cuenta con una brecha social referente al analfabetismo para mayores de 15 años de $10.5 \%$, así como su cobertura de educación media para el año 2014 del 39,2\%, no obstante, la meta de cobertura para el 2016 es de 55,7\% (DANE, 2017).

\subsubsection{Caracterización de la Institución Educativa Municipal Sagrado Corazón de Jesús}

Esta Institución es un centro educativo de tipo oficial con la cobertura más grande del municipio, en cuanto a población estudiantil se trata, ya que abarca dentro de su actividad la educación básica primaria, básica secundaria, educación media, así como también, la educación primaria y bachillerato por ciclos para adultos; el colegio en niveles académicos llama la atención en virtud a lo siguiente:

\footnotetext{
${ }^{2}$ Información brindada por el portal Nariño.info (2014)
} 
> Fue objeto de reconocimiento por el Ministerio de Educación Nacional -MENconsiderando su alto nivel en los Índices Sistemáticos de Calidad Educativa -ISCEen noviembre de 2015.

> Asimismo, la I.E.M Sagrado Corazón de Jesús en el año 2016 fue exaltada junto a otras instituciones, por parte de la Gobernación de Nariño a razón de: un PEI sobresaliente, por experiencias significativas en el eje Convivencia, el reconocimiento obtenido por una estudiante para ser beneficiaria del programa Ser Pilo Paga, y en lo referente a grupos y bandas musicales. (Secretaría de Gobernación de México, 2016)

> La I.E Sagrado Corazón de Jesús, en 2017, tuvo como potenciales beneficiarios del programa estatal Ser Pilo Paga 2 -SPP2- la totalidad de 7 estudiantes.

Este plantel, inició sus labores en 1923, siendo de carácter nacionalizado y dirigido por la comunidad religiosa de las Hermanas Bethlemitas; dentro de la comunidad también se ha distinguido por estar regida por principios religiosos y cristianos en su "quehacer educativo"; en específico, conciben su labor educadora como un medio evangelizador en los principios cristianos de amor, fraternidad, paz y misericordia desde una perspectiva ecuménica o universal acorde a los preceptos constitucionales referentes a la libertad de culto (PEI, p. 2).

Con el objetivo de demostrar el impacto que generan las disposiciones legales y constitucionales con respecto a la perspectiva de género como eje transversal del Estado y sus instituciones, se ha elegido a la Institución Municipal Sagrado Corazón de Jesús de la ciudad de Pasto (Nariño) para estudiar la aplicación de este eje dentro de su actividad educativa, debido a que esta institución educativa es de carácter público, la cual alberga una población estudiantil grande y cuyo cuerpo directivo ostenta la fe católica; aspecto que es de gran importancia si se tiene en cuenta la población estudiantil con la que cuenta la Institución y que se ilustra a continuación: 
Tabla 2. Número de estudiantes matriculados por grado en la Institución Educativa Sagrado Corazón de Jesús. 2016

\begin{tabular}{lll}
\multicolumn{2}{l}{\begin{tabular}{l}
\multicolumn{2}{l}{ Educación } \\
Grado
\end{tabular}} & \multicolumn{2}{l}{ Total } \\
\hline $\mathbf{1}$ & Transición & 22 \\
& Transición & \\
$\mathbf{2}$ & & 18 \\
& $\mathbf{1}$ & 50 \\
$\mathbf{2}$ & 46 \\
$\mathbf{3}$ & 53 \\
$\mathbf{4}$ & 58 \\
$\mathbf{5}$ & 54 \\
\hline Total & 301 \\
\hline Educación Básica Secundaria y Media \\
\hline $\mathbf{6}$ & $\mathbf{8 0}$ \\
$\mathbf{7}$ & 87 \\
$\mathbf{8}$ & 87 \\
$\mathbf{9}$ & 129 \\
$\mathbf{1 0}$ & 70 \\
$\mathbf{1 1}$ & 96 \\
\hline Total & $\mathbf{5 4 9}$ \\
\hline Gran Total & $\mathbf{8 5 0}$ \\
\hline Educación Formal Para Adultos \\
\hline Ciclo IV & $\mathbf{2 8}$ \\
Ciclo V & 20 \\
Ciclo Vi & 19 \\
Total & $\mathbf{6 7}$ \\
\hline
\end{tabular}

Fuente: Institución Educativa Municipal Sagrado Corazón de Jesús (2019)

Tal contexto permite el estudio a pequeña escala, por la dimensión territorial y poblacional del municipio, pero dentro de un panorama más amplio teniendo en cuenta los efectos que la aplicación o no de la perspectiva de género en la institución educativa tiene, a nivel social, con personas o comunidades que no son objeto de la actividad principal de la institución como, por ejemplo, la familia extensiva de los estudiantes o los propios núcleos familiares del personal de la institución. 
Expuesto lo anterior, se procedió al correspondiente análisis del Proyecto Educativo Institucional para el periodo 2017-2018 con el fin de determinar claramente los planes, programas y/o proyectos pedagógicos correspondientes a la inclusión de la perspectiva de género y los mecanismos mediante los cuales se difunde en la comunidad educativa.

\subsubsection{Análisis del Proyecto Educativo Institucional y el Manual de convivencia adscritos a la Institución Educativa Municipal Sagrado Corazón de Jesús}

Toda institución educativa parte de algunos cimientos que permiten a su planta docente, administrativa y estudiantil, impartir y recibir conocimiento, funcionar atendiendo a las leyes que los rigen y adoptar una serie de derechos y deberes que contribuyen a actuar bien y cumplir con los roles socialmente determinados, los cuales son el PEI, el Modelo Pedagógico, el Manual de Convivencia e incluso el Plan de Desarrollo; sin embargo, para que este procedimiento sea consecuente, todos aquellos actores que se encuentran en este entorno, deben conocer y contribuir a la construcción de valores y principios morales y éticos, que además de permitir una sana convivencia, aportan a la formación integral de los miembros de la comunidad educativa e impulsan la promoción del respeto por el otro y sus características particulares.

Es necesario mencionar que existe un marco jurídico-legal nacional e internacional que permite y reconoce la articulación de la perspectiva de género como parte estructural de los modelos estatales de educación en las sociedades globalizadas modernas. Esto deriva en un repensar de la educación como institución y/o estructura social, así como el papel que el individuo, la comunidad y el Estado juegan en la dinamización de dicha estructura. 
Por lo anterior los Proyectos Educativos Institucionales ${ }^{3}$ han sido concebidos como la herramienta efectiva por antonomasia para superar la discriminación e inequidad, desde las aulas y en cada una de las esferas de la vida del ser humano, transformando así la sociedad y su contexto ${ }^{4}$ en relación a un sentido de justicia, inclusión e igualdad, y desde la base misma: el ser humano.

Bajo este postulado, la Institución dentro de su PEI, ha establecido que su actividad pedagógica, administrativa y académica está encaminada garantizar una formación del estudiante: como ciudadano y como ser humano integral, según lo establezca las directrices del Ministerio de Educación -MEN-, que le permita al estudiante comprender, analizar, interpretar, explicar su realidad física y social; que lo motive para, además de aprender, superarse y fijarse metas altas para la vida; con el firme compromiso de la vivencia de la Justicia, la Solidaridad, la Fraternidad y el ejercicio del liderazgo en pro del desarrollo de los pueblos5. (PEI, p. 24)

De esta forma, la fundamentación de este documento como un factor epistemológico, sociológico y psicológico, orienta su accionar al reconocimiento del ser

${ }^{3}$ De acuerdo al Decreto 1860 de 1994, artículo 14, son cuatro los componentes de un Proyecto Educativo Institucional:

Componente de fundamentación: desde este eje, el PEI debería dar respuesta a preguntas como: ¿cuál es el concepto de educación que seguirá la Institución Educativa?, ¿qué modelo educativo (constructivista, personalizado, etc.) desarrollará?, ¿será una IE confesional o no?, etc.

Componente administrativo: aquí se define el personal necesario para llevar a cabo los objetivos del PEl. Planta docente, administrativa, directiva, y además, las necesidades de infraestructura.

Componente pedagógico y curricular: se define el enfoque pedagógico de la Institución, sus metodologías, plan de estudios, atención a poblaciones, entre otros.

Componente comunitario: se refiere a la relación de la IE con el entorno. La IE se planteará proyectos que abarquen a la comunidad en la cual se desarrolla, como proyectos ambientales, educativos, sociales, que involucren a la comunidad externa. (MEN, 2017, párr. 15)

${ }^{4}$ En este punto no está de más mencionar que a través del contexto de una comunidad, el conocimiento tiende a convertirse en un constructo social por cuanto es una representación de la realidad, condicionada a aspectos físicos, sociales, culturales y económicos, enmarcados a un contexto temporal; todo ello incide en la perpetuación de esas circunstancias particulares al planificar el currículo, como práctica permanente de la institución educativa. (Torres, s.f, párr. 4)

${ }^{5}$ Esto se hace consistente dentro de todo el PEI y Manual de convivencia. Al respecto, la Institución es enfática al manifestar que lo guía una filosofía humanista desde el punto religioso; por ello el centro educativo, entre otros valores y principios, fundamenta su 'servicio' o labor educativa dentro de la pedagogía del amor, la misericordia, la paz, respeto, etc. 
humano como un ser en constante cambio y evolución; que cohabita con otros seres humanos iguales entre sí, pero que, a su vez, aquellos 'otros' son diversos en múltiples maneras.

En el caso del manual de convivencia, la IEM busca infundir en los estudiantes el respeto y cortesía hacia las demás personas con que comparte el aula, 'tipificando' conductas inapropiadas dentro de la institución ${ }^{6}$. En general, el Manual establece que las agresiones verbales y físicas están prohibidas, se debe respetar los bienes propios de la institución, así como los bienes de propiedad de compañeros, docentes y demás personal de la misma, evitar el uso de las insignias institucionales o uniformes por fuera de horas o actividades académicas, que genere un detrimento al buen nombre del establecimiento, el consumo de sustancias psicoactivas o alcohol.

Sin embargo, y al igual que con el marco axiológico determinado en el PEl, se omite la inclusión de la violencia por cuestiones de género, orientación o identidad sexual dando tácitamente a entender que con buscar el respeto del 'otro' con miras de igualdad y justicia, la institución ataca de raíz la problemática social de discriminación de mujeres heterosexuales y personas con orientación sexual diversa.

\footnotetext{
${ }^{6}$ Un ejemplo de ello es el artículo 20 del Manual de Convivencia, establece como falta disciplinaria muy grave las "Prácticas de actos sexuales dentro de la Institución", si bien la Corte Constitucional en Sentencia T-364 de 2018 determinó que ante estas situaciones:

"La garantía del derecho a la privacidad depende en gran parte del lugar donde tienen lugar las acciones humanas. la mayoría de las actividades que llevan a cabo las personas tienen repercusiones sociales, aun así, pueden existir algunas acciones o actividades que solo interesan a la persona que las realice, y que de ninguna manera pueden ser objeto de restricciones (en lugares de servicios personales, de vestuario o descanso) (Corte Constitucional, Sentencia T-407, 2012).

"Los establecimientos educativos, la Corte ha expuesto, no se tratan de espacios públicos o privados, sino que caen en la categoría de semiprivados teniendo en cuenta que se trata de una comunidad en la cual existen códigos de convivencia y reglas preestablecidas, que también comparte cierta intimidad circunscrita a la vida común en el contexto cerrado del trabajo y del establecimiento educativo al cual solo acceden los trabajadores, o los estudiantes y profesores.

Por ello, la jurisprudencia de esta Corte ha concluido que es legítimo que las instituciones educativas desarrollen procedimientos disciplinarios cuandoquiera que se evidencie que una conducta puede afectar la convivencia de la comunidad académica o a algunos de sus integrantes, pero "no se podrá adjudicar consecuencias jurídicas restrictivas según el gusto, la tendencia o cualquier manifestación práctica de la sexualidad, pues esto pertenece a la esfera inviolable del proyecto de vida íntima". (Corte Constitucional, 2018) Se resalta.
} 
Un ejemplo de lo anterior, son algunos puntos consignados en el Manual de Convivencia con respecto de sus educandos "16. No ser discriminado en razón de su credo, raza, cultura, procedencia posición económica, ideológica o política." (Manual de Convivencia, art. 7.)

Con esta declaración, abiertamente la Institución Educativa desatiende el principio de diversidad y pluralismo que fundamenta la educación en Colombia actualmente; a su vez, en el mismo artículo, se manifiesta que otro derecho del estudiante es el de "17. Recibir por lo menos cada periodo capacitación o reflexiones acerca de la problemática actual (alcoholismo, drogadicción, sexualidad), por parte de los profesionales de apoyo o de entidades externas de la Institución." (Manual de Convivencia, p. 31)

Ante este hecho podría generarse el siguiente interrogante: ¿bajo qué criterios está siendo impartida la cátedra de sexualidad, cuando es más que claro que la realidad de las sexualidades diferentes a las heterosexuales, es un tema intencionalmente obviado dentro de la Institución?

Con lo anterior se logra identificar que el marco institucional que conforma el Manual de Convivencia y el PEI es muy ambiguo, por cuanto prohíbe conductas descalificadoras o irrespetuosas pero invisibiliza a las poblaciones vulnerables, desapareciéndolas de la realidad social de la comunidad educativa, y las desprotege en la medida que actos claramente discriminatorios pasan desapercibidos, o son minimizados, al no estar tipificados como conductas sancionables dentro del contexto de la Institución.

\subsubsection{Resultados del Estudio de Caso}

A continuación, se presentan algunos resultados obtenidos mediante la aplicación de los instrumentos de recolección de información, los cuales posibilitan tener una idea general de la importancia del PEI y del Manual de Convivencia para la Institución, su 
socialización ante la comunidad educativa y su respectivo cumplimiento, a partir de la perspectiva de docentes y directivos, padres de familia y estudiantes.

\section{- Cuerpo docente}

Los docentes debido a su vinculación laboral con la institución, se encuentran, en su mayoría, al tanto de los procesos llevados a cabo tanto en el PEI como en el manual de convivencia, como se observa en el gráfico 1.

El $33,33 \%$ de los docentes no ha participado en la elaboración del PEl y el $20 \%$ de ellos, no sabe si dentro de los objetivos contemplados en el documento, se conciba o no la perspectiva de género como un eje transversal para el desarrollo de la institución. El 46,67\% de los docentes plantea que esto no se cumple, aun cuando el $95,56 \%$ de ellos lo considera fundamental.

Además, para el $51,11 \%$ de la planta docente, no se está dando cumplimiento a las políticas de Estado en relación a la discriminación de sexo - género, motivo por el cual, una de las docentes expuso la siguiente observación:

"Nosotros como docentes debemos ser los primeros en recibir formación en asuntos de género, ya que nos permitirá tener una visión diferente con los alumnos" (Mujer, 49 años) 
Gráfico 1. Conocimiento y percepción de docentes frente al PEI y Manual de convivencia.

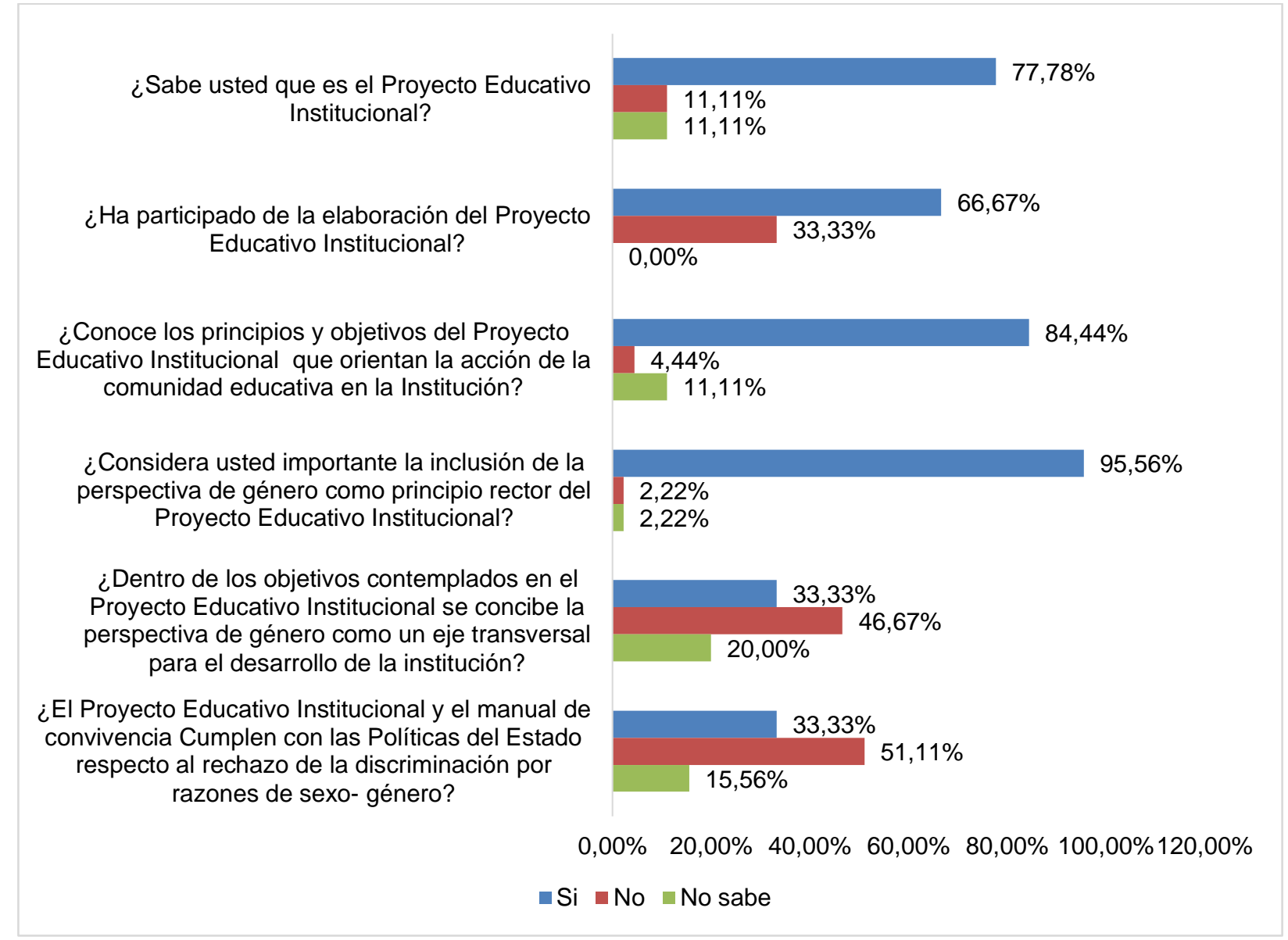

Fuente: esta investigación (2019)

Ante esta situación, los maestros exponen algunas debilidades con las cuales se hace posible explicar las principales fallas a la hora de dar un tratamiento adecuado del eje transversal de género dentro de la institución y que pueden visualizarse en el gráfico 2. 
Gráfico 2. Percepción de los docentes frente a la discriminación de género.

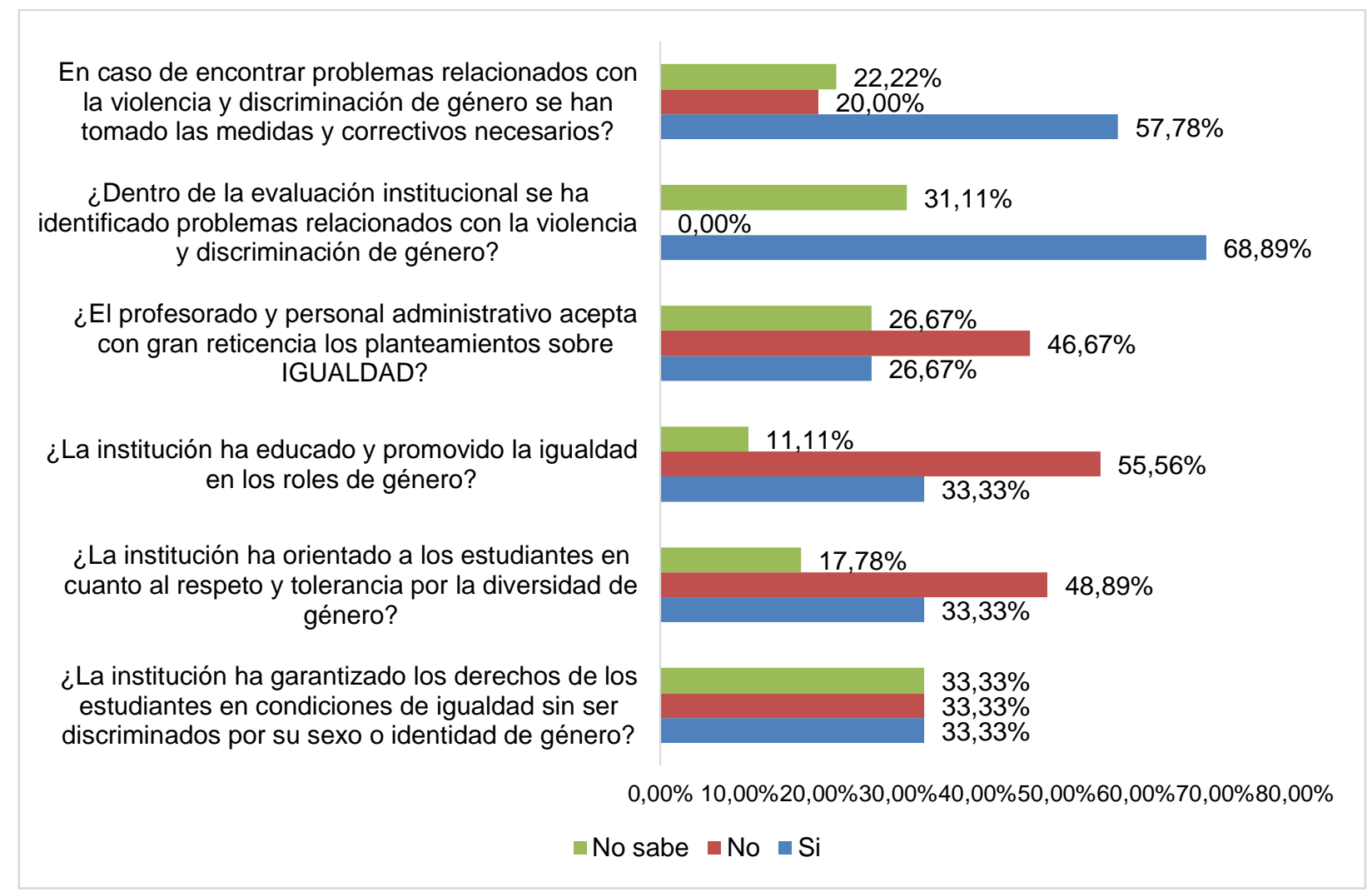

Fuente: esta investigación (2019)

El $57,78 \%$ de los docentes, expresan que para los casos de violencia y discriminación de género se han tomado correctivos relacionados con anotaciones en el observador académico o la suspensión de algunos días de clases. No obstante, para el $42,22 \%$ de ellos, no hay medidas al respecto o no sabe si son consideradas cuando se cometen estas fallas relacionadas al respeto por género.

Así mismo, aproximadamente el $50 \%$ opina que la institución no orienta a los estudiantes en cuanto al respeto y tolerancia por la diversidad de género, y el 55,56\% manifiesta que la institución educativa no promueve la igualdad en los roles de género, por lo cual, aquellas personas vulnerables, no pueden actuar con libertad dentro de su entorno.

El $46,67 \%$ de los encuestados afirma que tanto el personal docente como administrativo no acepta los planteamientos sobre igualdad, mientras que un $33 \%$ 
menciona que no se garantiza a los estudiantes condiciones de igualdad sin ser discriminados por su género u orientación sexual. Esto justificado principalmente, a causa de las creencias religiosas y culturales arraigadas en parte del personal de la institución.

En promedio, un $24 \%$ de los docentes encuestados no sabe lo que sucede al interior del plantel educativo en cuestión de perspectiva de género e identidad, lo que conlleva a plantear futuras cátedras que posibiliten a los docentes padres de familia y estudiantes informarse y entender lo que el concepto de género implica en la sociedad actual.

Cabe señalar además que, dentro del documento del PEI de la Institución Educativa Municipal, no se precisa bajo este modelo de aprendizaje una forma concisa de implementación o articulación de la perspectiva de género; advirtiendo así una primera debilidad por cuanto empieza a denotar que aquellos principios y valores que rigen la educación en el país, y que la Institución reitera en el texto del PEI, se queda como un mero fundamento axiológico de papel, o en la mera enunciación, por cuanto no hay una trascendencia concreta a la realidad.

\section{- $\quad$ Padres de familia}

El papel de los padres de familia en la educación de sus hijos, es fundamental, pues a partir de sus enseñanzas se forjan principios, conocimientos en moral, ética y valores, que se complementan con el trabajo diario de los docentes. Por tal motivo, de acuerdo con el PEI, la institución "en procura de una educación de calidad ha fortalecido el rol de los padres de familia como formadores y participantes activos del proceso de formación de sus hijos", contando con la asamblea de padres de familia y la asociación de padres, explicadas de la siguiente manera:

Asamblea de Padres de Familia. Conformada por todos los padres del establecimiento, quienes son los responsables del ejercicio de sus derechos y deberes en relación con el proceso educativo de sus hijos. 
Asociación de Padres de Familia. La asociación de madres y padres de familia de la institución Bethlemita trabaja por el bienestar integral de la familia a través de sus programas de formación e integración.

Esto se ve complementado, por el manual de convivencia, donde se expresa que

Los padres de familia tienen la obligación y la responsabilidad de educar y contribuir eficazmente para que los beneficios de la educación lleguen a sus hijos. Deben propiciar un ambiente familiar que favorezca la disposición para el estudio y participar activamente en su formación y preparación para la vida. Defender y respetar la institución (Manual de Convivencia, p. 37).

Por otra parte, dentro de las principales preocupaciones definidas en el PEI de la IEM, frente a la función de los padres como educadores, consideran el desinterés por parte de ellos para con las actividades del colegio, la baja enseñanza y respeto frente a la religión y la "permisividad" en el uso de anticonceptivos, lo cual deja de lado todo aquello, que implique el reconocimiento y respeto del concepto de género y los posibles episodios de discriminación y degradación (PEI, p. 48).

En este sentido, fue necesario develar la opinión de estos actores frente a la inclusión de perspectiva de género dentro de la enseñanza que sus hijos adquieren, tal como se muestra en el gráfico 3, lo que conllevó a encontrar que aún existen opiniones bastante divididas en torno a esta temática.

Para el $61 \%$ de las mujeres encuestadas no se debe actuar de una sola forma para ser aceptadas dentro de su comunidad y la sociedad en general y, para el caso de los hombres un 58,9\% de ellos admiten que su comportamiento no debe ser de manera única para ser aceptados. Caso opuesto que en éste punto exponen, un $36 \%$ y un $37,9 \%$ de los entrevistados, que para llevar una vida adecuada dentro de su municipio sí existen comportamientos que deben ser adoptados tanto por las mujeres como por los hombres, para no sufrir de ninguna clase de discriminación o crítica. 
El $45,1 \%$ de los padres de familia afirma que la institución debe marcar las diferencias entre hombres y mujeres y definir los roles más "apropiados" para cada uno de ellos y el $34,3 \%$ opina que la mujer no tiene los mismos derechos del hombre, por lo cual éste, no siempre comparte con la mujer el trabajo doméstico y los problemas derivados de la educación de los hijos, argumentando que son labores que le conciernen a la mujer específicamente, respuesta que engloba el $47,2 \%$ de las opiniones.

Gráfico 3. Percepción de los padres de familia frente a la perspectiva de género.

¿Cree usted que las mujeres deben comportarse de una sola forma para ser aceptadas?

¿Cree usted que los hombres deben comportarse de una sola forma para ser aceptados?

¿Considera que la institucion debe marcar las diferencias entre hombres y mujeres y definir los roles adecuados para cada uno de ellos?

¿Considera importante que la institución aborde la temática de género en las aulas?

¿En su hogar se promueve la igualdad de género y de roles?

¿Usted cree que el hombre en general comparte con la mujer el trabajo doméstico y los problemas derivados de la educación de los hijos / as?

¿Considera usted que la mujer tiene los mismos derechos que el hombre?

\section{$3,0 \%$}

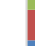

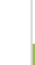

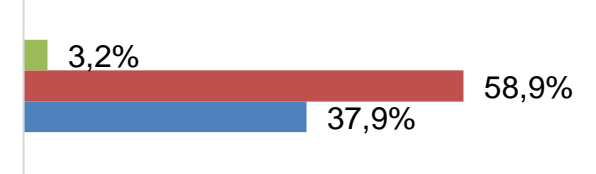

\section{$4,3 \%$}
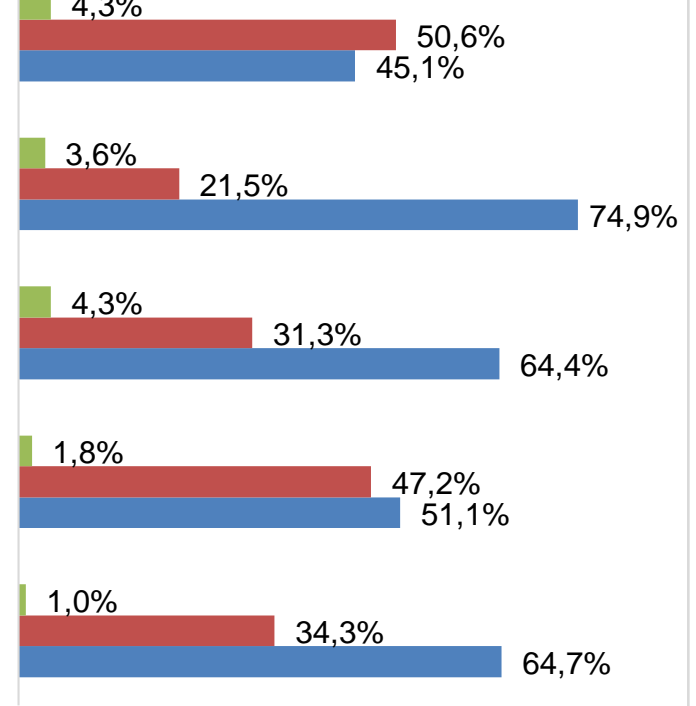

$0,0 \% 10,0 \% 20,0 \% 30,0 \% 40,0 \% 50,0 \% 60,0 \% 70,0 \% 80,0 \%$ $\square$ No sabe $\square$ No $\square \mathrm{Si}$

Fuente: esta investigación (2019)

No obstante, las anteriores respuestas, en aproximadamente el 65\% de los hogares se promueve la igualdad de género, mientras que en un $31,3 \%$ de ellos no se hace. 
Ahora bien, para los padres de familia la temática de género consta de alto interés en relación a la enseñanza que imparte la institución, debido a las respuestas otorgadas y sustentadas en el gráfico 4.

Gráfico 4. Percepción de los padres de familia frente a la discriminación por género.

¿Considera que se debe trabajar mas el tema de genero, identidad de genero e igualdad de genero en la institucion?

¿Sabe usted si algunos profesores o personal administrativo se niegan a aceptar los planteamientos sobre igualdad?

¿La institución ha orientado a los estudiantes en cuanto al respeto y tolerancia por la diversidad de género?

¿Considera que la institución trata a los estudiantes de manera igualitaria, sin ningún tipo de discriminación?

¿Considera que tratar el tema de género promueve actitudes no bien vistas en los estudiantes?
$4,23 \%$

$22,72 \%$

$73,05 \%$
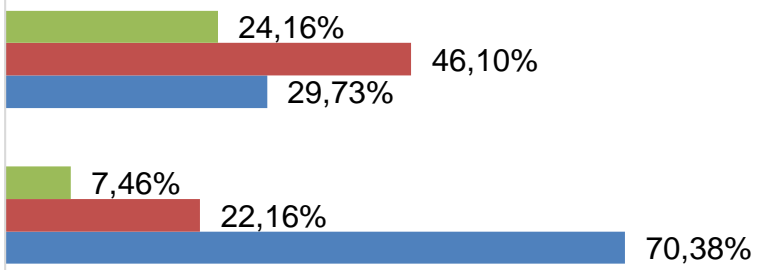

$4,12 \%$

$29,51 \%$ $66,37 \%$

$8,35 \%$ $51,34 \%$

$0,00 \% 10,00 \% 20,00 \% 30,00 \% 40,00 \% 50,00 \% 60,00 \% 70,00 \% 80,00 \%$ $\square$ No sabe $\square$ No $\square \mathrm{Si}$

Fuente: esta investigación (2019)

Aun cuando el $73,05 \%$ de los padres coincide en que es fundamental que se trabaje el en tema de género e identidad, el $22,72 \%$ manifiesta que no es necesario.

El $30 \%$ de padres de familia considera que el plantel educativo no trata de manera igualitaria a los estudiantes y que existe cierto tipo de discriminación en cuanto a tema de género se refiere. No obstante, un $40 \%$ de los mismos cree que tratar el tema de género, promueve actitudes no bien vistas en una Institución Educativa, aunque en menor proporción a los padres que opinan de manera opuesta, es decir, en un 51,34\%. 


\section{- Estudiantes}

En relación a los derechos de esta población, el manual de convivencia, expone dentro de su Artículo 7 que,

Todos los estudiantes tendrán los derechos que la constitución y las leyes de Colombia les confieren; y gozarán de los mismos derechos, libertades y oportunidades sin ninguna discriminación, siempre y cuando en su ejercicio no perjudiquen los principios filosóficos y religiosos que rigen en la Institución (Manual de Convivencia, p. 30).

Es en este punto, que el discernimiento del concepto de género queda en tela de juicio para su pleno cumplimiento, pues dentro del dogma religioso no se acepta a plenitud todo aquello que encierra el concepto de género, dado que, siguiendo las afirmaciones de uno de los principales representantes de la Iglesia Católica, el papa emérito Ratzinger, "la ideología de género es la última rebelión de la creatura contra su condición de creatura" (Citado en Yusta, 2018).

Así, dentro de la institución, todo aquello que no se considere correcto a los ojos de la iglesia o de Dios, no debe ser divulgado y mucho menos enseñado en las aulas de clases, yendo en contra de lo dictaminado en el orden jurídico nacional, pues al no existir en la estructura institucional del centro educativo una efectiva perspectiva de género que materialice los derechos y principios de igualdad y respeto, se pueden apreciar eventos de diferenciación sospechosa de discriminación en razón del género o la identidad sexual, ya que como lo ha señalado la Corte Constitucional

$\mathrm{Ni}$ el Estado, ni los particulares, están autorizados jurídicamente para imponer patrones estéticos excluyentes, mucho menos en los establecimientos educativos. El fundamento de esta regla es que la tolerancia y el respeto por la diferencia rigen el proceso de enseñanza y aprendizaje en un modelo de Estado Social de Derecho que optó por la defensa de la pluralidad y del multiculturalismo (Corte Constitucional, 2013).

En consideración de lo anterior, para la comunidad estudiantil, dentro de su convivir diario, se encuentran dificultades relacionadas con el orden regido por parte de los administrativos, docentes e incluso sus iguales, tal como se observa en el gráfico 5. 
En primer lugar, ante la débil inclusión de temáticas de género, se encontró que el $78 \%$ de ellos desea informarse sobre ello, especialmente de los términos de igualdad y equidad de género, considerando que para un $41,65 \%$, al interior de la institución no se dispone de mecanismos o rutas de acción para detectar y atender situaciones de maltrato, violencia y discriminación basada en género y que según el $46,68 \%$, en la institución no se llevan a cabo talleres, charlas o programas que incentiven la igualdad y equidad de género.

Gráfico 5. Percepción de los estudiantes frente a la inclusión de la perspectiva de género por parte de la Institución

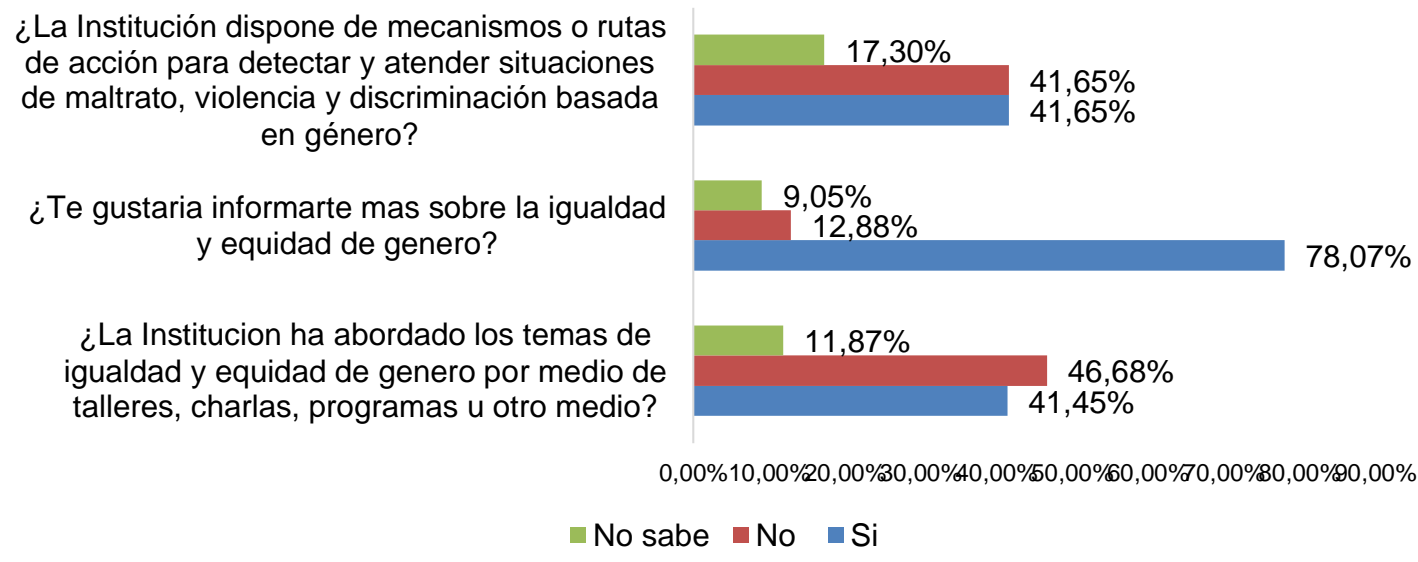

$41,65 \%$

$12,88 \%$

¿La Institucion ha abordado los temas de igualdad y equidad de genero por medio de talleres, charlas, programas u otro medio?

$0,00 \% 10,00 \% 20,00 \% 30,00 \% 40,00 \% 50,00 \% 60,00 \%, 00 \% 80,00 \%, 80,00 \%$ $\backsim$ No sabe $\backsim$ No $\backsim \mathrm{Si}$

Fuente: esta investigación (2019)

Lo anterior se ve corroborado con la explicación de una estudiante de octavo grado,

Se supone que siendo un colegio que hable tanto de los derechos de los niños no respetan nada de eso, antes peor hay discriminación. Aquí muchas niñas callamos el maltrato de los hombres, pero porque si decimos algo nos mandan a rectoría y es peor por los papás y por todo. Yo conozco que por esa situación se corta y la psicóloga no ayuda mucho porque la rectora la manda. Me gustaría cambiarme de colegio. (Mujer, 14 años)

Opinión que muestra, en primer lugar, la preocupación de los estudiantes frente a la problemática y a las debilidades que se tienen por parte del colegio respecto al 
actuar en situaciones de discriminación, maltrato y violencia de género, y en segundo lugar, su interés por acceder a más información respecto al tema, capacitarse y mejorar su perspectiva frente al mismo.

Teniendo en cuenta que, para los estudiantes la temática de género no es considerada a plenitud dentro del abordaje pedagógico y manual de convivencia, es necesario conocer su percepción sobre éste como eje transversal dentro de la institución, tal como se refleja en el gráfico 6 . El $63,38 \%$ de los estudiantes indican que, dentro de los planes de estudio establecidos en la Institución, se incluyen temáticas que se guían hacia la perspectiva de igualdad de género, sin embargo, el $18,71 \%$ y el $18,11 \%$ expresan que dicha perspectiva no es tenida en cuenta y no tienen conocimiento, respectivamente.

Gráfico 6. Percepción de los estudiantes sobre la perspectiva de género incluida en los planes de estudio de la Institución.

¿Los planes de estudio incluyen la perspectiva de igualdad entre hombres y mujeres?

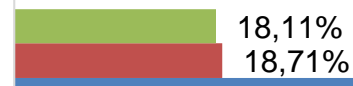

$18,71 \%$

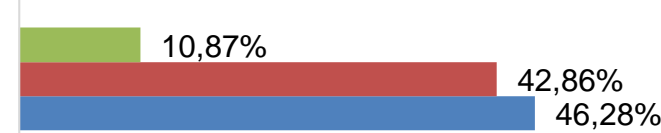

¿Buscan la corrección de los actos de discriminación de género?

¿Promueven la igualdad de género y roles de género?

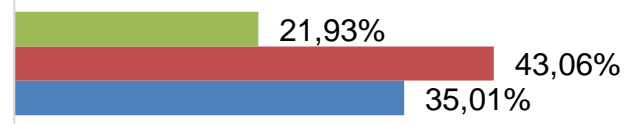

¿Reconocen los problemas de desigualdad entre hombres y mujeres?

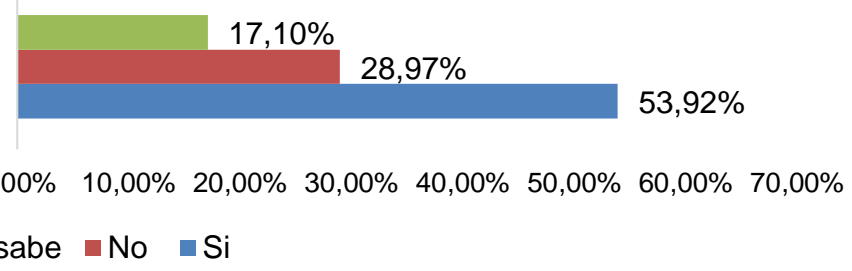

Fuente: esta investigación (2019)

De otro lado, la corrección de actos de discriminación de género, tiene una mayor disparidad de opiniones, puesto que el $46,28 \%$ de ellos expresan que sí se brindan soluciones a tales situaciones, no obstante, el $53,73 \%$ restante, no observa que se 
tomen medidas al respecto o no se han percatado de que se realicen en los casos que han evidenciado.

Ahora bien, respecto a la promoción de igualdad de género, el 43,06\% revelaron una respuesta negativa, pues no perciben que se realice de forma apropiada; mientras que el $35,01 \%$, respondió de forma opuesta, dado que para ellos existe promoción de igualdad de género dentro del entorno educativo de la institución.

En cuanto los resultados sobre la dinámica que los estudiantes hombres y mujeres tienen en el entorno educativo son preocupantes, debido a que el 53,92\% de los estudiantes perciben que existen problemas entre ellos, mientras que el $28,97 \%$, no lo determinan de esa forma.

Así, la igualdad de género dentro del entorno estudiantil, es considerada de importancia, pero no es plenamente observado por todos los alumnos dentro de los planes de estudio, en el entorno promocional y correctivo puesto que, en la práctica, continúan existiendo dificultades relacionales entre los géneros.

Por su parte, en la temática relacionada con la población LGBTI, se encontraron respuestas diversas como se indica en el gráfico 7 . 
Gráfico 7. Percepción de los estudiantes frente al respeto de la identidad de género en la Institución.

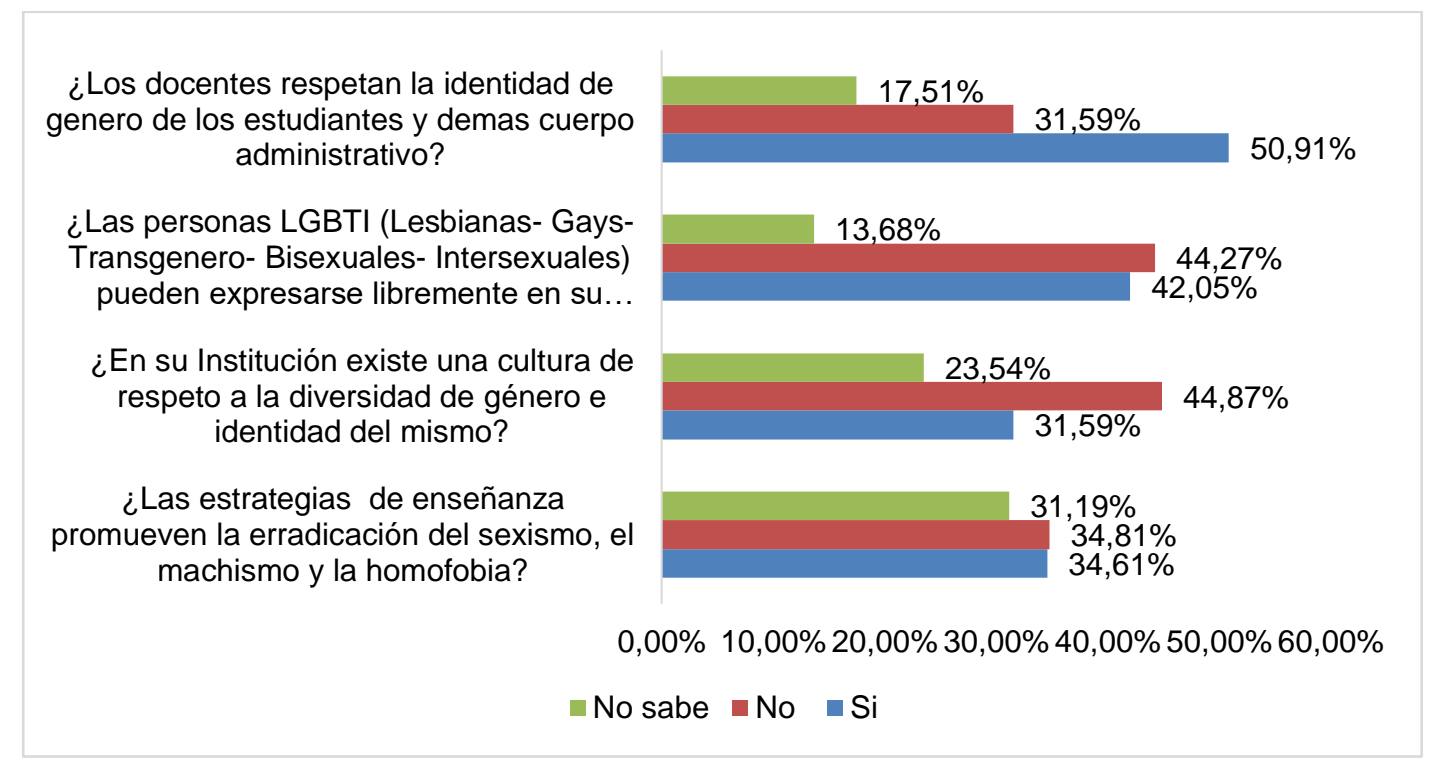

Fuente: esta investigación (2019)

La diversidad sexual en la percepción de los estudiantes tuvo opiniones variadas.

En primera instancia, los estudiantes explican, en su mayoría, que los docentes tienen respeto por la identidad de género tanto de ellos como del demás cuerpo administrativo en un 50,91\%, sin embargo, una gran proporción, situada en el 31,59\%, expresan que no se presenta un ambiente de respeto frente al otro dentro de este enfoque.

El 44,27\% manifiesta que no considera que la población LGTBI pueda expresarse libremente al interior del establecimiento educativo y un $13,68 \%$ desconoce la realidad. A partir de ello, el 44,87\% menciona que en la institución no existe una cultura de respeto a la diversidad de género, de ahí que el $34,81 \%$ y el $31,19 \%$ de los estudiantes piensen que no existen estrategias de enseñanza que promuevan la erradicación del sexismo, el machismo y la homofobia o no pueden identificarlas, respectivamente. 
Algunos comentarios de los estudiantes expresan la falta de apropiación del enfoque de género, el respeto por las diferencias y la existencia de discriminación dentro del entorno estudiantil, docente y administrativo.

\begin{abstract}
"Hace como dos años o menos hubo un inconveniente con un caso de la una persona LGTBI y ella tuvo que dejar esta Institución ya que la humillaban por ser así y tuvo que abandonar la Institución" (Mujer, 16 años)

"Realmente debido a la forma de pensar de la rectora en vez de ayudar a alcanzar una igualdad de género, la aumentan y empezando por la rectora que discrimina incluso en una formación afirmo que las personas LGTBI estaban enfermas al igual que la coordinadora" (Hombre, 16 años)
\end{abstract}

De acuerdo a estos señalamientos, los estudiantes tienen gran preocupación por las debilidades encontradas dentro del plan de enseñanza de la institución, pues el carácter religioso que rige las normas internas, no permite el avance y estimulación al respeto y aceptación de las personas con preferencias diferentes, y que se puede percibir en el manual de convivencia, tal como lo afirma un estudiante:

"Los manuales de convivencia no dicen nada del respeto entre hombres y mujeres, ni bullying, ni género, aquí hacen lo que quieran por encima de los derechos humanos" (Mujer, 14 años)

En adición, esta situación se ve empeorada, a causa de la opinión de algunos docentes:

"Considero que trabajar este tema resultará muy complejo aquí en la Institución porque cambiar las ideas de las religiosas es algo demasiado ambicioso. En realidad, será en vano" (Hombre, 56 años)

"En realidad, los temas de género no son de mi agrado, van en contra de mis principios, moral y ética" (Hombre, 57 años)

El factor religioso tiene gran influencia al interior de la Institución Educativa, y aunque no debería ser impedimento para que se tomen acciones frente a las situaciones de discriminación por género y vulnerabilidad de estos individuos, la realidad es totalmente diferente. 
Finalmente, es preciso entender que los apartes mencionados del Manual de Convivencia, son considerados como un mandato general aceptado públicamente por padres, docentes, y en especial, estudiantes. No obstante, no debe catalogarse como un obstáculo para aquellos estudiantes que pese su sexo biológico, no se identifican como tal y por ende optan por hacer uso del uniforme asignado al género o sexo de su identidad.

Sin embargo, observando la realidad, la falta de un marco determinado, cierto y efectivo orientado a la aprehensión de la perspectiva de género, desde instancias administrativas hasta los mismos estudiantes, hace que se perpetúe la concepción errónea de la sexualidad, la orientación, perspectiva y roles de género, preponderantes en sociedades conservadores y discriminatorias.

\subsection{Análisis de la inclusión de la perspectiva de género en el contexto social de la Institución Educativa Municipal Sagrado Corazón de Jesús.}

Siendo la perspectiva de género uno de los ejes transversales de la educación en Colombia, por cuanto se pretende promover el reconocimiento de la diversidad y el pluralismo en pro del respeto los Derechos Humanos Fundamentales, ${ }^{7}$ se ha propendido por la consecución de sociedades más justas, equitativas e incluyentes, desarrollando así los preceptos constitucionales contenidos en los artículos 13, 41 y 67 insc. 2 (1991); así como los fines del Estado Social de Derecho Colombiano.

En éste sentido, en el presente acápite se expone al lector la aplicación de la perspectiva dentro de la Institución Educativa Municipal Sagrado Corazón De Jesús,

\footnotetext{
${ }^{7}$ Así lo ha entendido la Corte Constitucional, para quien "la educación no es mera instrucción, es socialización secundaria destinada a complementar la que de manera primaria recibe el niño en el seno de la familia, con el fin de que pueda cumplir con su papel en la vida de relación; esta formación en los valores y los usos sociales debe estar orientada a preparar a los futuros ciudadanos para 'participar en la vida política, cívica y comunitaria del país' acatando la Constitución y las leyes. La tolerancia y el respeto por los sistemas de valores distintos deben presidir toda la enseñanza y el aprendizaje de los valores en un país que optó por el desarrollo de una nación pluricultural, en la que ya no hay un solo modelo de virtud al servicio del intento de unificar el comportamiento de todos en la vida de relación" (Sentencia SU$641,1998)$.
} 
del municipio de El Tambo, Nariño, y se analiza la luz del ordenamiento jurídico del Sistema de Educación Colombiano. De ésta forma, se abordó a través de los siguientes tópicos:

Primero se retoma el concepto de perspectiva de género en la educación en Colombia; luego, se prosigue con el análisis orientado a determinar el impacto social generado por la aplicación o no de la perspectiva de género como eje transversal en la educación, dentro del contexto de la Institución Educativa escogida, con relación a los docentes y estudiantes, así como madres y padres de familia, y finalmente se exponen las respectivas conclusiones generales y recomendaciones.

\section{Definiciones y conceptos propios de la comunidad educativa}

Como se expuso en su momento, la perspectiva de género se erige como la herramienta por antonomasia que permite el estudio de determinadas situaciones desde la comprensión de las diferencias físicas y biológicas de los individuos, y los roles a ellos atribuidos a consecuencia de las primeras, para poder deconstruir los estereotipos preponderantes hoy en día tendiente a lograr una igualdad material efectiva.

Bajo éste derrotero, con el fin de determinar la aplicación o no de la perspectiva de género como un eje transversal dentro de la labor educativa y formativa de la Institución Educativa Municipal Sagrado Corazón de Jesús, mediante la aplicación de encuestas y algunas entrevistas, se preguntó al personal de la comunidad educativa acerca de la perspectiva de género y la importancia que para ellos tiene los temas relacionados con género, identidad y orientación sexual; logrando logró evidenciar que no existe total claridad de todo aquello que compone y conlleva la identidad sexual del individuo, exactamente, hay una visión generalizada de que el sexo, el género, la orientación sexual son un mismo concepto, así como la igualdad o la equidad de género, tal y como se han recopilado en la siguiente tabla: 
Tabla 3. Principales categorías de perspectiva de género encontradas en la IEM

\begin{tabular}{|c|c|c|c|}
\hline $\begin{array}{l}\text { Concepto - } \\
\text { Categoría }\end{array}$ & Estudiantes & $\begin{array}{l}\text { Padres y Madres } \\
\text { de Familia }\end{array}$ & Docentes \\
\hline Género & \multirow[b]{2}{*}{$\begin{array}{l}\text { Estos tres conceptos } \\
\text { se confunden o se los } \\
\text { asimilarramo } \\
\text { sinónimos de género. }\end{array}$} & $\begin{array}{l}\text { Estos dos conceptos } \\
\text { hacen referencia al sexo } \\
\text { biológico } \\
\text { genéticamente que } \\
\text { corresponde a le } \\
\text { individuo de la especie } \\
\text { humana: hombre o mujer }\end{array}$ & \multirow[b]{2}{*}{$\begin{array}{l}\text { Se los asocia con el } \\
\text { concepto } \\
\text { equidad/igualdad de } \\
\text { género. }\end{array}$} \\
\hline $\begin{array}{l}\text { Orientación } \\
\text { Sexual }\end{array}$ & & \begin{tabular}{llr}
\multicolumn{3}{l}{ Se tiene en claro (para } \\
bien y para mal) que la \\
orientación & sexual & es \\
diferente & al & sexo \\
biológico & y & hace \\
referencia & al & gusto \\
sexual o afectivo que & que \\
cada ser & humano \\
desarrolla por otro.
\end{tabular} & \\
\hline Rol de Género & $\begin{array}{l}\text { Relacionado con lo } \\
\text { que se espera en } \\
\text { comportamiento, } \\
\text { personalidad, vida, } \\
\text { etc., del hombre y la } \\
\text { mujer. } \\
\quad \text { Asemejado } \\
\text { directamente con el } \\
\text { sexismo. }\end{array}$ & $\begin{array}{l}\text { Aquello que se espera } \\
\text { en comportamiento, } \\
\text { personalidad, vida, } \\
\text { trabajo etc., del hombre } \\
\text { y la mujer. }\end{array}$ & $\begin{array}{l}\text { Lo que se espera en } \\
\text { comportamiento, } \\
\text { personalidad, vida, } \\
\text { familia, trabajo etc., del } \\
\text { hombre y la mujer. }\end{array}$ \\
\hline $\begin{array}{l}\text { Igualdad de } \\
\text { género }\end{array}$ & $\begin{array}{l}\text { Se los relaciona } \\
\text { como uno solo. Se } \\
\text { entienden como la } \\
\text { igualdad rande } \\
\text { condiciones entre } \\
\text { hombres y mujeres, } \\
\text { es la respuesta a la } \\
\text { discriminación en } \\
\text { cuanto a las } \\
\text { capacidades de cada } \\
\text { sexo. }\end{array}$ & $\begin{array}{l}\text { Es un mismo concepto, } \\
\text { con ello se busca acabar } \\
\text { la discriminación y el } \\
\text { maltrato a la mujer, así } \\
\text { como el reconocimiento } \\
\text { de la mujer como un ser } \\
\text { en igualdad de } \\
\text { capacidades que el } \\
\text { hombre. }\end{array}$ & $\begin{array}{l}\text { Es un mismo concepto, } \\
\text { con ello se busca } \\
\text { acabar } \\
\text { discriminación y el } \\
\text { maltrato a la mujer, así } \\
\text { como el } \\
\text { reconocimiento de ser } \\
\text { un ser en igualdad de } \\
\text { capacidades que el } \\
\text { hombre. }\end{array}$ \\
\hline Discriminación & $\begin{array}{lr}\text { La identifican como } \\
\text { aquellas actitudes } \\
\text { negativas hacia una } \\
\text { persona } & \text { por } \\
\text { determinada } & \\
\text { condición; } & \text { es } \\
\text { relacionada } & \\
\text { directamente } & \text { al } \\
\text { término } & \text { de }\end{array}$ & $\begin{array}{l}\text { Se identifica como un } \\
\text { tipo de violencia o } \\
\text { actitud negativa } \\
\text { tendiente a diferenciar } \\
\text { desfavorablemente a } \\
\text { una persona por } \\
\text { distintas razones: } \\
\text { posición social o clase, } \\
\text { por temas de género e }\end{array}$ & $\begin{array}{l}\text { Actitudes negativas } \\
\text { que cualquier individuo } \\
\text { puede tomar contra } \\
\text { una persona por el } \\
\text { hecho de ser diferente. }\end{array}$ \\
\hline
\end{tabular}




\begin{tabular}{|c|c|c|c|}
\hline $\begin{array}{l}\text { Concepto - } \\
\text { Categoría }\end{array}$ & Estudiantes & $\begin{array}{l}\text { Padres y Madres } \\
\text { de Familia }\end{array}$ & Docentes \\
\hline & \begin{tabular}{lll}
\multicolumn{3}{l}{ discriminación } \\
basada en & la \\
orientación & sexual & o \\
el género. & &
\end{tabular} & identidad sexual, etc. & \\
\hline $\begin{array}{l}\text { Libertad de } \\
\text { Expresión }\end{array}$ & $\begin{array}{lrr}\text { Este derecho } & \text { se } \\
\text { confunde con } & \text { el } \\
\text { derecho al libre } \\
\text { desarrollo de la } \\
\text { personalidad. }\end{array}$ & $\begin{array}{l}\text { Al hablar de derechos } \\
\text { fundamentales de las } \\
\text { personas, se tiene una } \\
\text { concepción genérica de } \\
\text { que éstos se } \\
\text { fundamentan en el } \\
\text { respeto, la igualdad y la } \\
\text { libertad de expresión. }\end{array}$ & $\begin{array}{l}\text { Se reconoce como un } \\
\text { derecho fundamental } \\
\text { del estudiante que } \\
\text { protege el desarrollo } \\
\text { de la personalidad y de } \\
\text { un pensamiento propio. }\end{array}$ \\
\hline
\end{tabular}

Fuente: esta investigación. 2019

En este orden de ideas, deviene procedente el conceptuar las categorías anteriormente expuestas acudiendo especialmente a la Opinión Consultiva OC-24/17 del 24 de noviembre de 2017, emitida por la Corte Interamericana de Derechos Humanos - $\mathrm{CIDH}$-, documento que es vinculante para Colombia, y que se desarrolla observando las declaraciones sobre Derechos Humanos, Orientación Sexual e Identidad de Género de la ONU de la Organización de las Naciones Unidas -ONU(2008) y la Organización de los Estados Americanos -OEA- (2010); también se hace remisión a los Principios sobre la Aplicación de la Legislación Internacional de los Derechos Humanos en relación con la Orientación Sexual y la Identidad de Género, ó Principios de Yogyakarta (Indonesia) de Marzo de 2007, sin embargo, antes de comenzar, debe precisarse qué

\section{Género}

Se entiende como género, según Díaz (2003, págs. 4-5), como una construcción cultural que, a partir de la diferencia sexual, establece qué características definen a la

\footnotetext{
${ }^{8}$ Consulta en respuesta a una solicitud presentada por el Estado de Costa Rica que buscaba responder a cinco preguntas en torno a dos temas relacionados con derechos de personas LGTBI. El primero de ellos versa sobre el reconocimiento del derecho a la identidad de género y en particular sobre los procedimientos para tramitar las solicitudes de cambio de nombre en razón de la identidad de género. El segundo tema se refiere a los derechos patrimoniales de las parejas constituidas por personas del mismo sexo ( $\mathrm{CIDH}, \mathrm{OC}-24 / 17)$.
} 
mujer o al hombre en una sociedad determinada. Esta diferencia de roles sexuales marca de una manera diferenciada la participación de la mujer y el hombre en la vida social, incluyendo actitudes, comportamientos y valores que conforman estereotipos de lo que una sociedad dada estima como femenino o masculino. Sin embargo, Domínguez Blanco (2004, pág. 6), reconociendo lo anterior, asevera que la categoría de 'género' ha sufrido un proceso reconstructivo para articular a la diferencia sexual como otra diferencia igual a la clase, etnia, edad, discapacidad y la opción sexual ${ }^{9}$, en palabras de Stolke

en el mundo moderno mecanismos políticos e ideológicos moldean las experiencias e identidades de las mujeres de modo simultáneo aunque desigual no sólo por el hecho de ser mujeres, sino por su condición de clase y raza. Es decir, las desigualdades de género son racializadas y las desigualdades socioraciales son engendradas (pág, 93, 2004).

Aquí, mencionar que el término 'género' ha evolucionado de lo estrictamente femenino, es decir, de estar relegado a los temas feministas y de la lucha por igualdad en derechos y oportunidades de las mujeres respecto de los hombres, siendo un ejemplo palpable de ello que la comunidad perteneciente a la Institución Municipal Sagrado Corazón de Jesús especialmente padres, madres y directivos al ser preguntados sobre el tema, casi que automáticamente, referían la desigualdad de condiciones denunciadas en las luchas feministas.

Ha evolucionado como una categoría que permite desentrañar las formas relacionales entre los seres humanos, que usualmente tienden a la dominación e

\footnotetext{
${ }^{9}$ Aquí Verena Stolcke (2004) en su estudio denominado "La mujer es puro cuento: la cultura del género" realiza un muy detallado relato de cómo se desarrolló el concepto de 'género' a partir de las luchas feministas, del cual resulta supremamente interesante traer a colación que, a la par de las luchas por los derechos civiles de los afroamericanos en Estados Unidos, se cuestionó dentro de los movimientos feministas la lucha segregada que se había adelantado hasta el momento, puso sobre la mesa de discusión que las mujeres negras tuvieron que "movilizarse en dos frentes: por un lado, contra los hombres negros que las oprimían en tanto que mujeres y, por otro, contra el racismo de la población blanca que las explotaba y discriminaba" (pág. 92).

Las feministas negras introdujeron nuevos desafíos teóricos y políticos. Las denuncias de las feministas negras rompieron la visión indiferenciada de la identidad y subordinación de las mujeres al demostrar que
} 
imposición sobre el otro, con el fin de entender los puntos que dan base y origen a las desigualdades padecidas por todas las personas en asuntos tan íntimos como su identidad, en otras palabras, la categoría de género permite comprender el trato discriminatorio con base a los roles y atribuciones otorgadas a los seres humanos con base a su sexo, en palabras de Marta Lamas, "comprender qué es y cómo opera el género nos permite entender que es precisamente el orden simbólico, y no la "naturaleza", el que ha ido generando las percepciones sociales existentes sobre las mujeres y los hombres" (pág. 225. 1996).

Entender el género es la clave principal para distinguir lo natural de lo social, lo innato y común a todo ser humano y es la clave que permite el desarrollo de la perspectiva de género desde la apropiación y entendimiento de lo biológico.

\section{Orientación sexual.}

Se refiere a la identidad relacionada con temas como atracción sexo-erótica y sexo-afectiva, que abarcan las posibles variaciones entre la orientación hacia personas del sexo opuesto (heterosexual), y otras inclinaciones entre diversas personas del mismo sexo o de otros sexos (De la Torre, Hidalgo, \& Ruiz, 2017, pág. 26). De esta forma, la CIDH manifiesta que "éste es un concepto amplio que crea espacio para la auto- identificación. Además, la orientación sexual puede variar a lo largo de un continuo, incluyendo la atracción exclusiva y no exclusiva al mismo sexo o al sexo opuesto" (CIDH, 2017, pág. 19). La CIDH acude y reproduce la definición ofrecida dentro de los Principios de Yogyakarta, documento que ha conceptuado al respecto

Que la 'orientación sexual' se refiere a la capacidad de cada persona de sentir una profunda atracción emocional, afectiva y sexual por personas de un género diferente al suyo, o de su mismo género, o de más de un género, así como a la capacidad de mantener relaciones íntimas y sexuales con estas personas. (ICJ, 2007, pág. 8)

Por su parte, la Consejería de Derechos Humanos de la Presidencia de la República, expone como orientaciones sexuales las Heterosexuales quienes sienten atracción por personas del sexo opuesto, las personas Lesbianas y Gays quienes se 
sienten atraídas por personas de su mismo sexo y las personas Bisexuales que dirigen su atracción tanto hacia personas de su mismo sexo, como a personas del sexo 'opuesto' (Consejería de Derechos Humanos, s.f).

\section{Sexo.}

La CIDH (2017, pág. 15) estableció que "sexo" refiere a las características fisiológicas, a la suma de las características biológicas que define el espectro de las personas como mujeres y hombres o a la construcción biológica que se refiere a las características genéticas, hormonales, anatómicas y fisiológicas sobre cuya base una persona es clasificada como macho o hembra al nacer. Cabe mencionar en éste punto, que el concepto biológico de "sexo" no reconoce otras categorías más allá de la de "hembra" o macho"; sin embargo, es de mencionar que existen personas Intersexuales cuyos marcadores sexuales no corresponden a la concepción binaria existente. En este punto se hace referencia a todos aquellos individuos que han sido catalogados de manera equivocada como hermafrodita (Consejería de Derechos Humanos, s.f).

\section{Identidad de género.}

Se constituye por un complejo proceso individual, constituido por el sentimiento y la autoconciencia de pertenencia un determinado género, o a ninguno en específico (Diaz Rodriguez, 2003), en otras palabras: es el concepto que se tiene de uno mismo como ser sexual y de los sentimientos que esto conlleva; se relaciona con cómo vivimos y sentimos nuestro cuerpo desde la experiencia personal y cómo lo llevamos al ámbito público (Secretaría de Gobernación de México, 2016).

\section{Igualdad y equidad de género.}

En sí, la igualdad busca el mismo trato, derechos, oportunidades y tratamiento de las personas sin distinción a algún elemento que los haga distintos de la generalidad de su colectivo social. Por su parte, la equidad de género, como ya se ha mencionado anteriormente, es la evolución de la igualdad por la aplicación del componente de justicia; su premisa es la siguiente: si bien formalmente todos son iguales, la realidad exige que se acuda a una discriminación positiva hacia un grupo determinado, que es 
diferente y por dicha razón discriminado o puesto en una situación vulnerable, con el fin de que con determinadas acciones se compense a dicho grupo y se revierta la desigualdad preexistente.

\section{Derecho al libre desarrollo de la personalidad.}

Dentro de la comunidad estudiantil se ha confundido el derecho al libre desarrollo de la personalidad, dentro del tema de género, con el derecho a la libre expresión; en específico, se comprende entre los estudiantes que le asiste a todo individuo la potestad de ser y manifestarse como realmente es, asociando dentro de dicha concepción la manifestación de la sexualidad.

En este punto cabe aclarar que la libertad de expresión está orientada a garantizar a toda persona la posibilidad de hacer público su pensamiento y opinión (Congreso de la República, 1991), y en ese sentido la manifestación de la sexualidad de forma pública hace parte de una forma de expresión de su personalidad. Por su parte, los Principios de Yogyakarta establece una ampliación de la protección de la libertad de expresión en el principio 19 que establece:

Esto incluye la expresión de la identidad o la personalidad mediante el lenguaje, la apariencia y el comportamiento, la vestimenta, las características corporales, la elección de nombre o por cualquier otro medio, como también la libertad de buscar, recibir e impartir información e ideas de todos los tipos, incluso la concerniente a los derechos humanos, la orientación sexual y la identidad de género, a través de cualquier medio y sin tener en cuenta a las fronteras. (ICJ, 2007)

Finalmente, debe señalarse que frente a la libertad de expresión, le asiste a todo individuo el respeto y reconocimiento de los derechos y libertades de los demás, así como el sometimiento a los principios democráticos del Estado Social de Derecho.

\section{Discriminación.}

En este punto no hay más allá que traer a colación el concepto generalizado que se tiene del término, el cual no es equívoco, a saber la discriminación responde a todo 
aquel trato diferenciado exclusivo o preferencial, generalmente desfavorable, que corresponde el trato a la raza, religión, opinión política, incluso diferencias biológicas, de género o de identidad. Así mismo la CIDH ha manifestado que

La discriminación por percepción tiene el efecto o propósito de impedir o anular el reconocimiento, goce o ejercicio de los derechos humanos y libertades fundamentales de la persona objeto de dicha discriminación, independientemente de si dicha persona se auto-identifica o no con una determinada categoría. (CIDH, 2017, pág. 41)

En éste sentido, la CIDH previó que la falta de reconocimiento de la identidad de género o sexual podría resultar en una censura indirecta a las expresiones de género que se aparten de los estándares heteronormativos, generalizado la sensación de cumplir con estándares 'tradicionales' para poder contar con la misma protección legal y el reconocimiento de sus derechos en igualdad de condiciones respecto de aquellas personas que no se aparten de los mismos estándares (CIDH, 2017).

Por lo anterior, la sexualidad es un componente protegido por el derecho fundamental al libre desarrollo de la personalidad, contenido en el artículo 16 constitucional, y que hace parte de la dignidad humana.

Conceptuado lo anterior, frente a la comunidad educativa de la Institución Educativa Municipal Sagrado Corazón de Jesús, de forma positiva ésta investigación ha encontrado lo siguiente:

i) los estudiantes asimilan la discriminación basada en género como el rechazo de un individuo por motivo del "género que les atrae" (en realidad hablan de orientación sexual), es decir, si son heterosexuales $u$ homosexuales, o por razones estrictamente sexuales: discriminar porque se es hombre o mujer; por su parte, ii) los padres y madres de familia asimilan usualmente la discriminación basada en género a la realizada por el hecho de ser hombre o mujer (sexo), no obstante, reaccionan con aversión a temas referentes a otras orientaciones sexuales o identidades de género; y iii) los docentes encuentran similares los conceptos de sexo, orientación sexual y 
género, causando una asociación de la discriminación basada en género bastante similar a la de los estudiantes.

Lo anterior conlleva que ante un hecho discriminatorio y/o violento por razones de género, no se logre brindar una atención adecuada, por cuanto es imposible detectar la razón primigenia que origina el rechazo o la violencia, motivo que impide atacar el problema de raíz, esto deriva, indubitablemente, en una vulneración de derechos fundamentales de un sujeto de especial protección constitucional (el estudiante menor de edad), hecho que se torna inaceptable a la luz del Estado Social de Derecho.

Así, si una sociedad, o institución social como la educación, y sus integrantes no conoce y reconoce lo que involucra la identidad sexual de una persona, es difícil elaborar mecanismos, programas y proyectos que ayuden a las comunidades sociales históricamente rechazadas a ser menos desiguales, a cumplir con la meta de igualdad aceptada socialmente como necesaria, así como elevar la sensación de justicia.

\subsubsection{Docentes y Administrativos.}

Ahora, es claro que a Colombia le asiste una obligación internacional de promocionar los derechos humanos de todos las personas, así como la lucha efectiva contra la violencia y discriminación por razones de género, siendo la perspectiva de género una herramienta o aliada efectiva para dichos fines (De la Torre, Hidalgo, \& Ruiz, 2017).

En ese sentido, un directivo de la institución al ser interrogado sobre la aplicación de la perspectiva de género como componente o eje transversal del que hacer educativo de la Institución, afirma

La parte de equidad de género, está contemplado en el acápite de los principios [del PEI] literal e [...] es decir, contempla la equidad de género y la tolerancia, el fortalecimiento de estos componentes, para formar una ciudadanía moderna. Bien la forma en que se difunde y como se desarrolla hasta el momento es con 
las clases de sociales, se tocan éstas temáticas, y lo mismo desde psicoorientación, y la docente de apoyo aborda estos temas en algunas charlas a padres de familia y las charlas individuales con los estudiantes. (Hombre 56 años)

Con el ejemplo aportado se logra distinguir que: i) se desconoce por parte del directivo, qué es la perspectiva de género, toda vez refiere automáticamente a la equidad de género, evidenciando el grave desconocimiento de los conceptos ya aclarados anteriormente, y demostrando de ésta manera que éste funcionario tampoco ha recibido capacitación o instrucción alguna en temas de género; ii) que la perspectiva de género dentro de la institución al parecer no existe como eje transversal, en la medida de que es un tema relegado a la malla curricular de una asignatura en específico y por el personal de psico-orientación o la docente de apoyo.

Sin embargo, respecto al proyecto pedagógico de educación sexual de la I.E.M Sagrado Corazón de Jesús, lo expuesto por el Directivo entrevistado induce a cuestionar la pertinencia de dicho proyecto, cuando puede estar circunscrito a predicar la equidad de género sin comprender todo lo que ello implica.

Hay que tener en cuenta que la perspectiva de género no puede ser un elemento a trabajar desde una cátedra en específico de la malla curricular, por el contrario, es un elemento transversal de TODA la actividad administrativa y educadora de las instituciones educativas; que no debe concebirse como la mera divulgación de la equidad en género, sino como aquel elemento inmerso en toda actividad. Frente a este punto, De la Torre, Hidalgo \& Ruiz manifiestan que

No basta con enseñar las características biológicas de hombres y mujeres, o los métodos para prevenir un embarazo. Educar para la sexualidad es precisamente brindar herramientas conceptuales, actitudinales, comunicativas y valorativas que permitan a los adolescentes tomar decisiones con relación a su sexualidad que se correspondan con lo que quieren, sueñan y esperan de su realidad. (2017, pág. 23) 
Sin embargo, dentro de la Institución Educativa Municipal Sagrado Corazón de Jesús se ha optado por parte de los docentes, en tema de género y discriminación de género, por orientar las clases de forma neutral sin profundizar, así lo afirma el Directivo entrevistado quien manifiesta desde su experiencia que

No están a favor de la erradicación de estos paradigmas tan arraigado, puede haber una excepción en el área de sociales que si tocan éstos temas. (Hombre, 56 años)

Ésta manifestación concuerda con las cifras expuestas anteriormente, siendo un ejemplo de ello que para el $51.11 \%$ de los docentes encuestados el PEI y el Manual de convivencia no cumplen con las políticas estatales para la erradicación de la discriminación basada en género o sexo, de la misma manera que el $46.57 \%$ de los docentes opinen que dentro del PEI no se encuentra prevista la perspectiva de género como un eje transversal para el desarrollo de la Institución.

Por lo expuesto, el relegar temas de diversidad, sexualidad, y equidad de género, a psico-orientación y a determinadas áreas como ciencias sociales, va en contra vía del ordenamiento jurídico actual por cuanto la adopción y desarrollo de temas de género dentro de todos los ambientes y contextos escolares buscan fomentar la deconstrucción de paradigmas, roles o presunciones que invisibiliza o discrimina a un conjunto de personas, desde el mismo individuo aún en formación, siendo por ello un deber de toda la actividad educadora de la institución el

Transformar las prácticas pedagógicas para contribuir a la construcción de ambientes de aprendizajes democráticos y tolerantes que potencien la participación, la construcción colectiva de estrategias para la resolución de conflictos, el respeto a la dignidad humana, a la vida, a la integridad física y moral de los estudiantes. (Congreso de la República, 2013)

Dentro de la transformación de las prácticas pedagógicas, expone Nussbaum (Silva Carrerño \& Beltrán Martín, 2015, pág. 12) que es necesario acudir a una nueva 
visión la pedagogía de la educación, donde se de lugar a una perspectiva comprehensiva e incluyente de lo andrógino, esto es, de aquellas manifestaciones externas de una persona que no se corresponden con su naturaleza sexual, pero que, en todo caso, constituyen la dinámica de su personalidad ${ }^{10}$; evitando de esta manera la perpetuación de la violencia simbólica.

Por otra parte, respecto a las charlas realizadas por psicorientación y por la docente de apoyo, no han tenido una acogida positiva por el estudiantado de la Institución Educativa Municipal, por el contrario, los estudiantes de grados $9^{\circ}, 10^{\circ}$ y $11^{\circ}$ entrevistados manifestaron que las pocas charlas impartidas tienden a tratar temas de igualdad entre hombres y mujeres, particularmente de respeto y tolerancia; sin embargo, no son suficientes frente a la orientación sexual.

Entonces, una educación o una práctica pedagógica tendiente a la equidad de género no es elemento suficiente para eliminar los constructos sociales discriminatorios que afectan o vulneran derechos de niñas, niños, y adolescentes heterosexuales, homosexuales o no-binarios; y es mucho menos eficiente el componente de equidad de género, dentro de la perspectiva de género, si solo es un tema desarrollado por un elemento aislado de la malla curricular o del plan pedagógico, cuando es un factor de desarrollo obligatorio en todo ámbito educativo por mandato legal y convencional.

Por otra parte, se divisa que el desconocimiento o la falta de capacitación del personal docente y administrativo de la Institución en temas de género, orientación y sexualidad, generan un riesgo previsible por cuanto las contingencias que se presenten dentro del ambiente escolar no podrán ser atendidas de forma correcta por el personal institucional, en virtud a que estos no les es posible advertir focos de violencia por temas personalísimos (ej. Orientación sexual) por cuanto ésta realidad del ser humano les es desconocida o, como mínimo, le es una realidad visible. Entonces, si el fin de la labor educadora de la Institución Educativa es la consecución de los logros de la

\footnotetext{
${ }^{10}$ Al respecto Silva Carreño \& Beltrán Martin (2015): "El género constituye un elemento fundante de la identidad de la personal, no sólo de algunos grupos minoritarios sino de la sociedad en general, lo cual configura su alcance político en la constitución de la ciudadanía incluyente". (p. 7)
} 
educación en Colombia, tales como la tolerancia, el respeto a la diversidad y la igualdad en la diferencia, a la luz de los principios de dignidad humana, pluralidad, así como las garantías fundamentales contenidas en los artículos 1, 2, 5, 13 Constitucionales, también resulta necesario el capacitar en dichos elementos a los docentes, familias y demás personas que interactúan en el espacio escolar, para que ellos lo interioricen y lo hagan parte de su práctica y su día a día.

Para finalizar, debe recordarse que para abordar dichos temas es necesario atender a los destinatarios de las actividades pedagógicas y académicas quienes exigen o consideran necesario para una buena convivencia el tener las bases suficientes para poder comprender, respetar y que se les respete sus decisiones personales; ya que el ignorar los requerimientos realizados por tan importante población situación puede afectar el óptimo cumplimiento de los derechos humanos de los niños y adolescentes dentro de la institución, porque en materia de género igualdad e inclusión

tal vez uno de los asuntos más delicados en juego es la garantía de derechos de niñas, niños y adolescentes a quienes en medio de este escándalo no se consideran como sujetos de derechos, ni agentes sociales o de sus propias vidas, es decir, se les considera incapaces de discernir y tomar decisiones en un ambiente escolar que muestre distintas posturas y con base en sus propias emociones y experiencias [...] Es fundamental que las comunidades educativas, incluidos sus estamentos profesorales, estudiantiles y de madres y padres de familia, se comprometan a revisar instrumentos educativos, en particular, los manuales de convivencia que deben ajustarse a la norma constitucional, en particular al bloque de constitucional que hace de los instrumentos internacionales ratificados por Colombia y de la jurisprudencia, parte de la norma de normas (Esguerra, párr. 8, 2016). Negrillas añadidas.

\subsubsection{La perspectiva de género y los estudiantes.}

Mediante las entrevistas realizadas a los estudiantes, cuando se les cuestionó acerca de si conocían casos o si fueron ellos víctimas de rechazo o discriminación basada en género, se encontró la existencia de 2 casos que hacen palpable las consecuencias de la omisión de la perspectiva de género: una estudiante manifestó 
sentirse discriminada por su orientación sexual lesbiana y otros dos estudiantes hombres de grado $11^{\circ}$ documentaron el caso de un estudiante hombre de orientación homosexual.

Con respecto a este último caso:

Hace aproximadamente 2 años, un estudiante hombre de orientación homosexual decidió colocarse un piercing en la oreja ${ }^{11}$; la situación desató un caso de bullying por parte de los estudiantes (Mujer, Estudiante grado $9^{\circ}$ ) que escaló al punto de que la rectora, de manera pública, se refiriera al homosexualismo como algo anormal, manifestando textualmente que "uno debe ser del sexo que nació, como Dios lo mandó" (Hombre, Estudiante grado $11^{\circ}$ ). Finalmente, por la situación presentada y aunado a las manifestaciones de la dirección, y el estrés, el estudiante decidió retirarse del colegio y entrar a otro.

Lo manifestado por los estudiantes denota una clara vulneración del derecho al libre desarrollo de la personalidad por cuanto existió una intromisión en aspectos privados de la vida del estudiante, como lo es la orientación sexual, esfera protegida por la Corte Constitucional, por cuanto es una decisión libre, autónoma e incuestionable de la persona, por lo que todo comportamiento, de los particulares o del Estado, que (i) censure o restrinja una opción sexual, o (ii) imponga sanciones o, de manera amplia, consecuencias [...] negativas para el individuo, es una acción contraria a los postulados constitucionales (Corte Constitucional, 2013).

El escarnio público al que al parecer fue expuesto el estudiante, al cuestionar 'normalidad' de orientaciones sexuales diversas, genera una afectación al derecho al buen nombre, la dignidad humana y a la igualdad, así como una violación al principio de no discriminación del estudiante.

\footnotetext{
${ }^{11}$ Hecho que aparentemente contraviene el Manual de Convivencia, el cual en el literal $n$ establece No usar joyas (la Institución no responde por pérdida de joyas). Las mujeres únicamente usarán aretes pequeños y discretos." (p. 27)
} 
Ahora, los dos estudiantes refieren que el hecho manifestado, tuvo incidencia en la decisión del estudiante de cambiar de colegio por lo que podría constituir una vulneración al derecho a la educación, pero más que todo, la consolidación de una discriminación que está proscrita a la luz de la $\mathrm{CIDH}$, quien ha precisado que

Ninguna norma, decisión o práctica de derecho interno, sea por parte de autoridades estatales o por particulares, pueden disminuir o restringir, de modo alguno, los derechos de una persona a partir de su orientación sexual, su identidad de género y/o su expresión de género. (CIDH, OC14/17, 2017)

Actualmente, dentro de la institución se reportó, mediante las entrevistas realizadas, la existencia de dos $\operatorname{casos}^{12}$ : el primero de una estudiante mujer que se identifica ella misma como lesbiana, y el comentario de una estudiante de $9^{\circ}$ que refirió a su mejor amiga de orientación sexual diversa; ello con el fin de demostrar que no existe dentro de la IEM Sagrado Corazón de Jesús un espacio que propicie el correcto desarrollo de la identidad y la personalidad de los estudiantes.

\section{$>$ Camila*:}

Estudiante de sexo femenino, manifiesta que se identifica como lesbiana y revela que dentro de la institución no siente un ambiente seguro para poder, en sus palabras, 'salir del closet' ya que reconocen el ambiente homofóbico del mismo dónde se siente discriminada; aclara que no es la única, que otras compañeras también se sienten ésta inseguridad de expresarse, y no hacen pública su sexualidad por temor al bullying por parte de sus compañeros, así como la reacción de las familias.

\section{$>$ Luisa*:}

Estudiante, mujer, de grado $9^{\circ}$. Ella hace una apreciación muy parecida a la expuesta por 'Camila', a saber: que su amiga más cercana, cuya orientación sexual diversa, por miedo al bullying o la burla por parte de sus compañeros y la falta de apoyo familiar no hace evidente su gusto por las mujeres; considerando, en principio, el

\footnotetext{
${ }^{12}$ Estudiantes de secundaria, sus nombres fueron cambiados con el fin de proteger sus identidades.
} 
hecho de que sólo recibe apoyo de su hermana mayor, que su padre la maltrata y la madre por su parte, en caso de enterarse, podría agredirla también.

Refiere además que no se acude a las psicólogas por que no se siente 'cómoda'; si bien el área de psico-orientación ha realizado charlas en tema de género, "no son muy interesantes, no son específicas" y opina que sería adecuado llevar personas de sexualidades diversas para que hablen desde su experiencia.

En las situaciones anteriormente expuestas, es posible identificar como comunes denominadores de un ambiente escolar no propicio para el correcto desarrollo de la identidad del estudiante, dentro de la I.E.M. Sagrado Corazón de Jesús, llegando a límites que van en contra vía de lo dispuesto por la Ley 115 de 1994 y la Ley 1620 de 2013.

Así lo manifiestan Camila* y Luisa*, quienes refieren burlas, comentarios o 'murmullos' respecto a su sexualidad y preferencias, de la misma manera han sido objeto de miradas 'despectivas'13, actitudes de rechazo realizados por sus propios compañeros, constitutivos de discriminación y en cierta manera una violación al artículo 12 constitucional que incorpora la prohibición de los tratos crueles.

No obstante, dentro del texto del PEI de la Institución Educativa Sagrado Corazón de Jesús, se ha previsto una política ó, 'segundo lema' institucional, de "CERO BULLYING", fundamentado en principios de equidad y con el valor de la humildad, los cuales se busca fomentar dentro del ambiente escolar, y en este sentido, el Manual de Convivencia con miras a infundir en los estudiantes el respeto y cortesía hacia las demás personas con que comparte el aula, la Institución de manera directa y explícita 'tipifica' conductas inapropiadas dentro de la institución.

\footnotetext{
${ }^{13}$ Las estudiantes en sus entrevistas manifestaron que las personas con orientaciones sexuales diversas, son vistas con "asco".
} 
Sin embargo, dentro del PEI y del Manual de Convivencia, se omite la inclusión e identificación de los orígenes, focos o modalidades de violencia por cuestiones de género, orientación o identidad sexual dando tácitamente a entender que con buscar el respeto del 'otro' con miras de igualdad, justicia y equidad de género, la Institución ataca de raíz la problemática social de discriminación de mujeres y hombres heterosexuales así como de personas con orientación sexual diversa.

Aquí, el Decreto 1965 de 2013 ordenó a todos centros educativos del país la actualización de los Manuales de Convivencia con la creación de rutas capaces de manejar conflictos y conductas que afectan la convivencia escolar y los derechos humanos, sexuales y reproductivos; lo cual se logra, entre otras medidas, con la identificación de "las situaciones más comunes que afectan la convivencia escolar y el ejercicio de los derechos humanos, sexuales y reproductivos, las cuales deben ser identificadas y valoradas dentro del contexto propio del establecimiento educativo" (art. 29); empero, la experiencia de ésta investigación indica que NO se cumple con esta finalidad orientada a la creación de espacios escolares seguros, pacíficos, inclusivos y diversos que garantice el pleno desarrollo del educando.

Este fenómeno ha causado que los actos de discriminación o acoso por razones de género o identidad sexual, que en un campo 'heterosexual' sí serían atendidos de acuerdo a las faltas y sanciones del Manual de Convivencia, sean callados por los estudiantes víctimas de dichos actos, porque si bien reconocen o 'legitiman' las medidas o sanciones del Manual, las rutas de atención involucran a directivos y padres o madres de familia, lo que es un inconveniente para la denuncia por las razones ya expuestas.

Entonces, en virtud a que dentro de la Institución no se reconoce, ni material ni formalmente, la diversidad de elecciones de vida de cada persona, no es posible determinar actitudes y comportamientos que violenten 0 afecten las garantías fundamentales de determinados grupos sociales; conllevando, dentro de un espacio de aprendizaje, la perpetuación de cánones negativos y discriminatorios por parte del 
educando muchas veces por desconocimiento de los efectos que sus actitudes puedan ocasionar en el desarrollo de sus iguales.

\subsubsection{Contexto familiar de la IEM Sagrado Corazón de Jesús}

Ahora, otro inconveniente referido por los estudiantes, es que dentro de los ambientes familiares no se cuenta con un apoyo o espacio seguro que permita a los estudiantes expresarse plenamente y mucho menos acudir a su protección ante los acosos o malos tratos, violencia o discriminaciones, de los que pudieran ser víctimas en el colegio. Si se reconoce el contexto tradicionalista y conservador del municipio de El Tambo, las familias que integran o participan en la Institución Municipal existen dentro de un contexto social que tiende a discriminar la diferencia y la diversidad de opciones de vida, así como mantener roles de género machistas, violentos y coercitivos de hombres y mujeres.

Identificando lo anterior, los Proyectos Educativos y Manuales de Convivencia deben contemplar la realidad de los contextos familiares de los estudiantes, con el fin de responder a los requerimientos sociales actuales orientados a la actualización del ideario colectivo con bases democráticas de equidad, igualdad, respeto, equidad, diversidad y pluralidad; por ello a los padres y madres de familias la ley les ha conferido el derecho y el deber de participar en la creación los PEI y Manuales de Convivencia. (Corte Constitucional, 2011)

Cabe subrayar que otro inconveniente provocado a causa de la omisión de la perspectiva de género, es que, dentro de los contextos familiares de los estudiantes, las opciones $u$ orientaciones sexuales diversas a las heterosexuales son todavía un tabú que genera rechazo entre padres y madres de familia. Esto es paradójico si se tiene en cuenta los datos como:

El $73,05 \%$ de los padres coincide en que es fundamental que se trabaje en el tema de género e identidad, el $61 \%$ de las mujeres opina que no se debe actuar de una 
sola forma para ser aceptadas dentro de su comunidad y la sociedad en general y, para el caso de los hombres, un 58,9\%, su comportamiento no debe ser de manera única para ser aceptados; y lo más curioso de todo ello es que si bien hay una tasa alta de interiorización de la igualdad y la equidad de género dentro de los hogares de los encuestados, aún predominan ciertos cánones sociales tradicionales que no compaginan con lo profesado por los encuestados.

Si bien por parte de los hombres hay una gran mayoría que reconoce a la mujer como un ser capaz igual que ellos y con una fuerza de trabajo suficiente como para contribuir con el bienestar del hogar, sigue permeada la idea de que "Eso de hablar de género más hacen confundir con el trabajo asignado para cada uno, a los hombres se nos dificulta la crianza de los hijos y deberes de la casa, por eso salimos a trabajar". (Padre, grado $6^{\circ}$ )

A lo expuesto se le aúna el hecho de que para la gran mayoría de los padres y madres, el término género no está claro, puesto que si bien identifican y reconocen la equidad e igualdad de la mujer frente al hombre, la idea de una educación con perspectiva de género o que se imparta éste eje genera el temor de que con ello se les va a inculcar a los menores ideas que los 'desvíen' de lo que se considera normal en una sexualidad. (Ver Gráfico 4).

Entonces, si los padres de familia no tienen en claro todo lo que implica la identidad sexual de una persona, claramente, aquellas manifestaciones personales de sus hijos (y los demás) referentes a sus preferencias sexuales y afectivas, generan rechazo y miedo a la vez que se genera una inseguridad del padre o madre frente a su papel como padre o madre.

Así mismo cuando se preguntó ¿Por qué considera importante que la institución aborde la temática de género en las aulas? Se respondió: "Si, me parece importante que se aborde esta temática porque hay situaciones donde nosotros mismos como padres llevamos a nuestros hijos a creer que porque somos hombres no podemos 
hacer ciertas cosas y no es asî" (Padre, grado $7^{\circ}$ ); otro por su parte manifiesta que ante la promoción de lo que es género, identidad e igualdad de género es necesario seguir su desarrollo porque "Si bien, en el hogar se dan unas pautas acerca de la identidad de género, pero es de gran ayuda una explicación bien fundamentada, es decir, con un respaldo científico" (Padre, grado $9^{\circ}$ ).

Entonces, ¿por qué no brindar las herramientas necesarias para generar una mejor comunicación y orientación entre padres, madres e hijos en lo que atañe a la identidad del menor? Porque si bien hay interés sobre estos temas, dentro del ambiente educativo se ha decidido omitir y retirarlos de la realidad de la Institución Educativa, así como de los documentos formales que son el PEI y el Manual de Convivencia, situación que, como aquí se expuso, si bien ha llevado al desarrollo de una concepción más equitativa en oportunidades y derechos entre hombres y mujeres de la comunidad educativa, aún persisten viejos estigmas o paradigmas discriminatorios que necesitan ser erradicados. 


\section{Conclusiones}

De acuerdo a los planteamientos señalados en el presente documento, la perspectiva de género es la herramienta destinada a analizar y de-construir ésos viejos paradigmas, roles o estigmas que han determinado el desarrollo del individuo para que correspondan a constructos imaginarios propios de un contexto social, que no siempre propende por la igualdad material de las personas, ni la igualdad de oportunidades de los individuos, y mucho menos busca por aceptar las diferencias propias de cada ser humano.

En temas de perspectiva de género, la educación implica la correcta formación de una identidad personal y de una comunidad democrática, pluralista, tolerante y diversa; el modelo colaborativo de educación que actualmente opera dentro de la Institución Educativa Municipal Sagrado Corazón de Jesús, bajo el paradigma cristianocatólico de las Hermanas Bethlemitas, es ineficiente, ineficaz y propicia el contexto perfecto para la perpetuación de conductas y actitudes discriminatorias, así como la perpetuación de ciertos cánones sociales restrictivos para el desarrollo de la personalidad y la identidad.

Dentro de la Institución Educativa no existe un iniciativa por conocer o identificar el contexto social en que se desenvuelve, así como tampoco los posibles focos de peligro de vulneración de las garantías fundamentales de las personas que conforman el ambiente escolar, y mucho menos existe interés por combatir y cambiar ésas realidades; empezando por los documentos fundamentales de la actividad de la IEM Sagrado Corazón de Jesús que son el Proyecto Educativo Institucional y el Manual de Convivencia que poco o nada dicen frente a los diferentes flagelos a los que se exponen diariamente las personas en un contexto social que no comprende todo lo que implica la identidad, y en especial, la identidad sexual.

Y en tal sentido, ante la falta de conocimiento y aplicación pedagógica acerca de la perspectiva de género en la malla curricular de la Institución, resulta imperativo el 
establecer bases dentro del Proyecto Educativo institucional y el Manual de Convivencia que exija la práctica de un lenguaje y pedagogía incluyente dentro de la Institución, que no se limite a establecer que el docente Bethlemita "se involucra con su ser personal y social en la tarea educativa, en la construcción de una persona más responsable y de una sociedad más justa y más humana" (PEI, p. 62) sino que, desde la práctica pedagógica, logre inlfuir a la creación de un ambiente escolar incluyente, equitativo y diverso.

Un efecto de la falta de un marco institucional con perspectiva de género es que la comunidad educativa no logra dilucidar o diferenciar lo que es el género de lo sexual es más, según se expuso en la tabla 3 , se asocia los temas de género a lo estrictamente femenino, concepción errónea toda vez que dicho concepto ha evolucionado para ayudar a entender lo culturalmente atribuido a cada sexo para identificar las discriminaciones generadas bajo tal entendimiento y así combatirlas en miras de una sociedad más equitativa e igual materialmente, no formalmente.

$\mathrm{Ni}$ los estudiantes ni los docentes o directivos ni las familias conocen de forma clara que son y cuáles son las manifestaciones o representaciones de violencias 0 actos discriminatorios por cuestiones de género, de machismos e incluso de homofobia, por lo cual ningún actor dentro de la Institución está capacitado para evitarlos o dar una correcta atención a casos que requieran acciones afirmativas orientadas a cambiar aquellos comportamientos negativos discriminatorios.

El hecho de que la ley no haya contemplado la perspectiva de género dentro del sistema educativo de forma taxativa y concisa, no es óbice para no aplicarla, por cuanto existen otros elementos o fuentes que sí la contemplan, la desarrollan, y son de obligatorio cumplimiento no solo de los Estados, sino de las instituciones y las personas que los componen; y aquí cabe rememorar, como ejemplo, las ya mencionadas Declaraciones sobre Derechos Humanos, Orientación Sexual e Identidad de Género de la ONU y la OEA, la Declaración de Derechos Humanos de la ONU, la Convención para la Eliminación de todas las Formas de Discriminación contra la Mujer CEDAW, los 
Principios de Yogyakarta de 2007, los pronunciamientos de la $\mathrm{CIDH}$ en materia de género, ó documentos como el informe sobre "Leyes y prácticas discriminatorias y actos de violencia cometidos contra personas por su orientación sexual e identidad de género" realizado por el Alto Comisionado de las Naciones Unidas para los Derechos Humanos ante la Asamblea General de la ONU, que establece

La lucha contra este tipo de prejuicios e intimidación requiere esfuerzos concertados de las autoridades escolares y educativas y la integración de los principios de no discriminación y diversidad en los planes de estudios y el lenguaje utilizados en las escuelas. (A/HRC/19/41, 2011) Negrillas añadidas. 


\section{Recomendaciones}

Debe recalcarse que la educación en Colombia solo quiere responder a necesidades administrativas y metas axiológicas planteadas por el Ministerio de Educación Nacional, a lo establecido por la Ley General de Educación Ley 115 de 1994 así como a lo expuesto por la Ley 1620 de 2013; sin embargo, estos lineamientos no definen los mecanismos ni los espacios para realizar o llegar a cumplir dichas metas 0 fines, por lo cual se evidencia la necesidad de implementar planes, programas y proyectos, mediante el desarrollo de políticas públicas a todo nivel, orientados a la implementación de una educación con perspectiva de género dentro de las aulas colombianas.

La I.E.M Sagrado Corazón de Jesús debe comprender que la excelencia académica de los estudiantes es un factor importantísimo de calidad de la educación en Colombia, sin embargo, dotar a los estudiantes de conocimiento, ciencia y técnica no es suficiente para la elaboración de un proyecto de vida personal congruente, por cuanto el estudiante debe contar con herramientas que le permitan construir una identidad y personalidad propia a partir de su auto determinación y auto percepción; algo que sólo que logra mediante la orientación de personal capacitado en temas de género y derechos humanos.

Es necesario que tanto el PEI como el Manual de Convivencia de la Institución Educativa Municipal Sagrado Corazón de Jesús sea objeto de una minuciosa revisión, identificando contextos, falencias y fortalezas, de los entornos sociales y familiares que rodea la institución, ello en aplicación de la perspectiva de género como herramienta de análisis a los contextos sociales; y en tal entendido se hace necesario la 'tipificación' de conductas sancionables que constituyan violencia basa en género, para lo cual se recomienda a la Institución una aplicación de la Ley 1257 de 2008 emanada para atender, sensibilizar, castigar y prevenir la violencia en contra de la mujer (Congreso de la República, 2008), más si se tiene en cuenta que dicha Ley define de forma precisa 
qué debe entenderse por violencia física, psicológica y económica así como determina claramente los daños, o contingencias, generadas por dichas modalidades de violencia, sin embargo, su importancia, a la luz de la presente investigación, radica en los procedimientos establecidos para la atención de las víctimas de violencia basada en género, ésta Ley se constituye entonces en el instrumento primordial para la aplicación de la perspectiva de género en la Institución Municipal, al aportar definiciones y medidas para atender tales tipos de violencia de las que pueden ser y son víctimas los estudiantes, a través de su aplicación extensiva para generar una cobertura más allá del sexo femenino, protegiendo así las diferentes formas de expresarse e identificarse que tiene el ser humano además de generar un espacio o ambiente sano para ello desde el cual se combata la desigualdad real que viven hombres y mujeres, independiente de su género y/u orientación, en los múltiples aspecto de la vida todo a causa de la mal interpretación histórica de la identidad de la persona y su sometimiento a lo 'socialmente aceptable'.

Se debe replantear y reformular el PEI que se incluya la perspectiva de género de forma transversal en todos los currículos y programas pedagógicos de la institución; se incluyan actividades tendientes al reconocimiento e identificación de las diferencias así como su aprehensión; se institucionalice la capacitación en temas de género y sexualidad a toda la planta de docentes y, a su vez, se les exija actitudes y aptitudes determinadas a la hora de impartir sus clases que sean acordes a los nuevos requerimientos sociales (ej el uso de ejemplos que no apelen a roles de género sexistas: el niño juga con carros, la niña juega a la cocina y las muñecas); y bajo tal panorama se involucre a los padres y madres en actividades que efectivamente les interiorice todo lo que la identidad de una persona implica, también se debe identificar y adoptar metodologías que de manera sencilla y práctica les permita conocer las implicaciones de aquellas concepciones o estereotipos tradicionales y dañinos para el bienestar psíquico y social del estudiante.

Respecto a docentes y directivos, debe implementarse la obligación del uso de un lenguaje neutro, inclusivo, que no reproduzca los cánones o estereotipos que en inicio 
se busca combatir, dentro de las aulas de clases. En otras palabras, teniendo en cuenta que se puede transformar la sociedad desde las aulas mismas, al docente le asiste un deber de cuidado al mensaje que le imparte al estudiantado por medio de sus expresiones verbales.

Frente al Manual de Convivencia es necesaria su modificación con miras a reconocer la diversidad sexual como una de las tantas formas de pluralidad, con lo anterior se reconozca formalmente a la comunidad LGTBI, junto a las mujeres, como una población vulnerable dentro del contexto social de la Institución por razones de género, identidad u orientación sexual; con tal reconocimiento se hace necesario la tipificación de derechos, deberes y faltas sancionables dirigidos a la consecución de una verdadera equidad e igualdad de género, prohibiendo y sancionando todas aquellas actitudes 0 actos que vulneren la dignidad de una persona tan solo por una mala concepción de la sexualidad o de la identidad y al que se pueda detectar un criterio sospechoso de discriminación, formulando rutas de atención efectivas para corregir comportamientos indeseados a la luz de la Constitución y las actuales sociedades democráticas e incluyentes.

Desde un punto de vista amplio, lo aquí encontrado da más firmeza a aquellas reclamaciones de todos los actores del sistema educativo tendientes a cambiar o evolucionar el sistema educativo imperante en las aulas orientado a estrictamente a conocer las aptitudes, fortalezas y debilidades del educando para que su desarrollo intelectual y social en un ambiente sano; postura a la que se allanan estudiosos del impacto mental de los modelos educativos en los individuos como Guillermo Carvajal, médico psiquiatra y psicoanalista, quien recientemente expuso:

Las escuelas deben individualizar al niño para poder saber cuáles son sus potencias. En la primaria se les debe enseñar todo lo básico para poderse comunicar con el mundo, pero el profesor debe estar dedicado a ver sus potencialidades y a que las desarrolle. Las potencialidades, aclara, son un concepto similar al de las inteligencias múltiples como las llamó Howard Gardner. Todos las tienen. Entre esas están las matemáticas, los conceptos y la memoria. (Revista Semana, 2019) 


\section{Bibliografía}

ACEA, Agencia Ejecutiva en el Ámbito Educativo y Cultural. (2010). Recuperado de https://sede.educacion.gob.es/publiventa/descarga.action?f_codigo_agc=14475_ 19

Acosta \& David. (2011). Análisis y seguimiento socioeconómico de la política de género en el departamento de Nariño 2009-2011. Recuperado de http://biblioteca.udenar.edu.co:8085/bibliotecavirtual/viewer.aspx?\&var=84992

Amurrio, M., Larrinaga, A., \& E, y. d. (2008). Violencia de Género en las relaciones de pareja de adolescentes y jóvenes de Bilbo. Recuperado de https://dialnet.unirioja.es/descarga/Artículo/3262821.pdf

Azorín, C. (2017). Una mirada desde los organismos internacionales a la educación para todos. Recuperado de Universidad del Zulia: http://www.redalyc.org/pdf/310/31053772007.pdf

Brullet, M., \& Subirats, C. (1992). Rosa y Azul, La transmisión de los géneros en la escuela mixta. España: S.G. Colomina.

CIDH. (24 de 11 de 2017). OC 24/17. Recuperado de http://www.corteidh.or.cr/docs/opiniones/seriea_24_esp.pdf

Consejería de Derechos Humanos. (s.f). Orientación sexual, Identidad de Género y Derechos Humanos ¡Sus Derechos Valen! Recuperado de http://www.derechoshumanos.gov.co/observatorio/publicaciones/Documents/201 7/170213-plegable-lgbti.-webpdf.pdf

CPEM, C. P. (14 de 2010 de 2003). Acuerdo Nacional para la Equidad entre mujeres y hombres.

Recuperado de http://bdigital.unal.edu.co/53831/1/acuerdonacionalporlaequidad.PDF 
DANE. (2017). Boletín técnico de educación formal (EDUC). Recuperado de Departamento Administrativo Nacional de Estadística : https://www.dane.gov.co/files/investigaciones/boletines/educacion/bol_EDUC_17 .pdf

De la Torre, M., Hidalgo, K., \& Ruiz, C. (2017). Propuesta de Perspectiva de la Educación Sexual en Colombia desde el Análisis del Concepto de Sexualidad. Recuperado de http://repository.udistrital.edu.co/bitstream/11349/5672/1/delaTorreHidalgoRu\%C 3\%ADzMarcelaDianaDianaCarolina2017.pdf

Díaz Rodríguez, A. (2003). Colección Pedagógica Universitaria. Educación y género V. Recuperado de https://cdigital.uv.mx/bitstream/handle/123456789/5601/Eb\%20alba\%20diaz\%20 genero\%20educacion.pdf?sequence=2\&isAllowed=y

Díaz, M. (2009). Prevenir la Violencia de género desde la escuela. Revista de Estudios de Juventud $N^{\circ} 86$, https://issuu.com/injuve/docs/revista_86_completa.

Domínguez, M. (2004). Equidad de Género y Diversidad en la Educación Colombiana. Revista Electrónica de Educación y Psicología., http://revistas.utp.edu.co/index.php/repes/article/view/5205.

Eisenhardt, K. (1991). "Better stories and better constructs: the case for rigor and comparative logic". Academy of Management Review,, 16(3), 620-7.

Esguerra, C. (2016). La perspectiva de género en la educación no es ideología. Recuperado de Universidad de los Andes: https://cider.uniandes.edu.co/Paginas/Noticias.aspx?nid=101

Granja, S. (2016). A las niñas les ponen menos cuidado en las aulas de clase. Recuperado de El Tiempo: https://www.eltiempo.com/vida/educacion/las-ninassufren-desigualdad-de-genero-en-educacion-basica-50674 
Gutiérrez, N. (2017). Desigualdad de género causa deserción escolar. Recuperado de https://www.elnuevodiario.com.ni/nacionales/425710-desigualdad-genero-causadesercion-escolar/

ICJ, C. I. (3 de 2007). Principios de Yogyakarta. Recuperado de https://www.refworld.org.es/docid/48244e9f2.html

Lamas, M. (1996) La Perspectiva de Género. La Tarea, No. 8, pág. 216-29. Recuperado de https://www.dgespe.sep.gob.mx/public/genero/PDF/LECTURAS/S_01_13_La\%2 Operspectiva\%20de\%20g\%C3\%A9nero.pdf

Matias, S. G. (30 de octubre de 2016). A las niñas les ponen menos cuidado en las aulas de clase: Educación, clave para acabar con los estereotipos de género que pueden desembocar en violencia. El Tiempo.

Melero, N. (2011). El paradigma crítico y los aportes de la investigación acción participativa en la transformación de la realidad social: un análisis desde las ciencias sociales. 339-335. Recuperado de Universidad de Sevilla.: https://institucional.us.es/revistas/cuestiones/21/art_14.pdf

Naciones Unidas. (1979). Convención sobre la eliminación de todas las formas de discriminación contra la mujer. Recuperado de https://www.ohchr.org/sp/professionalinterest/pages/cedaw.aspx

Naciones Unidas. (17 de 11 de 2011). Informe del alto Comisionado de las Naciones Unidas para los Derechos Humanos. Recuperado de Leyes y prácticas discriminatorias y actos de violencia cometidos contra personas por su orientación sexual e identidad de género: https://www.ohchr.org/Documents/lssues/Discrimination/A.HRC.19.41_spanish.p df 
Naciones Unidas. (2015). Agenda 2030 y los objetivos de desarrollo sostenible. Recuperado de https://repositorio.cepal.org/bitstream/handle/11362/40155/18/S1700334_es.pdf

Navarrete, M. (2013). Enseñando la equidad de género a los estudiantes de grado octavo de la I. E. M Ciudadela de Pasto. Recuperado de Universidad de daniño: http://biblioteca.udenar.edu.co:8085/bibliotecavirtual/viewer.aspx?\&var=89495

Niña, R. N. (2016). Recomendaciones de Política de Género en educación.

Novoa, M. (2012). Diferencia entre la perespectiva de género y la ideología de género.

Observatorio de Género de Nariño. (2018). Dinámica sobre la situación de las mujeres en las subregiones del Departamento de Nariño Periodo Enero - Diciembre de 2017. Recuperado el Abril de 2019, de Universidad de Nariño: http://observatoriogenero.udenar.edu.co/wp-content/uploads/2018/09/CIFRASVIOLETA_V.pdf

OEA. (2017). Pronunciamiento conjunto sobre igualdad de género y violencia contra la mujer. . Recuperado de Organización de los Estados Americanos: http://www.oas.org/es/cidh/prensa/comunicados/2017/095.asp

ONU Mujeres. (2017). Nariño comprometido con la Igualdad de Género y la Innovación Social. Recuperado el Abril de 2019, de ONU Mujeres Colombia: http://colombia.unwomen.org/es/noticias-yeventos/Artículos/2017/08/narinojornada

Parrilla, M. (2002). Acerca del origen y sentido de la educación inclusiva. Revista de Educación $\quad N^{\circ}$ 327: 11-29. Recuperado de : http://www.mecd.gob.es/dctm/revistadeeducacion/Artículos327/re3270210520.pdf?documentld=0901e72b81259a76

PNUD, P. d. (1995). Recuperado de http://www.co.undp.org/content/colombia/es/home/ourwork/womenempowerment /in_depth.html 
PNUD,

P. d.

(2016).

Recuperado

de

http://www.co.undp.org/content/colombia/es/home/presscenter/pressreleases/20 16/08/05/onu-apoya-el-mejoramiento-de-la-calidad-de-la-educaci-n-comoherramienta-para-la-construcci-n-de-una-sociedad-en-paz-y-equitativa.html

Profamilia. (2015). Encuesta Nacional de Demografia y Salud. Recuperado de http://profamilia.org.co/docs/ENDS\%20\%20TOMO\%20l.pdf

Profamilia. (2015). Encuesta Nacional de Demografía y Salud-ENDS . Recuperado de Profamilia: http://profamilia.org.co/docs/TOMO\%20II.pdf

Ramírez, Y. (2017). Perspectiva de género en la escuela: un aporte a la construcción de ciudadanía desde la diferencia. Recuperado de Universidad Pedagógica Nacional:

http://repositorio.pedagogica.edu.co/bitstream/handle/20.500.12209/7813/TO21375. pdf? sequence $=1$ \&isAllowed $=y$

Revista Semana. (24 de mayo de 2019). Entrevista a Guillermo Carvajal: "La escuela murió y hay que cerrarla". Recuparado de https://www.semana.com/vidamoderna/Artículo/por-que-un-psicologo-piensa-que-las-escuelas-deberiandesaparecer/616849?fbclid=iwar2j0mowiaxskiwgh0o7bey7r6jzacpbifcn10yqeusv8plzhw5kfrb1ae

Rodríguez, \& Valldeoriola. (2014). Metolodología de la investigación. Recuperado de https://view.joomag.com/fundamentos-de-la-invcualitativa/0278011001446255260?page $=47$

Sanchez, J., \& R, R. (1992). Coeducación. En Temas transversales del currículum 2, Sevilla, Junta de Andalucía. Consejería de Educación y Ciencia. . Recuperado de

http://www.educarenigualdad.org/media/pdf/uploaded/old/Mat_129_temas\%20tra nversales\%20curriculum\%202.pdf 
Secretaría de Gobernación de México. (2016). ¿Qué es la identidad de género? Recuperado de https://www.gob.mx/segob/Artículos/que-es-la-identidad-degenero)

Silva Carrerño, w., \& Beltrán Martín, J. (2015). El rol de género como fundamento humanista de la formación para la ciudadanía. Recuperado de Revista de Investigación UNAD: https://doi.org/10.22490/25391887.1343

Solís, A. (2016). La perspectiva de género en la educación. Chihuahua, México: Escuela normal superior.

Stolke, V. (2004). La mujer es puro cuento: la cultura del género. Revista Estudios Feministas, 12(2), 77-105. https://dx.doi.org/10.1590/S0104026X2004000200005

UNESCO. (2000). Marco de Acción de Dakar. Senegal. . Recuperado de Organización de las Naciones Unidas para la Educación, la Ciencia y la Cultura -UNESCO-: http://unesdoc.unesco.org/images/0012/001211/121147s.pdf

UNESCO, O. d. (1990). Declaración Mundial sobre Educacion para Todos y el Marco de Acción para Satisfacer las necesidades bascas de aprendizaje. Recuperado de http://www.unesco.org/education/pdf/JOMTIE_S.PDF

UNESCO, O. d. (2018). Cumplir nuestros compromisos de igualdad de género en la educación.

Recuperado

de http://unesdoc.unesco.org/images/0026/002619/261945s.pdf

Unidas, N. (2015). Declaración de Incheon y Marco de Acción para la realización del objetivo de Desarrollo sostenible. Recuperado de http://unesdoc.unesco.org/images/0024/002456/245656s.pdf

United Nations Population Fund. (2005). state of world population 2005: The promise of equality. UNFPA. 
Vasco, G. (2013). Plan director para la coeducación y la prevención de la violencia de género en el sistema educativo. Servicio Central de Publicaciones del Gobierno Vasco.

Recuperado

de https://www.irekia.euskadi.eus/assets/attachments/3837/definitivo_plan_director_ coeducacion_.pdf?1385554368

\section{Legislación}

Congreso de la República. (1991). Constitución Política de Colombia.

Congreso de la República. (1994). Ley 115 de 1994, Ley general de educación. Por la cual se expide la ley general de educación. Recuperado de Congreso de la República: https://www.mineducacion.gov.co/1621/articles-

85906_archivo_pdf.pdf

Congreso de la República. (2008). Ley 1257 de 2008. Por la cual se dictan normas de sensibilización, prevención y sanción de formas de violencia y discriminación contra las mujeres. Diario Oficial: 47.193.

Congreso de la República. (2013). Ley 1620 de 2013, por la cual se crea el Sistema Nacional de Convivencia Escolar y Formación para el Ejercicio de los Derechos Humanos, la Educación para la Sexualidad y la Prevención y Mitigación de la Violencia Escolar. Recuperado de Ministerio de Educación Nacional: https://www.mineducacion.gov.co/cvn/1665/articles-319679_archivo_pdf.pdf

Decreto 1860 de 1994 . (1994). por el cual se reglamenta pacialmente la Ley 115 de 1994, en los aspectos pedagógicos y organizativos generales. Recuperado de Ministerio de educación nacional: https://www.mineducacion.gov.co/1621/articles-

172061_archivo_pdf_decreto1860_94.pdf 
Ministerio de Educación Nacional. (2017). Plan Nacional de Educación 2016-2026. Recuperado de http://www.plandecenal.edu.co/cms/media/herramientas/PNDE\%20FINAL_ISBN \%20web.pdf

Ministerio de Educación Nacional. (2017). Plan nacional decenal de educación 20162016. Recuperado de http://www.plandecenal.edu.co/cms/media/herramientas/PNDE\%20FINAL_ISBN \%20web.pdf

Naciones Unidas. (1948). Declaración Universal de Derechos Humanos. Recuperado de http://www.ohchr.org/EN/UDHR/Documents/UDHR_Translations/spn.pdf

Vicepresidencia de la República. (2012). Plan Nacional de Educación en Derechos Humanos. Recuperado de Defensoría del Pueblo: Vicepresidencia de la República - MEN - Defensoría del Pueblo. (2012). Plan nacional de educación en derechos humanos. Bogotá: Naciones Unidas - Usaid

\section{Jurisprudencia}

Corte Constitucional. (7 de 10 de 2011). Sentencia $T$ 759/11. Recuperado de Magistrado Ponente: Gabriel Eduardo Mendoza Martelo: http://www.corteconstitucional.gov.co/relatoria/2011/T-759-11.htm

Corte Constitucional. (23 de 08 de 2013). Sentencia T-562 de 2013. Recuperado de Magistrado Ponente: Mauricioo González Cuervo: http://www.corteconstitucional.gov.co/relatoria/2013/T-562-13.htm

Corte Constitucional. (2015). Sentencia T-478. MP. Gloria Ortiz. Recuperado de http://www.corteconstitucional.gov.co/relatoria/2015/t-478-15.htm 
Anexos 


\section{Anexo 1. Encuesta para estudiantes sobre apreciación de la perspectiva de género en el Proyecto Educativo Institucional PEI y el Manual de Convivencia}

\section{Presentación:}

El presente documento se exhibe como una de las herramientas de investigación que persigue el propósito de identificar en el PEI y en el Manual de Convivencia de la Institución Educativa Municipal Sagrado Corazón de Jesús del municipio del Tambo Nariño la inclusión de la perspectiva de género, las formas de difusión de la educación en género y el grado de aceptación e impacto de la misma en la comunidad educativa. Cabe resaltar que esta encuesta se realizará con fines exclusivamente académicos y que la misma NO ES UN EXAMEN por tanto todas las respuestas son válidas. Le solicitamos su colaboración. Es muy importante que conteste con la máxima sinceridad.

Para el desarrollo de la encuesta por favor tener en cuenta los siguientes conceptos:

\section{Sexo: ¿Con qué genitales he nacido?}

Condición biológica y genética por la cual nacemos con caracteres sexuales primarios masculinos, femeninos o combinados (intersexualidad). Esto incluye órganos sexuales internos y externos, cromosomas y hormonas. Nuestro sexo no determina nuestra identidad ni la orientación sexual.

\section{Género: ¿Qué características se asocian al hombre/mujer?}

Se refiere a los roles socialmente construidos, los comportamientos, actividades y atributos que una sociedad dada considera apropiados para los hombres y las mujeres. Así, el rol sexual o de género (¿cómo soy y actúo al sentirme mujer u hombre?) consiste en los rasgos de personalidad y pautas de comportamiento socialmente considerados masculinos o femeninos en un marco cultural o histórico concreto. 


\section{Identidad de género: ¿Con qué género me identifico?}

Sentimiento de pertenencia al género masculino o femenino (ser/sentirse hombre o mujer). Suele establecerse en los primeros años de infancia y afecta al modo en que sentimos y expresamos emocionalmente nuestro género.

Grado

Hombre

Mujer

Otro

Edad

Responda a las siguientes preguntas marcando con una $\mathrm{X}$ su repuesta:

\begin{tabular}{|c|c|c|c|}
\hline $\begin{array}{l}\text { Las normas de convivencia, el Proyecto Educativo } \\
\text { Institucional, los Planes de estudio de la misma y el } \\
\text { personal administrativo y docente }\end{array}$ & Si & No & $\begin{array}{c}\text { No } \\
\text { sabe }\end{array}$ \\
\hline $\begin{array}{l}\text { 1. ¿Reconocen los problemas de desigualdad entre } \\
\text { hombres y mujeres? }\end{array}$ & & & \\
\hline 2. ¿Promueven la igualdad de género y roles de género’ & & & \\
\hline $\begin{array}{l}\text { 3. ¿Buscan la corrección de los actos de discriminación de } \\
\text { género? }\end{array}$ & & & \\
\hline $\begin{array}{l}\text { 4. ¿Los planes de estudio incluyen la perspectiva de } \\
\text { igualdad entre hombres y mujeres? }\end{array}$ & & & \\
\hline $\begin{array}{l}\text { 5. ¿Los planes de estudio incorporan los derechos de } \\
\text { personas LGTBI (Lesbianas- Gays- Transgenero- } \\
\text { Bisexuales- Intersexuales)? }\end{array}$ & & & \\
\hline $\begin{array}{l}\text { 6. ¿Las estrategias de enseñanza promueven la } \\
\text { erradicación del sexismo, el machismo y la homofobia? }\end{array}$ & & & \\
\hline $\begin{array}{l}\text { 7. ¿La igualdad y equidad entre hombres y mujeres hacen } \\
\text { parte de la cultura de la institución? }\end{array}$ & & & \\
\hline $\begin{array}{l}\text { 8. ¿En su institución existe una cultura de respeto a la } \\
\text { diversidad de género e identidad del mismo? }\end{array}$ & & & \\
\hline $\begin{array}{l}\text { 9. ¿Las personas LGBTI (Lesbianas- Gays- Transgenero- } \\
\text { Bisexuales- Intersexuales) pueden expresarse } \\
\text { libremente en su institución? }\end{array}$ & & & \\
\hline $\begin{array}{l}\text { 10. ¿La institución dispone de mecanismos o rutas de } \\
\text { acción para detectar y atender situaciones de maltrato, } \\
\text { violencia y discriminación basada en género? }\end{array}$ & & & \\
\hline $\begin{array}{l}\text { 11. ¿Los docentes respetan la identidad de género de los } \\
\text { estudiantes y demás cuerpo administrativo? }\end{array}$ & & & \\
\hline $\begin{array}{l}\text { 12. ¿La institución ha abordado los temas de igualdad y } \\
\text { equidad de género por medio de talleres, charlas, } \\
\text { programas u otro medio? }\end{array}$ & & & \\
\hline
\end{tabular}


Si desea precisar sobre algún punto en particular o resaltar algo que no se ha abordado en el presente cuestionario por favor hágalo en el siguiente espacio.

Observaciones.

¡Muchas gracias! 


\section{Anexo 2. Entrevista para estudiantes sobre apreciación de la perspectiva de género en el Proyecto Educativo Institucional PEI y el Manual de Convivencia}

Fecha:

Hora:

Lugar: institución Municipal Sagrado Corazón de Jesús del municipio del Tambo Nariño.

Entrevistador: Jully Vanessa Cuases González

Entrevistado (nombre, edad, género, cargo):

El presente documento se exhibe como una de las herramientas de investigación que persigue el propósito de identificar en el PEI y el Manual de Convivencia de la Institución Educativa Municipal Sagrado Corazón de Jesús del municipio del Tambo Nariño la inclusión de la perspectiva de género, las formas de difusión de la educación en género y el grado de aceptación e impacto de la misma en la comunidad educativa. Cabe resaltar que esta entrevista se realizará con fines exclusivamente académicos, por tanto, la información obtenida se analizará de manera general sin individualizar a la persona que haya respondido el presente cuestionario. Por ello, le pedimos responder con la máxima sinceridad.

Para el desarrollo de la encuesta por favor tener en cuenta los siguientes conceptos:

\section{Sexo: ¿Con qué genitales he nacido?}

Condición biológica y genética por la cual nacemos con caracteres sexuales primarios masculinos, femeninos o combinados (intersexualidad). Esto incluye órganos sexuales internos y externos, cromosomas y hormonas. Nuestro sexo no determina nuestra identidad ni la orientación sexual. 


\section{Género: ¿Qué características se asocian al hombre/mujer?}

Se refiere a los roles socialmente construidos, los comportamientos, actividades y atributos que una sociedad dada considera apropiados para los hombres y las mujeres. Así, el rol sexual o de género (¿cómo soy y actúo al sentirme mujer u hombre?) consiste en los rasgos de personalidad y pautas de comportamiento que se consideran masculinos o femeninos en un marco cultural o histórico concreto.

\section{Identidad de género: ¿Con qué género me identifico?}

Sentimiento de pertenencia al género masculino o femenino (sentirse hombre o mujer). Suele establecerse en los primeros años de infancia y afecta al modo en que sentimos y expresamos emocionalmente nuestro género.

Preguntas.

1. ¿Podrían definir que es para ustedes un Proyecto Educativo Institucional?

2. ¿Les han explicado cuales son los principios y objetivos del Proyecto Educativo Institucional de este colegio? ¿Cuáles consideran importantes? ¿cuáles consideran se deberían incorporar y por qué?

3. ¿Conocen el Manual de Convivencia Escolar del establecimiento? ¿de qué trata?

4. ¿El manual de convivencia contiene mecanismos para prevenir y sancionar la violencia escolar y discriminación basada en género?

5. ¿Al interior de su institución existen problemas de desigualdad y violencia basada en género? ¿Pueden dar un ejemplo?

6. ¿Las normas de su institución y los docentes Promueven la igualdad de género y roles de género?

7. ¿La institución dispone de mecanismos o rutas de acción para detectar y atender situaciones de maltrato, violencia y discriminación basada en género? ¿Cuál es? ¿la han utilizado?

8. ¿Ustedes se han sentido o conocen a alguien que se haya sentido amenazado, avergonzado o intimidado por ser hombre o mujer?; ¿en qué eventos? ¿qué han hecho al respecto?

9. ¿La institución se ha enterado, intervenido y corregido estas situaciones? 
10. ¿Quién de ustedes cree que hombres deben comportarse de una sola forma y las mujeres de otra para ser aceptados y aceptadas? ¿Por qué?

11. ¿La institución ha abordado los temas de igualdad y equidad de género? ¿Cuándo, cómo y quién lo ha hecho?

12. ¿Consideran necesario abordar temas de igualdad de género dentro de la institución?

¡Muchas gracias! 


\section{Anexo 3. Encuesta para personal administrativo y docentes sobre la apreciación de la perspectiva de género en el proyecto educativo institucional PEI y el Manual de Convivencia}

\section{Presentación:}

El presente documento se exhibe como una de las herramientas de investigación que persigue el propósito de identificar en el PEI y el Manual de Convivencia de la Institución Educativa Municipal Sagrado Corazón de Jesús del municipio del Tambo Nariño la inclusión de la perspectiva de género, las formas de difusión de la educación en género y el grado de aceptación e impacto de la misma en la comunidad educativa. Cabe resaltar que esta encuesta se realizará con fines exclusivamente académicos y que la misma NO ES UN EXAMEN por tanto todas las respuestas son válidas. Le pedimos su colaboración. Es muy importante que conteste con la máxima sinceridad.

Para el desarrollo de la encuesta por favor tener en cuenta los siguientes conceptos:

Sexo. Refiere a la definición de "hombre" o "mujer" asignado al momento de nacer a partir de variadas condiciones anatómicas y fisiológicas.

Género. El género se sostiene sobre la distinción y jerarquización de los significados de lo masculino, como categoría superior, sobre lo femenino como categoría inferior. Las representaciones culturales de lo masculino y lo femenino varían históricamente, pero son percibidas como realidades naturales que se derivan de las diferencias anatómicas que distinguen a los sexos.

Identidad de género. Es la vivencia interna e individual del género, la cual estructura la experiencia vital de las personas en relación al propio cuerpo y a expresiones de género como la vestimenta, el modo de hablar y de actuar. Esta identidad puede corresponder o no con el sexo biológico asignado al nacer. 
Perspectiva de género. La perspectiva o visión de género es una categoría analítica que toma los estudios que surgen desde las diferentes vertientes académicas de los feminismos para, desde esa plataforma teórica, cuestionar los estereotipos y elaborar nuevos contenidos que permitan incidir en el imaginario colectivo de una sociedad al servicio de la igualdad y la equidad; la misma se constituye entonces en una estrategia para convertir las preocupaciones y las experiencias de las mujeres y los hombres en una dimensión integral del diseño, implementación, monitoreo y evaluación de las políticas y programas en todas las esferas políticas, económicas, y sociales para que las mujeres y los hombres se beneficien igualmente y la desigualdad no se perpetúe

Hombre

Mujer

Otro

Edad

Responda a las siguientes preguntas marcando con una $\mathrm{X}$ su repuesta:

\begin{tabular}{|c|c|c|c|}
\hline $\begin{array}{c}\text { Sobre el Proyecto Educativo Institucional y el manual de } \\
\text { convivencia }\end{array}$ & $\mathrm{Si}$ & No & $\begin{array}{c}\text { No } \\
\text { sabe }\end{array}$ \\
\hline 1. ¿Sabe usted que es el Proyecto Educativo Institucional? & & & \\
\hline $\begin{array}{l}\text { 2. ¿Ha participado de la elaboración del Proyecto Educativo } \\
\text { Institucional? }\end{array}$ & & & \\
\hline $\begin{array}{l}\text { 3. ¿Conoce los principios y objetivos del Proyecto Educativo } \\
\text { Institucional que orientan la acción de la comunidad educativa } \\
\text { en la institución? }\end{array}$ & & & \\
\hline $\begin{array}{l}\text { 4. ¿Considera usted importante la inclusión de la } \\
\text { perspectiva de género como principio rector del Proyecto } \\
\text { Educativo Institucional? }\end{array}$ & & & \\
\hline $\begin{array}{l}\text { 5. ¿Dentro de los objetivos contemplados en el Proyecto } \\
\text { Educativo Institucional se concibe la perspectiva de género } \\
\text { como un eje transversal para el desarrollo de la institución? }\end{array}$ & & & \\
\hline $\begin{array}{l}\text { 6. ¿El Proyecto Educativo Institucional y el manual de } \\
\text { convivencia Cumplen con las Políticas del Estado respecto al } \\
\text { rechazo de la discriminación por razones de sexo- género? }\end{array}$ & & & \\
\hline $\begin{array}{l}\text { 7. ¿La institución ha garantizado los derechos de los } \\
\text { estudiantes en condiciones de igualdad sin ser discriminados } \\
\text { por su sexo o identidad de género? }\end{array}$ & & & \\
\hline $\begin{array}{l}\text { 8. ¿La institución ha orientado a los estudiantes en cuanto al } \\
\text { respeto y tolerancia por la diversidad de género? }\end{array}$ & & & \\
\hline $\begin{array}{l}\text { 9. ¿La institución ha educado y promovido la igualdad en los } \\
\text { roles de género? }\end{array}$ & & & \\
\hline $\begin{array}{l}\text { 10. ¿El profesorado y personal administrativo acepta con } \\
\text { gran reticencia los planteamientos sobre IGUALDAD? }\end{array}$ & & & \\
\hline
\end{tabular}




\begin{tabular}{|c|c|c|c|}
\hline $\begin{array}{c}\text { Sobre el Proyecto Educativo Institucional y el manual de } \\
\text { convivencia }\end{array}$ & $\mathrm{Si}$ & No & $\begin{array}{l}\text { No } \\
\text { sabe }\end{array}$ \\
\hline $\begin{array}{l}\text { 11. ¿Dentro de la evaluación institucional se ha identificado } \\
\text { problemas relacionados con la violencia y discriminación de } \\
\text { género? }\end{array}$ & & & \\
\hline $\begin{array}{l}\text { 12. En caso de encontrar problemas relacionados con la } \\
\text { violencia y discriminación de género se han tomado las medidas } \\
\text { y correctivos necesarios? }\end{array}$ & & & \\
\hline
\end{tabular}

Si desea precisar sobre algún punto en particular o resaltar algo que no se ha abordado en el presente cuestionario por favor hágalo en el siguiente espacio.

Observaciones. 


\section{Anexo 4. Entrevista para docentes sobre la apreciación de la perspectiva de género en el Proyecto Educativo Institucional PEI}

Fecha:

Hora:

Lugar: institución Municipal Sagrado Corazón de Jesús del municipio del Tambo Nariño.

Entrevistador: Jully Vanessa Cuases González

Entrevistado (nombre, edad, género, cargo):

El presente documento se exhibe como una de las herramientas de investigación que persigue el propósito de identificar en el PEI y el Manual de Convivencia de la Institución Educativa Municipal Sagrado Corazón de Jesús del municipio del Tambo Nariño la inclusión de la perspectiva de género, las formas de difusión de la educación en género y el grado de aceptación e impacto de la misma en la comunidad educativa. Cabe resaltar que esta entrevista se realizará con fines exclusivamente académicos, por tanto, la información obtenida se analizará de manera general sin individualizar a la persona que haya respondido el presente cuestionario. Por ello, le pedimos responder con la máxima sinceridad.

Para el desarrollo de la encuesta por favor tener en cuenta los siguientes conceptos:

Sexo. Refiere a la definición de "hombre" o "mujer" asignado al momento de nacer a partir de variadas condiciones anatómicas y fisiológicas.

Género. El género se sostiene sobre la distinción y jerarquización de los significados de lo masculino, como categoría superior, sobre lo femenino como categoría inferior. Las representaciones culturales de lo masculino y lo femenino varían históricamente, pero son percibidas como realidades naturales que se derivan de las diferencias anatómicas que distinguen a los sexos. 
Identidad de género. Es la vivencia interna e individual del género, la cual estructura la experiencia vital de las personas en relación al propio cuerpo y a expresiones de género como la vestimenta, el modo de hablar y de actuar. Esta identidad puede corresponder o no con el sexo biológico asignado al nacer

Perspectiva de género. La perspectiva o visión de género es una categoría analítica que toma los estudios que surgen desde las diferentes vertientes académicas de los feminismos para, desde esa plataforma teórica, cuestionar los estereotipos y elaborar nuevos contenidos que permitan incidir en el imaginario colectivo de una sociedad al servicio de la igualdad y la equidad; la misma se constituye entonces en una estrategia para convertir las preocupaciones y las experiencias de las mujeres y los hombres en una dimensión integral del diseño, implementación, monitoreo y evaluación de las políticas y programas en todas las esferas políticas, económicas, y sociales para que las mujeres y los hombres se beneficien igualmente y la desigualdad no se perpetúe.

\section{Preguntas:}

1. La ley general de educación y su decreto reglamentario (Ley 115 de 1994 y el Decreto 1860 de 1994) instan a las instituciones educativas a la elaboración en conjunto con la comunidad educativa de un Proyecto educativo institucional que oriente su proceder hacia el logro de ciertos fines contemplados en la ley; en este entendido podría informarnos ¿Qué componentes abarca la elaboración de este documento?

2. ¿Puede usted señalar en cuál o cuáles de los componentes del PEI y del Manual de Convivencia se contempla la perspectiva de género? ¿cómo se aborda? ¿cómo se ha difundido a la comunidad educativa?

3. ¿Dentro de los objetivos contemplados en el Proyecto Educativo de esta institución se concibe la perspectiva de género como un eje transversal para el desarrollo de la institución? ¿Por qué? ¿si la respuesta es afirmativa cómo se puede identificar? 
4. ¿El componente de gestión académica contemplado en el PEI contempla en cualquiera de sus acápites la perspectiva de género? ¿Cuáles?

5. ¿Las estrategias de enseñanza utilizadas por los decentes a nivel general promueven la erradicación del sexismo, el machismo y la homofobia o por el contrario profundizan estas situaciones?

6. Conforme la ley 1620 de 2013 y su decreto reglamentario 1965 de 2013 por medio de los cueles se crea y reglamenta el sistema nacional de convivencia escolar y formación para el ejercicio de los derechos humanos, la educación para la sexualidad y la prevención y mitigación de la violencia escolar. ¿Puede usted informarnos el impacto de dicha iniciativa al interior de la institución?

7. ¿Existe una ruta de atención integral para la convivencia escolar? ¿en qué consiste? ¿quién la coordina?

8. ¿Dentro de la evaluación institucional se ha identificado problemas relacionados con la violencia y discriminación basada en el género?

9. En caso de encontrar problemas relacionados con la violencia y discriminación de género ¿se han tomado las medidas y correctivos necesarios conforme lo señala la ley? ¿Cómo?

10. ¿Considera usted importante abordar los temas de igualdad y equidad de género con la comunidad educativa? ¿Por qué?

11. ¿Considera que la gestión académica de la institución es eficaz en materia de igualdad de género o le falta ahondar más en este contexto?

12. ¿Según su criterio como debería abordarse la perspectiva de género en el PEI y en el Manual de Convivencia y cuál sería la mejor manera para difundirlo en la comunidad educativa?

¡Muchas gracias! 


\section{Anexo 5. Encuesta para padres de familia sobre la apreciación de la perspectiva de género en el Proyecto Educativo Institucional PEI y el Manual de Convivencia}

\section{Presentación:}

El presente documento se exhibe como una de las herramientas de investigación que persigue el propósito de identificar en el PEI y el Manual de Convivencia de la Institución Educativa Municipal Sagrado Corazón de Jesús del municipio del Tambo Nariño la inclusión de la perspectiva de género, las formas de difusión de la educación en género y el grado de aceptación e impacto de la misma en la comunidad educativa. Cabe resaltar que esta encuesta se realizará con fines exclusivamente académicos y que la misma NO ES UN EXAMEN por tanto todas las respuestas son válidas. Le pedimos su colaboración. Es muy importante que conteste con la máxima sinceridad.

Si no puede contestar una pregunta o si la pregunta no tiene sentido para usted, por favor pregúntele a la persona que le entregó este cuestionario

CONFIDENCIALIDAD: Sus respuestas serán anónimas y absolutamente confidenciales. Los cuestionarios serán procesados por personas externas. Además, como usted puede ver, en ningún momento se le pide su nombre.

Para el desarrollo de la encuesta por favor tener en cuenta los siguientes conceptos:

Sexo. Es una variable biológica y genética que divide a los seres humanos en mujer u hombre. La diferencia entre ambos se encuentra en los genitales, el aparato reproductor y otras diferencias corporales 
Género. El género refiere a un conjunto de prácticas, disposiciones, papeles, roles, responsabilidades, atributos, espacios, comportamientos, actitudes, etc. que la sociedad asigna a hombres y a mujeres de manera diferenciada, estableciendo un modelo que legitima a nivel social, el deber ser de las mujeres y el deber ser de los hombres en todas las esferas de la vida humana"

Identidad de género. Además de expresarse y asumir roles, las personas sienten, se perciben y se identifican con un determinado género. Esta profunda identificación que cada persona tiene con un género u otro es lo que se llama identidad de género y puede corresponderse o no con el sexo biológico de las personas

Roles de género. Los roles determinan acciones y comprenden las expectativas y normas que una sociedad establece sobre cómo debe actuar y sentir una persona en función de que sea mujer o hombre, prefigurando, así, una posición en la estructura social y representando unas funciones que se atribuyen y que son asumidas diferencialmente por mujeres y hombres.

Los roles femeninos son los relacionados con todas las tareas asociadas a la reproducción, crianza, cuidados, sustento emocional... y están inscritos, fundamentalmente, en el ámbito doméstico.

Los roles masculinos están asociados a las tareas que tienen que ver con el productivo, el mantenimiento y sustento económico, principalmente desarrollados en el ámbito público.

Hombre

Mujer

Otro

Edad

Grado

Responda a las siguientes preguntas marcando con una $\mathrm{X}$ su repuesta: 


\begin{tabular}{|c|c|c|c|}
\hline $\begin{array}{c}\text { Sobre el Proyecto Educativo Institucional y el manual de } \\
\text { convivencia }\end{array}$ & Si & No & $\begin{array}{l}\text { No } \\
\text { sabe }\end{array}$ \\
\hline $\begin{array}{l}\text { 1. ¿Considera usted que la mujer tiene los mismos } \\
\text { derechos que el hombre? }\end{array}$ & & & \\
\hline $\begin{array}{l}2 . \quad \text { ¿usted cree que el hombre en general comparte con } \\
\text { la mujer el trabajo doméstico y los problemas derivados de } \\
\text { la educación de los hijos / as? }\end{array}$ & & & \\
\hline $\begin{array}{l}\text { 3. ¿En su hogar se promueve la igualdad de género y } \\
\text { de roles? }\end{array}$ & & & \\
\hline $\begin{array}{l}\text { Si su respuesta ha sido afirmativa explique cómo se tra } \\
\text { igualdad de género; por el contrario, si la respuesta ha si } \\
\text { justifique la razón por la que no se promueve la igualdad de g }\end{array}$ & & & $\begin{array}{l}\text { gar la } \\
\text { r favor } \\
\text { gar. }\end{array}$ \\
\hline $\begin{array}{l}\text { 4. ¿Considera importante que la institución aborde la } \\
\text { temática de género en las aulas? }\end{array}$ & & & \\
\hline ¿Por qué? & & & \\
\hline $\begin{array}{l}\text { 5. ¿Considera que la institución debe marcar las } \\
\text { diferencias entre hombres y mujeres y definir los roles } \\
\text { adecuados para cada uno de ellos? }\end{array}$ & & & \\
\hline $\begin{array}{l}\text { 6. ¿Cree usted que los hombres deben comportarse de } \\
\text { una sola forma para ser aceptados? }\end{array}$ & & & \\
\hline $\begin{array}{l}\text { ¿Si su respuesta fue afirmativa ¿cuál es el comportamiento } \\
\text { aceptable para un hombre? }\end{array}$ & & & \\
\hline $\begin{array}{l}\text { 7. ¿Cree usted que las mujeres deben comportarse de } \\
\text { una sola forma para ser aceptadas? }\end{array}$ & & & \\
\hline $\begin{array}{l}\text { ¿Si su respuesta fue afirmativa ¿cuál es el comportamient } \\
\text { mujer? }\end{array}$ & & & a una \\
\hline $\begin{array}{l}\text { 8. ¿Considera que tratar el tema de género promueve } \\
\text { actitudes no bien vistas en los estudiantes? }\end{array}$ & & & \\
\hline ¿Por qué? & & & \\
\hline $\begin{array}{l}\text { 9. ¿Considera que la institución trata a los estudiantes } \\
\text { de manera igualitaria, sin ningún tipo de discriminación? }\end{array}$ & & & \\
\hline $\begin{array}{l}\text { 10. ¿La institución ha orientado a los estudiantes en } \\
\text { cuanto al respeto y tolerancia por la diversidad de género? }\end{array}$ & & & \\
\hline $\begin{array}{l}\text { ¿Sabe usted si algunos profesores o personal } \\
\text { administrativo se niegan a aceptar los planteamientos sobre } \\
\text { igualdad? }\end{array}$ & & & \\
\hline $\begin{array}{l}\text { 12. ¿Considera que se debe trabajar más el tema de } \\
\text { género, identidad de género e igualdad de género en la } \\
\text { institución? }\end{array}$ & & & \\
\hline ¿Por qué? & & & \\
\hline
\end{tabular}


Si desea precisar sobre algun punto en particular o resaltar algo que no se ha abordado en el presente cuestionario por favor hagalo en el siguiente espacio.

Observaciones.

¡Muchas gracias! 